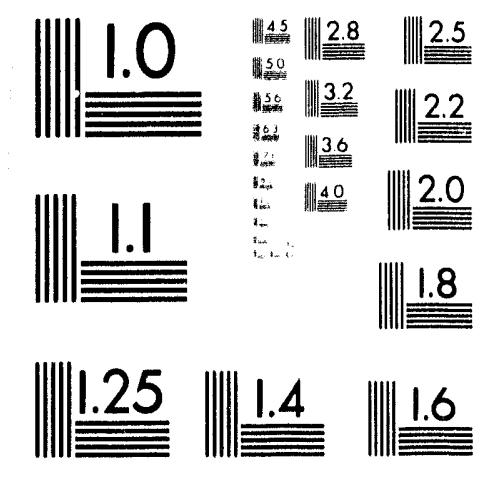



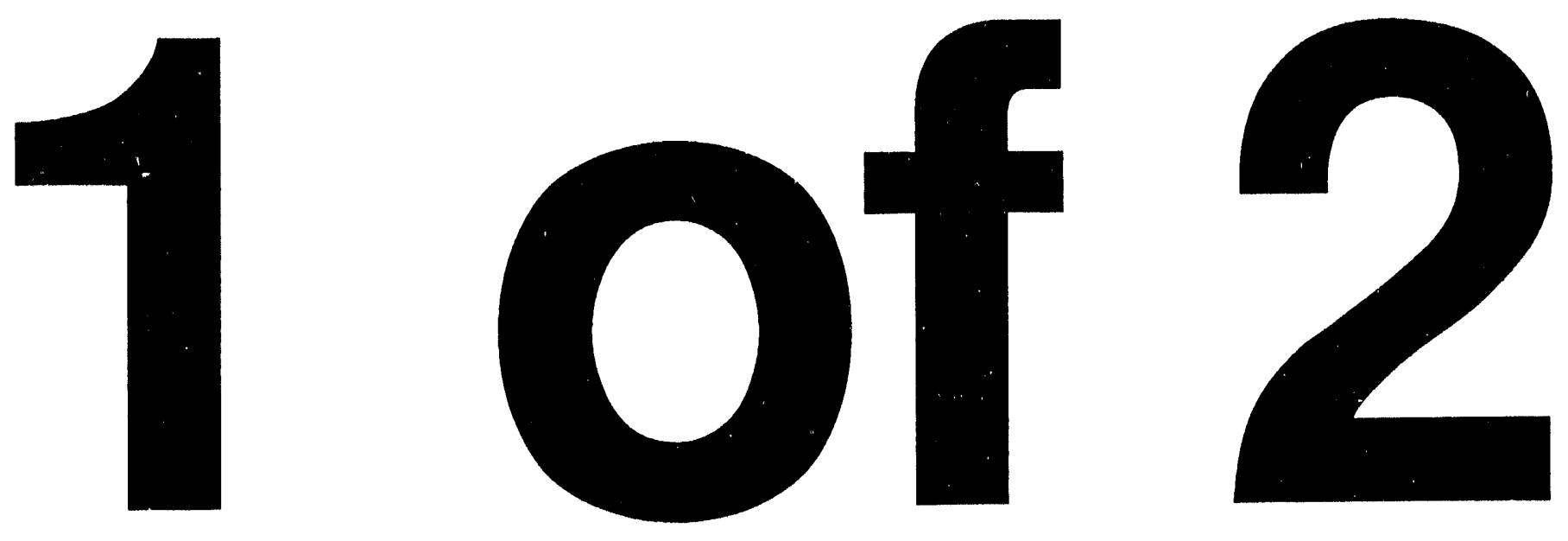


\section{Validated Heat-Transfer and Pressure-Drop Prediction Methods Based on the Discrete-Element Method: Phase II, Two-Dimensional Rib Roughness}

by C.A. James," B.K. Hodge," and R.P. Taylor*

Energy Systems Division,

Argonne National Laboratory, 9700 South Cass Avenue, Argonne, Illinois 60439

May 1993

Work sponsored by United States Department of Energy, Assistant Secretary for Conservation and Renewable Energy, Office of Renewable Energy Conversion

- James, Hodge, and Taylor are affiliated with the Mechanical and Nuclear Engineering Department, Mississippi State University. 


\section{DISCLAIMER}

This document was prepared by C.A. James, B.K. Hodge, and R.P. Taylor, Mechanical and Nuclear Engineering Department, Mississippi State University (Mississippi State, Miss.), for Argonne National Laboratory under contract 12952402. With the exception of minor modifications made to satisfy format requirements, the document is reproduced here as received. 


\section{CONTENTS}

ACKNOWLEDGMENTS $\ldots \ldots \ldots \ldots \ldots \ldots \ldots \ldots \ldots \ldots \ldots \ldots$ ix

NOMENCLATURE $\ldots \ldots \ldots \ldots \ldots \ldots \ldots \ldots \ldots \ldots \ldots \ldots \ldots$

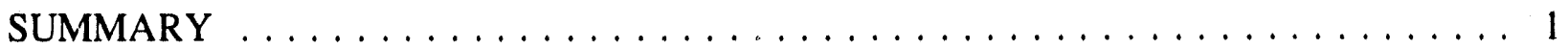

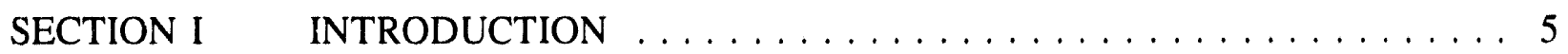

SECTION II FORMULATION OF THE DISCRETE-ELEMENT GOVERNING EQUATIONS FOR FULLY DEVELOPED FLOW IN

A RIB-ROUGHENED TUBE . . . . . . . . . . . . . . . . . . 9

II.1 The Continuity Equation . . . . . . . . . . . . 10

II.2 Fully Developed Flow in Rib-Roughened Tubes . . . . . . 11

II.3 The Momentum Equation ................ 13

II.4 The Energy Equation $\ldots \ldots \ldots \ldots \ldots \ldots \ldots$

II.5 Thermally Developed Flow in Rib-Roughened Tubes . . . . 18

II.6 Constant Heat-Flux Energy Equation . . . . . . . . . . . . . 21

II.7 Constant Wall-Temperature Energy Equation . . . . . . . . . 24

SECTION III EMPIRICAL CLOSURE $\ldots \ldots \ldots \ldots \ldots \ldots \ldots$

III.1 Turbulence Models . . . . . . . . . . . . . . 26

III.1.1 Turbulent Eddy Viscosity . . . . . . . . . . . . . 26

III.1.2 Turbulent Eddy Conductivity . . . . . . . . . . . . . 27

III.2 Roughness Models . . . . . . . . . . . . . . . . . . 29

III.2.1 Blockage Factors . . . . . . . . . . . . . . . . . . . . . 29

III.2.2 Rib-Element Form-Drag Coefficient . . . . . . . . . . 31

III.2.3 Rib-Element Nusselt Number . . . . . . . . . . . . . . . . . . 34

SECTION IV $\quad$ SOLUTION PROCEDURE $\ldots \ldots \ldots \ldots \ldots \ldots \ldots$

IV.1 Momentum Equation $\ldots \ldots \ldots \ldots$

IV.2 Energy Equation - Constant Heat Flux . . . . . . . . . . . 37

IV.3 Energy Equation - Constant Wall Temperature . . . . . . . 37

SECTION V CALIBRATION AND COMPARISON WITH EXPERIMENTS $\ldots \ldots .38$

V.1 Smooth Wall ................... 38

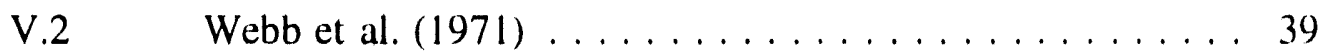

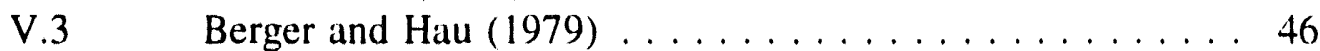

V.4 Mendes and Mauricio (1987) . . . . . . . . . . . . . 49

V.5 Baughn and Roby (1992) .............. 51 


\section{CONTENTS (Cont.)}

SECTION VI UNCERTAINTY AND RANGE OF VALIDITY $\ldots \ldots \ldots \ldots \ldots .52$

SECTION VII CONCLUSIONS AND RECOMMENDATIONS . . . . . . . . . 54

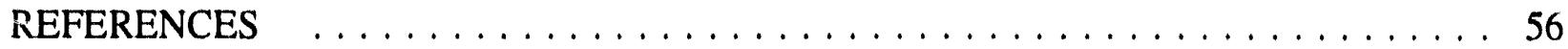

APPENDIX A: ALTERNATIVE FORMULATIONS AND ROUGHNESS MODEL.S FOR THE ENERGY EQUATION $\ldots \ldots \ldots \ldots \ldots 63$

APPENDIX B: THE IMPLICIT FINITE-DIFFERENCE METHOD $\ldots \ldots \ldots \ldots, 71$

APPENDIX C: $\quad$ EXPERIMENTAL DATA AND PROGRAM INPUT . . . . . . . 79

\section{TABLES}

$1 \quad$ Laminar Flow Comparisons $\ldots \ldots \ldots \ldots \ldots \ldots \ldots$

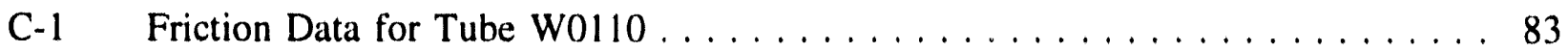

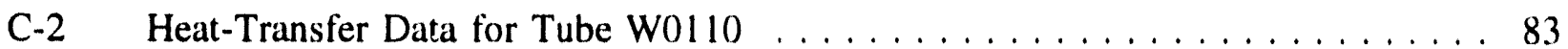

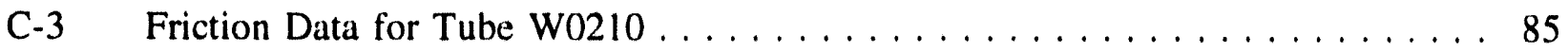

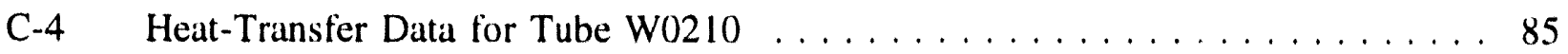

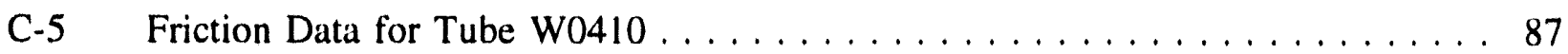

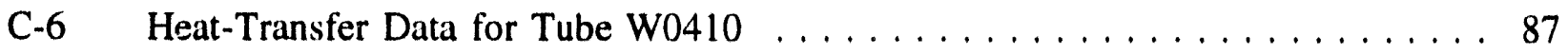

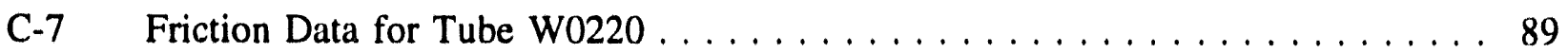

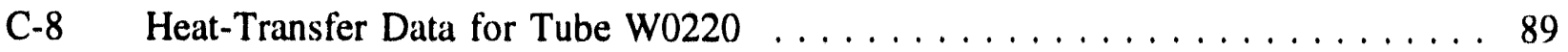

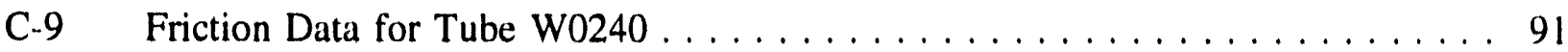

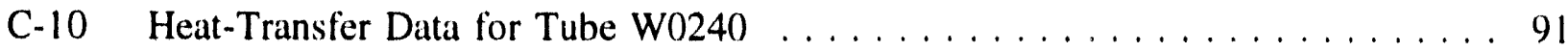

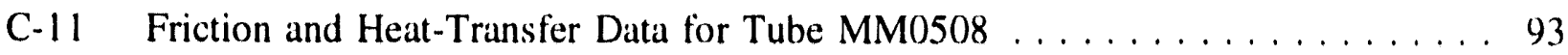

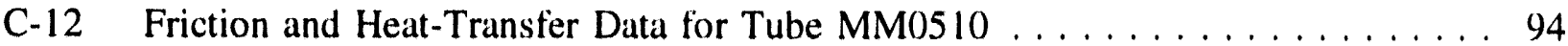




\section{TABLES (Cont.)}

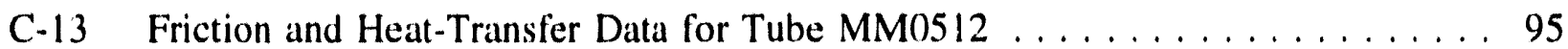

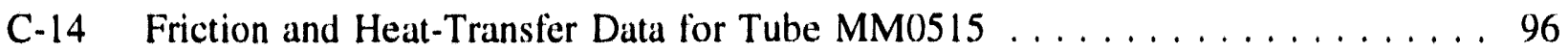

C-15 Friction and Heat-Transfer Data for Tube MM1010 . . . . . . . . . . . 97

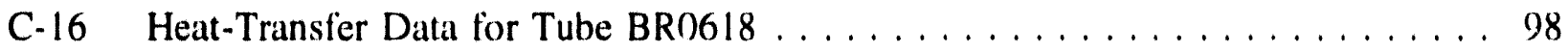

\section{FIGURES}

1 Typical Rib-Roughened Surface with Flow Separation and Reattachment. . . . . 6

2 Control Volume for Tube Flow with Two-Dimensional Rib-Type Roughness

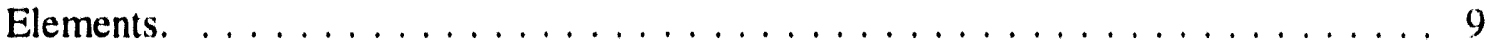

3 Flow Development in the Entrance Region of a Tube $\ldots \ldots \ldots \ldots \ldots \ldots 11$

4 Control Volume Illustrating the Force Balance on an Infinitesimal

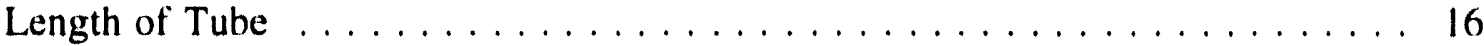

5 Schematic Illustration of Thermally Developed Flow. $\ldots \ldots \ldots \ldots \ldots \ldots 19$

6 Control Volume Illustrating the Energy Balance on an Infinitesimal Length of Heated Tube . . . . . . . . . . . . . . . . . . . . . . . . . . . . 22

$7 \quad$ Simplified Flow Model of Separation and Reattachment Mechanism. . . . . . . 29

8 Comparison of the Smooth-Wall Predictions with the Swamee-Jain (i 976) Correlation. . . . . . . . . . . . . . . . . . . . . . 39

9 Comparison of the Smooth-Wall Nusselt Number Predictions with the Dittus-Boelter equation $\ldots \ldots \ldots \ldots \ldots \ldots \ldots \ldots \ldots \ldots$

10 Comparison of Friction Factor Predictions with the Data of Webb et al. (1971) for $L / k=10$ and Varying $k / D$ and $w / k$ Ratios.

11 Comparison of Friction Factor Predictions with the Data of Webb et al. (1971) for $k / D=0.02, w / k=0.52$, and Varying $L / k$ Ratios.

12 Comparison of Nusselt Number Predictions with the Data of Webb et al.

(1971) for ihe $k / D=0.01, L / k=10$ Geometry with Various Prandtl Numbers. 


\section{FIGURES (Cont.)}

13 Comparison of Nusselt Number Predictions with the Data of Webb et al. (1971) for the $k / D=0.02, L / k=10$ Geometry with Various Prandtl Numbers.

14 Comparison of Nusselt Number Predictions with the Data of Webb et al. (1971) for the $k / D=0.04, L / k=10$ Geonetry with Various Prandtl Numbers.

15 Comparison of Nusselt Number Predictions with the Data of Webb et al. (1971) for the $k / D=0.02, L / k=20$ Geometry with Various

Prandtl Numbers.

16 Comparison of Nusselt Number Predictions with the Data of Webb et al. (1971) for the $k / D=0.02, L / k=40$ Geometry with Various

Prandtl Numbers.

17 Comparison of Nusselt Number Predictions with the Data of Berger and Hau (1979).

18 Comparison of Friction Factor Predictions with the Data of Mendes and Mauricio (1987).

19 Comparison of Nusselt Number Predictions with the Data of Mendes and Mauricio (1987).

20 Comparison of Nusselt Number Predictions with the Data of Baughn and Roby (1992).

B-1 Schematic Layout of Expanding Grid.

B-2 Matrix from Linearized Equations: (a) Tridiagonal Form and

(b) Transformed Form 


\section{ACKNOWLEDGMENTS}

This work was supported under Contract 12952402 from Argonne National

Laboratory. We gratefully acknowledge the support and encouragement of Thomas Rabas of Argonne. 


\section{NOMENCLATURE}

$A_{n} \quad$ Coefficient in finite-difference equations, Equation B-8a

$\mathrm{A}^{+} \quad$ Constant in the van Driest damping function in mixing-length model, Equation 57

$A_{p} \quad$ Projected area of a rib within the control volume, $2 \pi r(\delta y)$

$\mathrm{A}_{\mathrm{rc}} \quad$ Area open to radial conduction between ribs, Equation 20

$A_{s} \quad$ Surface area of roughness element within control volume

$\mathrm{A}_{\mathrm{x}} \quad$ Area normal to $\mathrm{x}$-axis, Figure 2 and Equation 2

$A_{y} \quad$ Area normal to $y$-axis, Figure 2 and Equation 2

$B_{n} \quad$ Coefficient in finite-difference equations, Equation B-8b

$c_{p} \quad$ Specific heat of fluid

C Empirical constant in alternative rib Nusselt number model, Equation A-1

$\mathrm{C}_{\mathrm{D}} \quad$ Local-element drag coefficient, Equation 7

$\mathrm{C}_{\mathrm{n}} \quad$ Coefficient in finite-difference equations, Equation B-8c

$\mathrm{C}_{\mathrm{p}} \quad$ Local-element pressure coefficient, Equation 69

$\mathrm{C}_{1}, \mathrm{C}_{2} \quad$ Empirical constants in pressure-coefficient relation, Equations 70 and 73

d Effective radial-flow blockage for a single rib, Figure 7 and Equation 66

D Tube diameter

$D_{n} \quad$ Coefficient in the finite-difference equations, Equation B-8d

$\mathrm{E}_{\mathrm{n}} \quad$ Coefficient in canonical equations, Equation B-11d

$\mathrm{E}_{\mathrm{r}} \quad$ Ratio of rib heat-transfer coefficient to smooth-wall heat-transfer coefficient

$\mathrm{f}_{\mathrm{f}} \quad$ Fanning friction factor, Equation 12

$f_{D} \quad$ Darcy friction factor, $4 f_{f}$

$\mathrm{F}_{\mathrm{A}} \quad$ Area-factor parameter for roughness element, text below Equation 21 


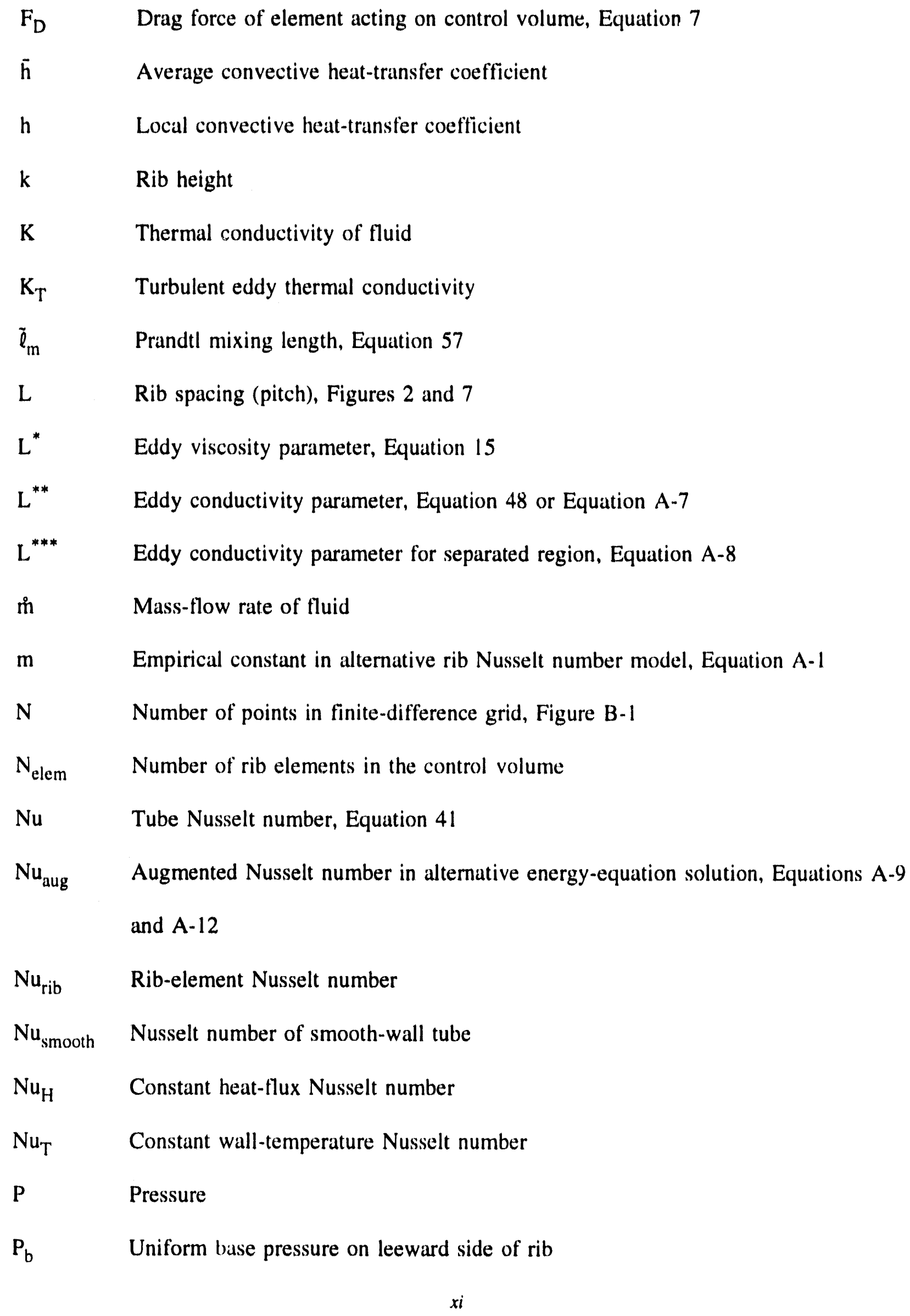


$\operatorname{Pr} \quad$ Molecular Prandtl number, Equation 60

$\mathrm{Pr}_{\mathrm{T}} \quad$ Turbulent Prandtl number. Equation 59

$\stackrel{q}{ } \quad$ Heat flux

Q Rate of heat transfer between control volume and rib cuments

r Local radius

$\mathbf{R} \quad$ Tube radius; also, grid step-size ratio in Equation B-2

$\mathrm{Re}_{\mathrm{D}} \quad$ Tube Rej nolds number, Equation 16

$\mathrm{Re}_{\mathrm{k}} \quad$ Rib Reynolds number, Equation $\mathrm{A}-2$

T Local fluid temperature

$\mathrm{T}_{0} \quad$ Wall temperature

$T_{\text {rib }} \quad$ Rib temperature (taken to be $T_{0}$ )

u Local axial velocity

v Local radial velocity

$U_{m} \quad$ Mean axial velocity

$\mathrm{U}^{*} \quad$ Friction velocity, Equations 71 and 72

w Rib width; also, solution variable in the finite-difference equation (B-1)

$\mathrm{x} \quad$ Streamwise coordinate (along tube axis)

$\mathrm{X} \quad$ Any distance $\mathrm{x}$ beyond the hydrodynamic entrance length

$\mathrm{X}_{\mathrm{e}} \quad$ Hydrodynamic entrance length, Figure 3

y Coordinate normal to tube wall, $1-\mathrm{r}$

Greek

$\alpha \quad$ Thermal diffusivity, $K /\left(\rho c_{p}\right)$

$\beta_{x} \quad$ Blockage factor, percent area open to flow in $x$-direction 
$\beta_{y} \quad$ Blockage factor, percent area open to flow in y-direction

$\beta_{\mathrm{s}} \quad$ Radial heat conduction blockage factor, $(\mathrm{L}-\mathrm{w}) / \mathrm{L}$ or Equation A-5

$\gamma \quad$ Reattachment length downstream of rib element divided by rib height; also, coefficient of linearized differential equation, Equation B-1

$\gamma_{L} \quad \gamma$ for a square rib as a function of $L / k$

$\gamma_{w} \quad \gamma$ for a single rib as a function of $w / k$

$\gamma_{\mathrm{SS}} \quad \gamma$ for a single square rib

$\delta \mathrm{x} \quad$ Length of control volume, Figure 2

by Thickness of control volume, Figure 2

$\eta \quad$ Coordinate in finite-difference solution, $\tilde{y}$

$\theta \quad$ Dimensionless temperature, Equation 28

$\lambda_{\mathrm{n}} \quad$ Coefficient in canonical equations, Equation B-11c

$\mu \quad$ Dynamic viscosity of fluid

$\mu_{\mathrm{T}} \quad$ Turbulent eddy viscosity

$v \quad$ Kinematic viscosity of fluid, $\mu / \rho$

$\rho \quad$ Density of fluid

$\tau \quad$ Fluid shearing stress

$\tau_{\mathrm{w}} \quad$ Fluid shearing stress acting on the wall

$\omega \quad$ Weighting factor in alternative energy-equation solution, Equation A-11

$\underline{\text { Superscripts }}$

$\because \quad$ Indicates nondimensionalization (i.e., $\tilde{y}=y / R$, except $\tilde{u}=u / U_{m}$ )

$+\quad$ Indicates an inner-region dimensionless coordinate 


\section{$\underline{\text { Subscripti }}$}

cycle Indicates that the quantity is averaged over the length of the rib cycle i Iteration count

m Indicates a mean value

ref Indicates reference to a smooth-wall value

$0 \quad$ Indicates value evaluated at wall $(y=0)$ 


\title{
VALIDATED HEAT-TRANSFER AND PRESSURE-DROP PREDICTION METHODS BASED ON THE DISCRETE-ELEMENT METHOD: PHASE II, TWO-DIMENSIONAL RIB ROUGHNESS
}

by

\author{
C.A. James, B.K. Hodge, and R.P. Taylor
}

\section{SUMMARY}

Enhanced heat-transfer surfaces can significantly increase the thermal performance of heat exchangers. However, industrial applications of such surfaces are limited; a major barrier to their use is the lack of reliable methods for the prediction of pressure-drop and heat-transfer performance. Validated methods used to predict the performance of proposed enhanced heat-transfer surfaces can be divided into three categories: (1) first-principle predictions, (2) mechanistic-based models, and (3) empirical correlations.

First-principle prediction methods solve the appropriate Reynolds-averaged equations using turbulence models. These methods compute the complete spatial details of the flow and energy fields in a time-averaged sense. Turbulent closure for the first-principle methods is based on empirical data at a very fundamental level. At the present time, these methods are primarily research tools. Although they give the most detailed information, their use requires considerable computational resources and technical expertise.

Much of the pressure-drop and heat-transfer data available to engineers has traditionally been presented as empirical correlations. Using dimensional analysis and statistical curve-fit techniques, relatively simple relationships between dimensionless groups can be established. For smooth-wall tubes, these relationships are typically friction factors as a function of Reynolds number and Nusselt number as a function of Reynolds and Prandtl numbers. For enhanced surfaces, the number of dimensionless groups increases, and expressions that fit the data over more than narrow bands are difficult to ascertain. The empirical correlations cannot be used to extrapolate into untested regions for the investigation of possible optimized geometries. 
Mechanistic-based models attempt to use the experimental information at an intermediate level between the first-principle method and the empirical correlation approaches. Mechanisms are postulated for the interaction of the flow field and the surface-roughness elements. The mechanistic-based models result in a set of differential equations, which are averaged temporally and spatially in the axial direction. These methods are much less computationally complex than the first-principle methods, and they have a broader range of application than the empirical correlations. Thus, mechanistic-based models provide the heatexchanger specialist with an economical tool for enhanced-surface selection and design.

In this report, a mechanistic model is developed and validated for predicting friction factors and Nusselt numbers for hydrodynamically and thermally fully developed, constantproperty, turbulent flows in tubes with two-dimensional rib-roughness in the separationreattachment regime. Mechanistic models that account for surface-roughness effects are broadlv classified as either equivalent sandgrain or discrete-element models. The equivalent sandgrain model, which attempts to relate the characteristics of a roughened surface to a wellaccepted standard, is not viewed here as a predictive tool. The discrete-element model captures the physical effects of flow over a roughened surface by considering skin-friction and heat-transfer contributions of both the smooth surface between roughness elements and of the roughness elements themselves. In the discrete-element method, the effects of the roughness elements on the flow field are incorporated into the Reynolds-averaged governing equations (continuity, $\mathrm{x}$-momentum, and energy) by considering that the roughness elements create a blockage to the flow field, exert drag forces on the flow field, and transfer heat to or from the flow field. The discrete-element method does not attempt to resolve the details of the flow over and around the roughness elements, but it endeavors to capture the spatially averaged effects of the roughness elements over a control volume containing a significant sample of roughness elements.

Closure in the discrete-element approach is required for both the turbulence and the roughness models. Turbulent closure is achieved with a conventional mixing-length model with van Driest damping, and roughness-model closure is achieved by numerically determining the values of roughness-model functional relations required to produce agreement with selected empirical data from the literature. The discrete-element momentum equation is 
solved for the velocity profile by using an iterative approach; the converged velocity profile is used to find both the constant keat-flux and temperature solutions at the surface for the energy equation. Agreement with classical relations for the turbulent friction factor and Nusselt number for smooth walls is excellent.

The mechanistic model for rib roughness takes into account the lengths of the separated regions upstream and downstream of the rib, the form-drag that the rib exerts on the fluid, the effect of rib height on the viscous sublayer, the effective value of a turbulent Prandtl number for rib-roughness flows, and the local enhancement of heat transfer on the rib. Roughness-model functional relations are determined from the extensive data set of Webb et al. (1971). The rib-roughness-model friction-factor computations are in excellent agreement with these data. The hydraulically smooth, transitionally rough, and fully rough flow regimes are accurately delineated and predicted. Friction-factor predictions with other data sets from the literature are good to excellent, with significant deviations of the predictions from the data only for rib height-to-diameter ratios of $10 \%$ or greater. Nusselt number predictions for the data of Webb et al. and for other data sets from the literature are good to excellent. The validated range for the rib-roughness model encompasses rib height-to-diameter ratios from 0.01 to 0.0625 , rib height-to-width ratios from 0.254 to 1 , and rib pitch-to-height ratios from 10 to 40 . Within this validation range, the uncertainties in the model predictions are \pm 7 to $\pm 16 \%$ for the friction factor and \pm 11 to $\pm 27 \%$ for the Nusselt number. 


\section{SECTION I \\ INTRODUCTION}

Surface roughness is a commonly used approach for enhancing the rate of heat transfer of surfaces, such as in heat-exchanger tubes. Because the improved thermal performance of roughened surfaces is at the expense of increased flow resistance (increased pressure drop or friction factor), accurate prediction techniques for determining the friction factors and Nusselt numbers for roughened surfaces are required if such features are to be considered as design options.

This report presents the results of the second phase of a research program sponsored by Argonne National Laboratory (ANL) to validate models for the prediction of friction factors and Nusselt numbers for fully developed turbulent flow in enhanced heat-exchanger tubes. The first phase (Taylor and Hodge 1992a) was concerned with validating a roughness model for turbulent flow in tubes internally roughened with three-dimensional distributed roughness elements, such as sandgrains, spheres, hemispheres, and cones. The second phase is concerned with devising and validating methods for the prediction of friction factors and Nusselt numbers for turbulent flow in tubes internally roughened with repeated, twodimensional ribs aligned perpendicular to the flow, as shown in Figure 1. The ribs are spaced sufficiently far apart that the leeward-side separated flow reattaches to the wall before again separating in order to negotiate the next rib. This heat-transfer enhancement mechanism is called the separation and reattachment mechanism, after Rabas (1989). This work is limited to rectangular rib shapes.

One approach to predicting the heat-transfer and frictional characteristics of enhanced tube geometries is to numerically solve the flow field about the specified roughness geometry by using the Reynolds-averaged Navier-Stokes equations. Arman and Rabas (1992), for example, discuss details of the development of a Navier-Stokes technique for repeated ribtype roughness inside tubes. This method is an excellent tool for gaining insight into the mechanisms of heat transfer and the frictional characteristics of enhanced surfaces, but at present it is not suitable as a design tool because of the computer resources and the user expertise required. 


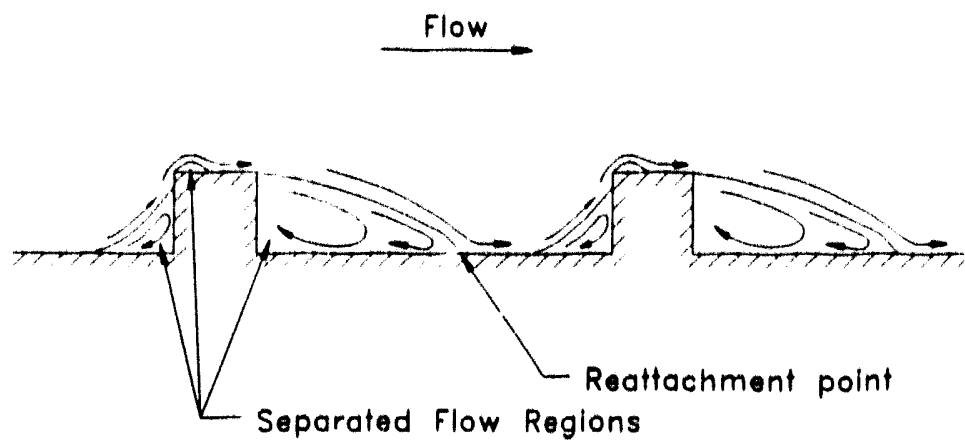

Fig. 1 Typical rib-roughened surface with flow separation and reattachment.

An alternative approach is to devise a mechanism-based model that captures the physical effects of the flow over a roughened surface and to use that model to predict the heat-transfer and frictional characteristics of the roughened surface. Such modeling efforts typically fall into two basic categories: (1) the equivalent sandgrain approach and (2) the discrete-element approach.

The equivalent sandgrain approach, introduced by Schlichting (1936), describes the frictional characteristics of a rough surface as being equivalent to a particular sandgrain size, $k_{s}$, based on the extensive sandgrain roughness experiments of Nikuradse (1933). A wellknown example of this approach for determining friction factors in commercial pipes and tubing is the classic Moody diagram (1944). In the Moody diagram, the roughness value assigned to a particular tube is actually an equivalent sandgrain size, a hydrodynamic parameter, not the measured roughness of the tube surface. Some shortcomings of the equivalent sandgrain approach are that (1) experimental data are required for a surface, (2) many surfaces do not behave as equivalent sandgrain throughout a wide Reynolds number range, and (3) direct application of the Reynolds analogy to determine the heat-transfer coefficients from the friction characteristics is not successful for all torms of roughness (different types of rough surfaces with identical values of $k_{s}$ may exhibit different heattransfer characteristics).

The discrete-clement approach follows the basic idea that the skin triction and heattransfer characteristics of a rough surface are composed of two distinct contributions: (1) that due to the roughness elements and (2) that due to the smooth surface between the roughness 
elements. This concept was introduced by Schlichting (1936) as an alternative explanation of the surface resistance mechanisms in the same paper in which he introduced the equivalent sandgrain roughness concept. In the discrete-element method, the effects of the roughness elements on the flow field are incorporated into the governing equations by considering that the roughness elements create a blockage to the flow field, exert drag forces on the flow field, and transfer heat locally to or from the flow field. This approach incorporates more of the fundamental physics of the flow than methods based on the traditional equivalent sandgrain concept and requires only generalized empirical input, rather than specific experimental data for each surface under consideration. The primary objective is to determine the overall friction and heat-transfer (Nusselt number) characteristics of the roughened surface. The discrete-element method does not attempt to resolve the details of the complicated flow field in the vicinity of each roughness element, but rather attempts to capture the averaged effects of the roughness elements over a small but finite space containing a signilicant sample of roughness elements.

Various prediction methods based on the discrete-element method have been presented (Finson 1975, Adarns and Hodge 1977, Finson and Wu 1979, Finson and Clark 1980, Lin and Bywater 1980, Finson 1982, Christoph 1982, Christoph and Pletcher 1983). For more than a decade, researchers at Mississippi State University (MSU) have been studying surface roughness effects and implementing the discrete-element method to predict these effects. Taylor et al. (1984, 1985), starting with the basic idea proposed by Schlichting and building on the works cited above, derived the discrete-element method for twodimensional boundary-layer flow. Excellent agreement between this discrete-element method and experimental data has been obtained for both heat transfer and skin friction in aerodynamic turbulent boundary layers over surfaces roughened with three-dimensional distributed roughness elements (Hosni et al. 1989, 1991) and for friction factors and Nusselt numbers in fully developed turbulence in tubes roughened with three-dimensional roughness elements (Scaggs et al. 1988a, Taylor et al. 1988, Scaggs et al. 1988b, and Taylor and Hodge 1992a, 1992b).

The formulations of the two-dimensional rib-roughness models follow the same approach as the three-dimensional formulation of Taylor and Hodge (1992a, 1992b), with the 
recognition that the basic mechanisms governing the physical interaction of two-dimensional roughness with the flow differ significantly from those of three-dimensional distributed roughness. In considering the mechanisms of flow over two-dimensional ribs, the present investigation incorporates many of the basic premises of an earlier exploratory effort (Taylor and Hodge 1985a, 1989) in predicting frictional characteristics of rib roughness. The effort reported herein results in a marked improvement in the prediction of friction factors for ribroughened tubes when compared with the earlier exploratory study. The present model also includes an energy-equation solution for prediction of Nusselt numbers for rib-roughened tubes. Computed predictions using this technique also compare very favorably with experimental data from the heat-transfer literature. The general organization of the work presented herein is discussed in the following paragraph.

Section II presents the derivation of the discrete-element form of the governing equations of continuity, momentum, and energy exchange. This section also discusses the concepts of hydrodynamically and thermally fully developed flow as applied to flow through rib-roughened tubes. Section III discusses the empirical turbulence and roughness models necessary for closure of the governing equations. Section IV outlines the solution procedure. Section $\mathrm{V}$ presents the calibration of the roughness models and comparison of the computed results with experimental data sets. Section VI examines the range of geometries over which the present models have been validated and the expected uncertainties in friction factor and Nusselt number within these ranges. Section VII provides concluding remarks and recommendations for further study.

Appendix A reviews alternative formulations and modeling techniques for the energy equation. Appendix B summarizes the finite-difference procedure used in the solution procedure. Appendix $\mathrm{C}$ identifies the tube geometries used in the validation and gives the physical geometries and experimental data points for each. 


\section{SECTION II \\ FORMULATION OF THE DISCRETE-ELEMENT GOVERNING EQUATIONS FOR FULLY DEVELOPED FLOW IN A RIB-ROUGHENED TUBE}

In the discrete-element method, the effects of roughness on the flow field are considered an integral part of the flow problem. The roughness effects are directly incorporated into the governing equations by applying the laws of conservation of mass, momentum, and energy to a control volume, which accounts for the effects of the roughness elements as well as the smooth portions of the wall on the fluid within the control volume. Such a control volume for a circular tube with rectangular ribs is shown in Figure 2. This control volume is a cylindrical shell of thickness $\delta y$ located such that the roughness elements penetrate the control volume. The length, $\delta x$, spans several roughness elements so that the details of the flow field between the elements are not resolved, but are accounted for in a spatially averaged sense by a roughness model. The roughness clfects on the control volume are the physical blockages to the flow, the drag forces exerted by the elements, and the lncal heat transfer to or from the elements.

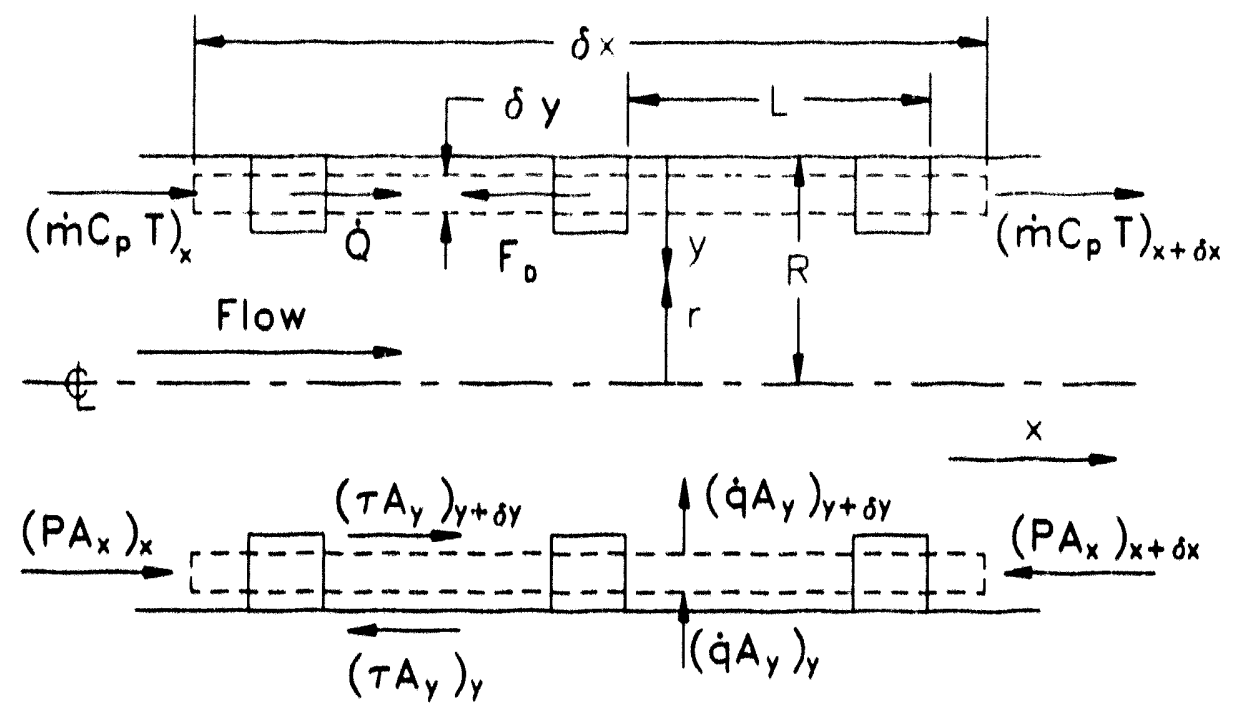

Fig. 2 Control volume for tube flow with two-dimensional rib-type roughness elements. 
For single-phase fluids, the flow is taken to be steady and incompressible, with constant fluid properties and negligible viscous dissipation. Moreover, only hydrodynamically and thermally fully developed conditions are considered.

The rib-roughness geometry considered is uniformly spaced, rectangular-shaped ribs of constant height and width aligned perpendicular to the tube axis and spaced sufficiently far apart that the separation and reattachment mechanism is present. The equations derived in this section, however, are not limited to ribs of rectangular shape or to rib spacings in which the separation and reattachment mechanism is present, but apply to any rib geometry in which the size, shape, and spacing are uniform with the ribs perpendicular to the tube axis. The additional restrictions that the ribs be of rectangular shape with sepuration and reattachment are necessary only in the particular roughness models to be discussed in Section III.

\section{II.1 The Continuity Equation}

The continuity equation is obtained by applying conservation of mass to the fluid passing through the control volume. Because the amount of mass within the control volume is constant for steady flow, con "ervation of mass simply states that the rate of mass leaving the control volume must equal the rate of mass entering the control volume. With mass-flow rate $m=\rho u A_{x}$, a mass-flow balance on the control volume shown in Figure 2 results in

$$
\left(\rho u A_{x}\right)_{x+\delta x}-\left(\rho u A_{x}\right)_{x}+\left(\rho \vee A_{y}\right)_{y+\delta y}-\left(\rho v A_{y}\right)_{y}=0
$$

The areas $A_{x}$ and $A_{y}$ are given by

$$
\begin{aligned}
& A_{x}=2 \pi r(\delta y) \beta_{x} \\
& A_{y}=2 \pi r(\delta x) \beta_{y}
\end{aligned}
$$

The blockage factors $\beta_{x}$ and $\beta_{y}$ account for the presence of the roughness elements and are defined as the fraction of area open to flow in the planes perpendicular to the axial ( $x$ ) and radial (y) directions, respectively. Substituting these expressions into Equation 1, dividing by $\delta x \delta y$, taking the limit as $\delta x$ and $\delta y$ approach zero, and assuming constant density yields 


$$
r \frac{\partial}{\partial x}\left(u \beta_{x}\right)+\frac{\partial}{\partial y}\left(r v \beta_{y}\right)=0
$$

Note that it may seem inconsistent to let $\delta x$ approach zero after assuming that $\delta x$ is a finite length spanning several ribs, but, as discussed in the following section, $\delta x$ can be considered to approach zero in comparison with the overall tube length required to satisfy the fully developed flow assumption.

\subsection{Fully Developed Flow in Rib-Roughened Tubes}

Figure 3 depicts the developing flow region near the entrance of a tube. A uniform. steady flow enters the tube from a reservoir, and the no-slip condition requires the fluid velocity to be zero at the tube wall. A viscous boundary layer forms on the tube wall and grows in thickness as the flow progresses downstream. The uniform, inviscid core region gradually disappeurs as the boundary layer grows to fill the entire tube after some distance $X_{e}$, called the hydrodynamic entrance length. For $x>X_{c}$ the velocity profiles are essentially unchanged, and the flow is said to be hydrodynamically fully developed.

Based on these observations, the usual starting point in the analysis of fully developed smooth-wall tube flow is to assume an axial velocity that varies radially. With

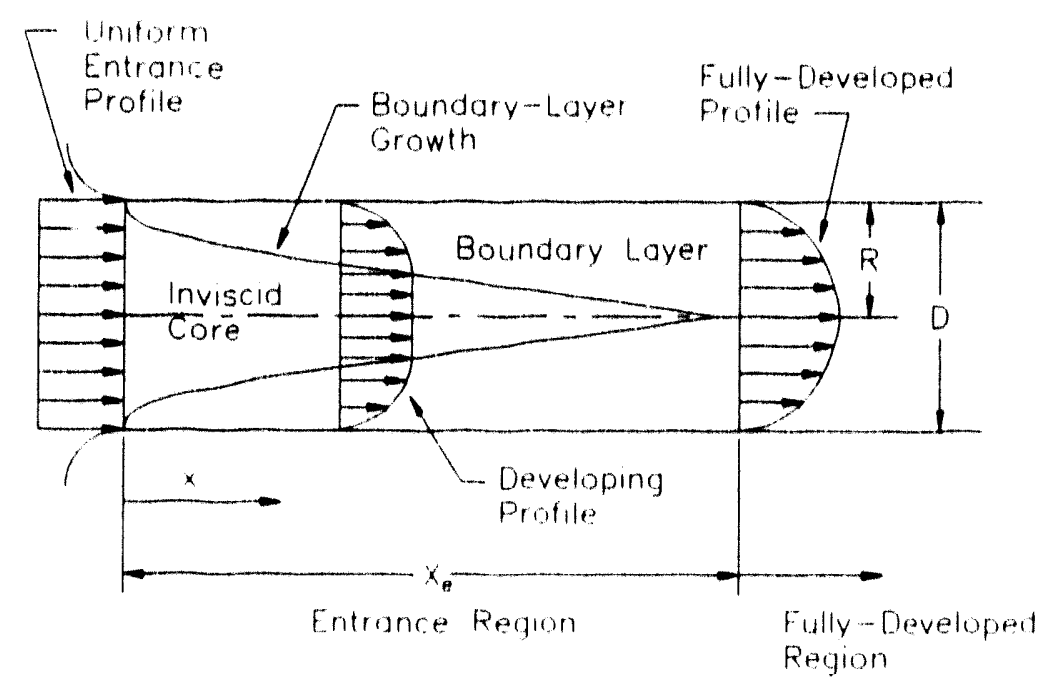

Fig. 3 Flow development in the entrance region of a tube. 
these assumptions, $v=0$ and $u=u(r)$, and the smooth-wall continuity equation reduces to $\partial u / \partial x=d u / d x=0$. This condition leads to simplification of the remaining governing equations. These fully developed flow characteristics are frequently applied to rib-roughened tube tlow with little regard for meaning or appropriateness. Some discussion of the meaning of fully developed flow for rib-roughened tubes is in order.

It is easy to verify the appropriateness of the fully developed flow assumption in smooth-wall tubes using scaling arguments. The continuity equation for a smooth-wall tube is identical to that for the rib-roughened tube as given by Equation 3, with $\beta_{x}=\beta_{y}=1$. A scale analysis of this equation for a section of tube located some distance $X$ from the tube entrance such that $X>X_{c}>R$ shows that, with $y-r \sim R$ and $X \sim X$, the scale of the radial velocity is

$$
v \sim\left(\frac{R}{X}\right) u
$$

It is evident from Equation 4 that the radial velocity, $v$, is negligible as compared to the axial velocity, $u$. With $v \sim 0$, the continuity equation reduces to $\partial u / \partial x=d u / d x=0$. Thus, fully developed flow exists in any section of tube located sufficiently far from the entrance that the scale of $v$ is negligible.

Invoking either of the above arguments (intuitive or scaling) to justify the existence of fully developed flow in a rib-roughened tube should raise some suspicions. One would expect that in the vicinity of the rib elements, significant radial components of velocity ( $v$ ), velocity gradient $(\partial v / \partial y)$, and pressure gradient $(\partial P / \partial y)$ would nullify the $\partial u / \partial x=0$ assumption and its resulting simplifications.

However, if the regions in the vicinity of the rib elements where $\partial u / \partial x \neq 0$ are small enough that within the main flow field or core of the tube $\partial u / \partial x=0$, then assumptions applicable to full development apply. Experiments have shown that the region where $\partial u / \partial x \neq$ 0 extends about three rib heights from the wall into the core flow (Berger and Hau 1979).

The ribs in most rib-roughened enhanced heat-transfer tubes are small enough that the overall flow can be treated as fully developed. 
If the ribs are large enough to produce a repeated series of vena contractae in the main flow field, there is significant core-flow acceleration and deceleration and, $\partial u / \partial x \neq 0$ everywhere within the tube. However, if the rib geometry and rib spacing, L, are constant, the velocity profile becomes periodic in $\mathrm{x}$ after a few rib cycles. The velocity profile at a location $x$ is then identical to the velocity profiles at the corresponding locations $(x+n L)$ of any succeeding rib cycle. Such a flow is termed periodic fully developed flow. If the axial velocity is averaged over a complete rib cycle such that

$$
u_{c y c l e}=\frac{1}{L} \int_{c y c l e} u d x
$$

then $\partial u_{\text {cycle }} / \partial x=0$. With the control-volume length, $\delta x$, spanning several rib elements, the $x$ averaging of $u$ as well as $\beta_{x}$ is automatically accomplished in the derivation of the continuity equation as $\delta \mathrm{x}$ is made to approach zero (in comparison with $\mathrm{X}$ ). Because the $\mathrm{x}$-averaging process is inherent in this method, the cycle subscript may be dropped, and it is henceforth to be understood that all variables are spatially averaged in the $\mathrm{x}$-direction over the control volume And so, for the purposes of this analysis, the $\partial u / \partial x=0$ assumption applies for fully developed rib-roughened flow, as well as for smooth-wall flow inside tubes. For constant rib shape and pitch, it is also apparent that $\partial \beta_{x} / \partial x=0$.

With the spatially averaged notion qualified, it is now appropriate to return to the scale analysis of Equation 3, this time with blockage effects included. In the spatially averaged scnse, $\beta_{x}-\beta_{y}$. Also, because the effects of the details between the roughness elements are replaced by a roughness model, $\mathrm{x}$ scales on the global level of $\mathrm{X}$ as in the smooth-wall case, rather than scaling on the local level of boundary-layer development between ribs. With $\beta_{x} \sim \beta_{y}$ and $x \sim X$, the scale of $v$ is given again by Equation 4 , which shows that on the global level $\mathrm{v} \sim 0$ and is negligible in the analysis.

\section{II.3 The Momentum Equation}

The momentum equation in the axial direction is obtained by applying conservation of momentum to the fluid passing through the control volume. For steady, fully developed 
flow, the external forces on the control volume must sum to zero. Balancing the pressure forces, drag forces, and shear forces shown in Figure 2 results in

$$
0=\left(P A_{x}\right)_{x}-\left(P A_{x}\right)_{x+8 x}-F_{D}-\left(\tau A_{y}\right)_{y}+\left(\tau A_{y}\right)_{y+8 y}
$$

The drag force, $F_{D}$, exerted on the flow field by the rib elements may be expressed in terms of a local drag coefficient, $C_{D}$, such that

$$
F_{D}=\frac{1}{2} \rho u^{2} C_{D} A_{p} N_{\text {elem }}
$$

where $A_{p}$ is the projected area of a slice of a single rib within the control volume and $N_{\text {elem }}$ $=(\delta x) / \mathrm{L}$ is the number of elements within the control volume. Below the crests of the ribs, $A_{p}=2 \pi r(\delta y)$, but above the crest of the ribs, $A_{p}=0$. Introducing an artificial drag coefficient of $C_{D}=0$ above the crests of the ribs accomplishes the same effect as a zero projected area; therefore, it is appropriate as well as convenient to let $A_{p}=2 \pi r(\delta y)$ both above and below the crests of the ribs. Substituting into Equation 6, using the two expressions in Equation 2 for $A_{x}$ and $A_{y}$, dividing by $\delta x \delta y$, and taking the limit as $\delta x$ and Sy approach zero yields

$$
0=r \frac{\partial}{\partial x}\left(\beta_{x} P\right)+\frac{1}{2} \rho C_{D} \frac{r}{L} u^{2}-\frac{\partial}{\partial y}\left(\beta_{y} r \tau\right)
$$

Introducing the turbulent eddy viscosity to express the turbulent shear stress as a gradient diffusion term analogous to molecular shear stress (the Boussinesq hypothesis, White 1991), the total shear stress can be modeled as

$$
\tau=\mu\left(1+\frac{\mu_{T}}{\mu}\right) \frac{\partial u}{\partial y}
$$


Substituting Equation 9 into Equation 8 and applying the fully developed flow simplifications $\left(\partial \beta_{x} / \partial x=0\right.$ and $\partial P / \partial x=d P / d x=$ constant $)$, the momentum equation for constant property flow reduces to the following ordinary differential equation:

$$
r \beta_{x} \frac{d P}{d x}+\frac{1}{2} \rho C_{D} \frac{r}{L} u^{2}-\mu \frac{d}{d y}\left[r \beta_{y}\left(1+\frac{\mu_{T}}{\mu}\right) \frac{d u}{d y}\right]=0
$$

The boundary conditions are taken to be

$$
\begin{aligned}
& y=0, \quad u=0 \\
& y=R, \frac{d u}{d y}=0
\end{aligned}
$$

The momentum equation may be cast in a more convenient form by introducing dimensionless quantities and parameters. Combining the Fanning friction factor, defined as

$$
f_{f} \equiv \frac{\tau_{w}}{\frac{1}{2} \rho U_{m}^{2}}
$$

with the force balance on the tube cross section of Figure 4, given by

$$
2 \pi R \tau_{w} d x=[P-(P+d P)] \pi R^{2}
$$

yields Equation 14 , the expression for $\mathrm{dP} / \mathrm{dx}$ in terms of the friction factor:

$$
\frac{d P}{d x}=-\rho f_{f} \frac{U_{m}^{2}}{R}
$$

Introducing the dimensionless variables $\tilde{u}=u / U_{m}, \tilde{y}=y / R, \tilde{r}=r / R=1-\tilde{y}$, defining the eddy viscosity parameter as

$$
L^{*}=\tilde{r} \beta_{y}\left(1+\frac{\mu_{T}}{\mu}\right)
$$




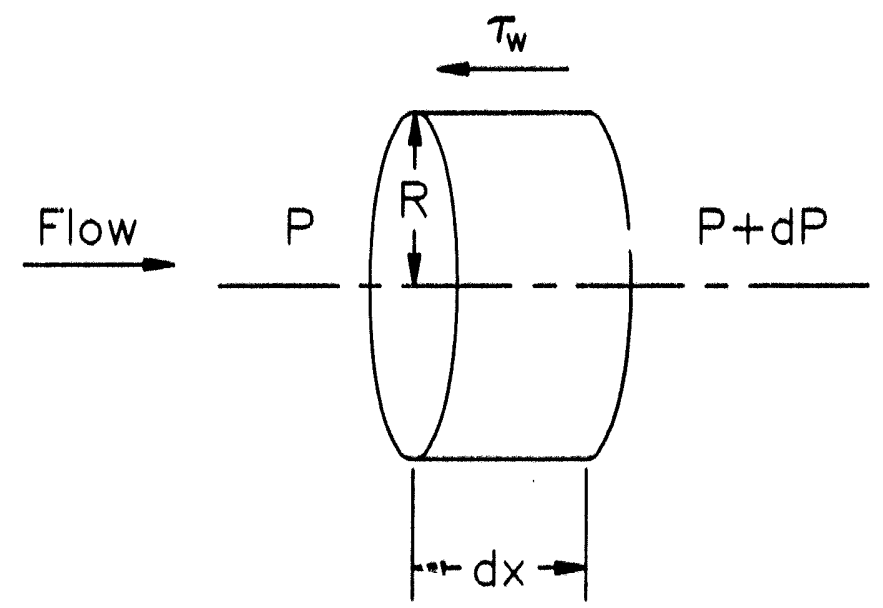

Fig. 4 Control volume lllustrating the force balance on an infinitesimal length of tube.

and the tube Reynolds number as

$$
\operatorname{Re}_{D}=\frac{2 \rho U_{m} R}{\mu}
$$

rearranging, and letting prime $(/$ denote differentiation with respect to ỹ yields

$$
\tilde{u}^{\prime \prime}+\frac{L^{* \prime}}{L^{*}} \tilde{u}^{\prime}-\left(\frac{1}{4 L^{*}} \operatorname{Re}_{D} \frac{1-\tilde{y}}{\tilde{L}} C_{D^{\prime}} \tilde{u}\right) \tilde{u}+\frac{1}{2 L^{*}} \beta_{x} \operatorname{Re}_{D} f_{f}(1-\tilde{y})=0
$$

with boundary conditions

$$
\begin{array}{ll}
\tilde{y}=0, & \tilde{u}=0 \\
\tilde{y}=1, & \tilde{u}^{\prime}=0
\end{array}
$$

\section{II.4 The Energy Equation}

The energy equation is obtained by applying conservation of energy to the fluid passing through the control volume. For this development, it is assumed that one can neglect the viscous shear work done on the fluid, that the changes in kinetic and potential energy are negligible in comparison with changes in internal energy, and that the heat conducted axially through the control volume is negligible compared to the heat conducted radially. When considering these assumptions, the conservation of energy statement for the control volume is

$$
\dot{Q}+\left(\dot{q} A_{r c}\right)_{y}-\left(\dot{q} A_{r c}\right)_{y+\delta y}=\left(\dot{m} c_{p} T\right)_{x+\delta x}-\left(\dot{m} c_{p} T\right)_{x}
$$


The area $A_{r c}$ is the area open to radial conduction between the rib elements, given by

$$
A_{r c}=2 \pi r 8 x \beta_{s}
$$

where $\beta_{s}$ is the smooth-wall fraction of the control volume length, or simply (L-w)/L.

The $\mathbf{Q}$ represents the heat transferred locally to the fluid directly from the rib elements, which can be expressed in terms of a local convective heat-transfer coefficient, $h_{\text {rib' }}$, the rib surface area exposed to the control volume, $A_{s}$, and the local temperature difference between the rib and fluid as

$$
Q=h_{r i b} A_{s} N_{\text {elem }}\left(T_{r i b}-T\right)
$$

It is convenient to express $A_{s}$ for ribs in a circular tube as $A_{s}=2 \pi r F_{A}$; for rectangular ribs, the area factor, $F_{A}$, is equal to $2 \delta y$ below the crests of the ribs, the rib width (w) at the crest of the ribs, and zero above the crests. Using the tube diameter as the characteristic length, the rih Nusselt number is defined as

$$
N u_{r b b}=\frac{h_{r b b}(2 R)}{K}
$$

Taking the rib temperature to be the wall temperature $\left(T_{\text {rib }}=T_{0}\right)$, substituting the expressions for $A_{s}$ and $N_{\text {elem }}$ and Equation 22 into Equation 21 yields

$$
\dot{Q}=N u_{r i b} K F_{A} \frac{\pi r 8 x}{R L}\left(T_{0}-T\right)
$$

Using the expressions for $m, A_{x}, A_{r c}$ and $Q$ in Equation 19, dividing by $\delta x \delta y$, and taking the limit as $\delta \mathrm{x}$ and $\delta \mathrm{y}$ approach zero results in

$$
\frac{N u_{r i b} K F_{A} r}{2 R L \delta y}\left(T_{0}-T\right)-r \frac{\partial}{\partial x}\left(\rho u \beta_{x} c_{p} T\right)-\frac{\partial}{\partial y}\left(r \beta_{s} q\right)=0
$$

Introducing the turbulent eddy conductivity, $\mathrm{K}_{\mathrm{T}}$, the Boussinesq hypothesis for turbulent heat flux allows the total heat flux to be expressed as 


$$
q=-K\left(1+\frac{K_{T}}{K}\right) \frac{\partial T}{\partial y}
$$

Substituting this expression for $\mathrm{q}$ into Equation 24 and noting that for constant-property, fully developed flow, $\partial\left(\rho u \beta_{x} c_{p}\right) / \partial x=0$, the energy equation becomes

$$
\frac{N u_{H b} K F_{A} r}{2 R L \delta y}\left(T_{0}-n-\rho u r \beta_{x} c_{p} \frac{\partial T}{\partial x}+K \frac{\partial}{\partial y}\left[r \beta_{s}\left(1+\frac{K_{T}}{K}\right) \frac{\partial T}{\partial y}\right]=0\right.
$$

with boundary conditions

$$
\begin{array}{ll}
y=0, & T=T_{0} \\
y=R, & \frac{\partial T}{\partial y}=0
\end{array}
$$

\section{II.5 Thermally Developed Flow in Rib-Roughened Tubes}

As discussed in Section II.2, the entrance region of a tube is a developing-flow region in which a viscous boundary layer develops and grows until the viscous effects reach the tube centerline and the velocity profile becomes fully developed, with $\partial u / \partial x=0$. A similar phenomenon occurs with the temperature-protile development at the entrance of a heated or cooled tube. Figure 5 shows conceptually the effect of subjecting a fully developed isothermal flow to a sudden change in tube surface temperature. The thermal boundary-layer thickness increases as the surface heat-conduction effects are diffused radially inward until they merge at the tube centerline. The resulting thermally developed temperature profile is not defined by $\partial \mathrm{T} / \partial \mathrm{x}=0$; such a condition would imply an adiabatic flow. The thermally developed conditions are instead such that the dimensionless temperature no longer varies with $x$; that is, $\partial \theta / \partial x=0$. 


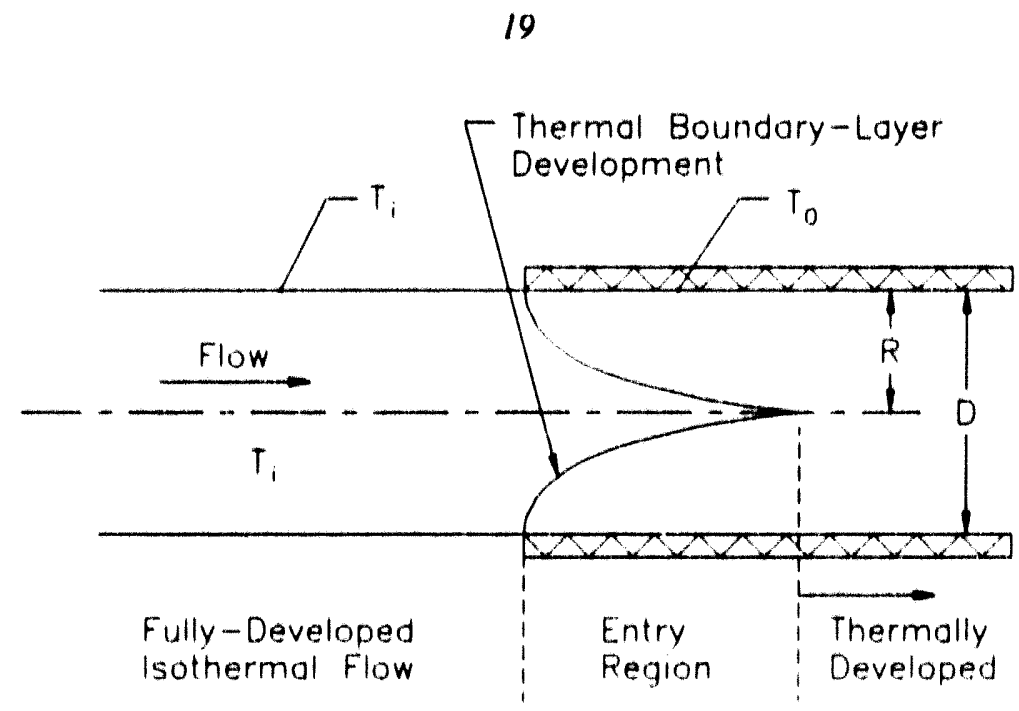

Fig. 5 Schematic Illustration of thermally developed now.

$$
\theta=\frac{T_{0}-T}{T_{0}-T_{m}}
$$

The mean temperature, $T_{m}$ (sometimes called the bulk temperature or mixing cup temperature), is the fluid temperature at a particular $\mathrm{x}$ location, energy-averaged over the cross section and defined by

$$
T_{m}=\frac{\int_{A} \rho u c_{p} T d A}{\int_{A} \rho u c_{p} d A}
$$

For constant-property, smooth-wall tube flow this reduces to

$$
T_{m}=\frac{2}{U_{m} R^{2}} \int_{0}^{R} u T r d r
$$

In experimental work, it is easier to determine that thermally developed flow is achieved when the local convective heat-transfer coefficient, $h$, defined such that

$$
q_{0}=h\left(T_{0}-T_{m}\right)
$$

becomes independent of the streamwise coordinate, $x$. This characteristic is not mere coincidence but is a direct result of the $\partial \theta / \partial x=0$ condition. With $\partial \theta / \partial x=0$, it follows that $\theta$ and (thus) $\partial \theta / \partial y$ are functions only of $y$, so that 


$$
\frac{\partial \theta}{\partial y}=\frac{\partial}{\partial y}\left(\frac{T_{0}-T}{T_{0}-T_{m}}\right)=\frac{-(\partial T / \partial y)}{T_{0}-T_{m}} * f(x)
$$

Since the velocity of the fluid at the wall is zero, the heat transferred in the fluid layer immediately adjacent to the wall is by conduction and is given by Fourier's Law

$$
q=-K\left(\frac{\partial T}{\partial y}\right)_{0}
$$

Combining Equations 31 and 33 and substituting into Equation 32 yields

$$
\frac{-(\partial T / \partial y)_{0}}{T_{0}-T_{m}}=\frac{h\left(T_{0}-T_{m}\right)}{K\left(T_{0}-T_{m}\right)} * f(x)
$$

Thus, for constant property, thermally developed thows, $h$ is independent of $x$.

The above requirements of thermally developed flow apply only to smooth-wall tube flows, but they are often taken as empirical facts that apply to rough-wall tube flows as well. Taylor and Hodge (1992a) treat these assumptions theoretically and conclude that threedimensional distributed-roughness-dominated flows become thermally developed (as characterized by a constant heat-transfer coefficient) much faster than smooth-wall llows, and that for such flows, $\partial \theta / \partial x=0$ also applies. For flow through a rib-roughened tube, however. the local heat-transfer coefficient, h, varies considerably in the streamwise direction due to the separation and reattachment mechanism between the ribs. This local heat-transfier distribution has been the subject of a number of experimental investigations (see Baughn and Roby 1992. Berger and Hau 1979, for example). In such experiments, it has been found that after a few rib cycles the local heat-transfer coefficients become periodic with rib cycles. This condition is analogous to the periodic velocity profiles of periodic, fully developed flow and is often appropriately referred to in the heat-transfer literature as periodic, thermally developed flow. A result of this periodic behavior is that the heat-transfer coefficient $x$-averaged over a complete rib cycle 


$$
\bar{h}_{\text {cyck }}=\frac{1}{L} \int_{\text {cych }} h d x
$$

is independent of $x$. Similarly, the dimensionless temperature profile $x$-averaged in the same manner leads to the conclusion that $\partial \theta_{\text {cycle }} / \partial x=0$. As mentioned in the discussion of fully developed flow, this $x$-averaging is accomplished automatically via the specificution of the control-volume length so that $\partial \theta_{\text {cycle }} / \partial x=\partial \theta / \partial x=0$. This property, coupled with the constant heat-flux and constant wall-temperature boundary conditions leads to the simplified encrgy equations discussed in the following sections.

\section{II.6 Constant Heat-Flux Energy Equation}

The constunt heat-flux boundary condition is often encountered in practice in applications such as counterflow heat exchangers with matched thermal capacities and in electrical-heating applications. Electrical heating is also a popular method for producing and maintaining constant heat-flux boundary conditions in laboratory experiments.

Solving Equation 28 for $\mathrm{T}$ yiclds

$$
T=T_{0}-\left(T_{0}-T_{m}\right) \theta
$$

Combining this with Equation 31 results in

$$
T=T_{0}-\frac{q_{0}}{h} \theta
$$

For constant heat flux, differentiating Equations 31 and 37 with respect to $x$, with $\partial \theta / \partial x=0$. leads to

$$
\frac{\partial T}{\partial x}=\frac{\partial T_{0}}{\partial x}=\frac{\partial T_{m}}{\partial x}
$$

An energy balance on the section of tube shown in Figure 6 results in Equation 39.

$$
h(2 \pi R d x)\left(T_{0}-T_{m}\right)=\rho U_{m}\left(\pi R^{2}\right) c_{\rho} d T_{m}
$$




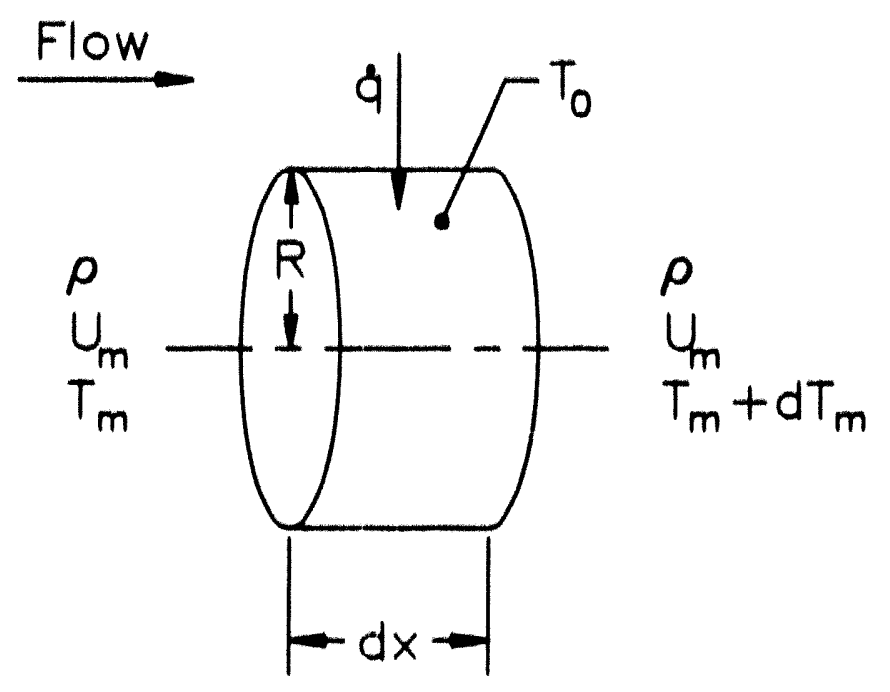

Fig. 6 Control volume Illustruting the enoray balance on an infinitesimal length of hented tube.

Rearranging and noting the result of Equation 38 yields

$$
\frac{\partial T}{\partial x}=\frac{\partial T_{m}}{\partial x}=\frac{2 h\left(T_{0}-T_{m}\right)}{\rho U_{m} R c_{p}}
$$

Defining the Nusselt number as

$$
N u=\frac{h D}{K}=\frac{h(2 R)}{K}
$$

and substituting into Equation $4(1)$ results in

$$
\frac{\partial T}{\partial x}=\frac{\alpha}{U_{m} R^{2}} N u\left(T_{0}-T_{m}\right)
$$

Using this expression for $\partial \mathrm{T} / \partial \mathrm{x}$ in the energy equation (26) produces

$$
\begin{aligned}
\frac{N u_{r b} K}{2 R} \frac{F_{A} r}{L \delta y}\left(T_{0}-T\right)-\rho u r \beta_{x} c_{p} \frac{\alpha}{U_{m} R^{2}} N u\left(T_{0}-T_{m}\right) \\
+K \frac{\partial}{\partial y}\left[r \beta_{s}\left(1+\frac{K_{T}}{K}\right) \frac{\partial T}{\partial y}\right]=0
\end{aligned}
$$


Equation 36 may be differentiuted with respect to $y$ in terms of the dimensionless variable $\tilde{y}=y / R$, resulting in Equation 44.

$$
\frac{\partial T}{\partial y}=\frac{\partial T}{\partial y} \frac{\partial y}{\partial y}=\frac{1}{R}\left[-\left(T_{0}-T_{m}\right) \frac{\partial \theta}{\partial y} \mid\right.
$$

Introducing the normalized variables $\tilde{a}=w / U_{m}, \tilde{L}=L / R, \tilde{F}_{A}=F_{A} / R$, and $\bar{f}=r / R=1-\bar{y}$ and substituting Equation 44 into Equation 43 yields, after considerable algebra,

$$
\frac{N u_{r b} F_{A}}{2 L \partial g} \theta-\beta_{x} u N u-\frac{1}{\partial y}\left[\beta_{s}\left(1+\frac{K_{T}}{K}\right) \frac{\partial \theta}{\partial y}\right]=0
$$

From the thermally developed thow property $\partial \theta / \partial x=0$, it follows that $\partial \theta / \partial \tilde{y}=d \theta / d \bar{y}$, and because the remaining terms within brackets are at most a function of $\bar{y}$, the purtial differential equation simplifies to an ordinary differential equation, given by

$$
\frac{N u_{r b} \hat{F}_{A}}{2 L \delta y} \theta-\beta_{x} a N u-\frac{1}{d y} \frac{d}{d y}\left[\beta_{,}\left(1+\frac{K_{T}}{K}\right) \frac{d \theta}{d y}\right]=0
$$

The normulized boundury conditions become

$$
\begin{aligned}
& y=0, \quad \theta=0 \\
& y=1, \quad \frac{d \theta}{d y}=0
\end{aligned}
$$

Defining the eddy conductivity purameter as

$$
L \cdot=\beta \beta_{s}\left(1+\frac{K_{T}}{K}\right)
$$

and normalizing the temperature protile by the tube Nusselt number such that

$$
\theta=\frac{\theta}{N u}
$$


the constant heat-flux energy equation (46) then becomes Equation 50:

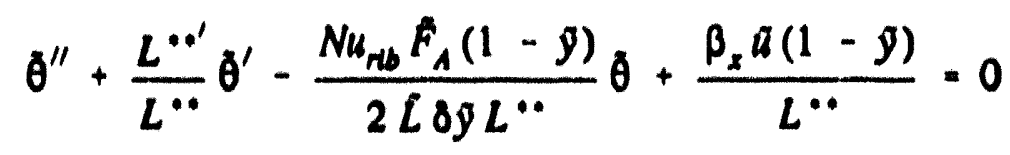

The boundary conditions are

$$
\begin{aligned}
& y=0, \quad \bar{\theta}=0 \\
& y=1, \quad \theta^{\prime}=0
\end{aligned}
$$

\section{II.7 Constant Wall-Temperature Energy Equation}

The constant wall-temperature boundary condition is encountered in practical applications, such as single-component evaporators und cundensers. Because of experimental difficulties, it is not often used in laboratory experiments. However, because of the heat/mass-transfer analogy, mass-transfer experiments, such as the naphthalene sublimation technique of Mendes and Mauricio (1987), produce results that are analogous to constant wall-temperature boundary conditions.

Differentiating Equation 36 with respect to $x$ results in

$$
\frac{\partial T}{\partial x}=\frac{\partial T_{m}}{\partial x} \theta
$$

Combining this with Equation 39 and reurranging yields

$$
\frac{\partial T}{\partial x}=\theta \frac{\alpha}{U_{m} R^{2}} N u\left(T_{0}-T_{m}\right)
$$


3

Substituting this constant wall-temperature expression for $\partial \mathrm{T} / \partial \mathrm{x}$ into Equation 26 yields

$$
\begin{aligned}
\frac{N u_{\mu b} K}{2 R} \frac{F_{A} r}{L \delta y}\left(T_{0}-T\right)-\rho u r \beta_{x} c_{p} \theta \frac{\alpha}{U_{m} R^{2}} N u\left(T_{0}-T_{m}\right) \\
+K \frac{\partial}{\partial y}\left[r \beta_{s}\left(1+\frac{K_{T}}{K}\right) \frac{\partial T}{\partial y}\right]=0
\end{aligned}
$$

Following the procedure used to obtain Equation 50 from Equation 43, the energy equation for constant wall temperature becomes the following ordinary differential equation in dimensionless form:

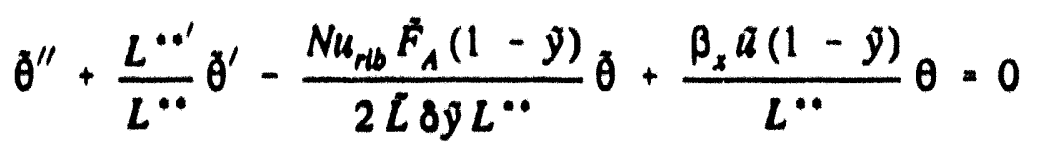

The boundary conditions are

$$
\begin{array}{ll}
y=0, & \theta=\theta=0 \\
y=1, & \theta^{\prime}=\theta^{\prime}=0
\end{array}
$$




\section{SECTION III EMPIRICAL CLOSURE}

The equations in the previous section were derived with the concept that the turbulent fluctuations in the flow variables are averaged over time, so that all flow variables are time-averaged quantities. The details of turbulence are replaced by empirical models for $\mu_{\mathrm{T}}$ and $K_{\mathrm{T}}$ via turbulence modeling. Similarly, the detuils lost by spatially averaging the roughness effects in the derivation of the governing equations must be replaced by appropriate empirical roughness models. This section discusses the turbulence models for turbulent eddy viscosity, $\mu_{\mathrm{r}}$, and turbulent eddy conductivity, $\mathrm{K}_{\mathrm{T}}$, the roughness models for the roughnesselement drag coefficient, $\mathrm{C}_{\mathrm{D}}$, the roughness-element Nusselt number, $\mathrm{Nu}_{\mathrm{rib}}$, and the blockage factors, $\beta_{x}$ and $\beta_{y}$.

\section{III.1 Turbulence Models}

III.1.1 Turbulent eddy viscosity. Turbulent closure for $\mu_{\top}$ is achieved using the two-band algebraic model suggested by Kays and Crawford (1980). In the neighborhood of the wall, the eddy viscosity, cast in terms of the Prandtl mixing length with van Driest damping, appears as Equation 57.

$$
\begin{aligned}
& \frac{\mu_{T}}{\mu}=\frac{1}{2} \operatorname{Re}_{D} \tilde{\ell}_{m}^{2}\left|\frac{\partial \tilde{u}}{\partial y}\right| \\
& \check{l}_{m}=0.4 \mathrm{~g}\left[1-\exp \left(\frac{-\frac{1}{2} R e_{D} \sqrt{\frac{f_{f}}{2} y}}{A^{*}}\right)\right]
\end{aligned}
$$

The $\mathrm{A}^{+}$is an empirical damping constant, the value of which is indicative of the capacity of the wall and viscous sublayer to damp out turbulent fluctuations. For zero-pressure-gradient flows, as well as for the slightly favorable pressure gradients associated with smooth-wall 
passage flow, the value of $\mathrm{A}^{+}$is traditionally taken to be 26 . Farther out into the turbulent core of the tube, $\mu_{\mathrm{T}}$ is modeled by

$$
\frac{\mu_{T}}{\mu}=0.4 \frac{1}{2} R e_{D} \frac{\sqrt{f_{f} / 2}}{6}
$$

Equation 57 is used from the wall out to the point where it gives the same value of $\mu_{\mathrm{T}} / \mu$ as Equation 58. From that point out to the tube centerline, Equation 58 is used.

III.1.2 Turbulent eddy conductivity. The turbulent eddy conductivity, $\mathrm{K}_{\mathrm{T}}$, is intimately tied to the turbulent eddy viscosity, $\mu_{\mathrm{T}}$, because energy and momentum transfer processes in a turbulent flow are dominated by the turbulent fluctuations. For this reason and to avoid postulating a separate energy-equation turbulence model, it is both convenient and customary to define a turbulent Prandtl number, $\operatorname{Pr}_{\mathrm{T}}$, as

$$
\operatorname{Pr}_{T}=\frac{c_{p} \mu_{T}}{K_{T}}
$$

which is directly analogous to the molecular Prandtl number

$$
\operatorname{Pr}=\frac{v}{\alpha}=\frac{c_{p} \mu}{K}
$$

With $\mu_{\mathrm{T}} / \mu$ already determined from Equation 57 or 58 , the turbulent eddy conductivity may be modeled as

$$
\frac{K_{T}}{K}=\frac{\mu_{T}}{\mu} \frac{P r}{P r_{T}}
$$

Note that $\operatorname{Pr}$ is a fluid property, independent of the flow field and indicative of the relative transport properties of the fluid, while $\mathrm{Pr}_{\mathrm{T}}$ is a flow-field property indicative of the turbulence-generated transport properties of the flow field.

It is often appropriate to assume $\operatorname{Pr}_{\mathrm{T}}=1$, because the turbulent-energy and momentum-transport mechanisms are both driven by the fluctuating motions of turbulent eddies. Indeed, this is one of the bases for the celebrated Reynolds analogy for turbulent flow discussed in many heat-transfer texts. However, although the turbulent-momentum and energy-transport mechanisms are both a result of turbulent eddy fluctuations, the details of the 
mechanisms are not identical. As a result, $\operatorname{Pr}_{\mathrm{T}}$ may vary slightly from unity and can vary on a local level throughout the flow field.

This local variation of $\mathrm{Pr}_{\mathrm{T}}$ in the various types of turbulent flows has not been fully resolved. Because of experimental difficulty and uncertainty involved in determining local turbulent Prandtl numbers, the information in the literature regarding this subject is sparse and often inconsistent. Reynolds (1975) provides a good review of the literature on $\mathrm{Pr}_{\mathrm{T}}$.

For turbulent flow in a smooth tube, it has been found (Schlichting 1979) that $\operatorname{Pr}_{\mathrm{T}}$ decreases from a value of about 1 at the wall to a value of about 0.67 in the center of the tube. Similar results have been reported for boundary-layer flow with $\operatorname{Pr}_{\mathrm{T}}$ decreasing to 0.5 (Schlichting) at the edge of the boundary layer (or 0.7, as suggested by White 1991). Measurements in turbulent jets and wakes (Schlichting) indicate that a turbulent Prandtl number of 0.5 should be used for free turbulence.

In boundary-layer and passage flows, a common and very successful approach is to assume an average, constant turbulent Prandtl number (White 1991) as in Equation 62.

$$
P r_{T} \approx 0.9 \text { or } 1.0 \quad \operatorname{Pr}>0.7
$$

This approach has also been applied successfully in the three-dimensional distributed roughness models of Taylor et al. (1985a) and Taylor and Hodge (1992a, 1992b).

The interface between the main flow field and the separated flow behind a step or a rib is essentially a free shear layer or mixing layer (see Bradshaw and Wong 1971). At the point of reattachment downstream of the rib or step, the free shear layer impinges upon the wall, bringing what was previously the central region of the mixing layer, along with its characteristics, into close contact with the wall. Because the near-wall flow field over twodimensional rib-type roughness comprises numerous separated flows reattaching between ribs, the flow is modeled as retaining some of the $\operatorname{Pr}_{\mathrm{T}}$ characteristics of a free shear layer, rather than increasing to unity at the wall. Thus, a constant value of $\operatorname{Pr}_{\mathrm{T}} \approx 0.7$, corresponding to the experimental value for the centerline or core flow of a tube, is used for the present work. 


\section{III.2 Roughness Models}

III.2.1 Blockage factors. The blockage for three-dimensional distributed roughness is a function of the roughness geometry only (Taylor and Hodge 1992a, 1992b) and does not require empirical closure. However, due to the significant streamline curvature and the separation/reattachment mechanisms present in the flow over two-dimensional rib roughness, the blockage is a function not only of the roughness geometry, but also of the mechanics of the flow field. Figure 7, after Lawn (1976) and Taylor et al. (1985b, 1989), shows a simplified model of the flow separation and reattachment in the vicinity of the rib elements. The ribs are situated sufficiently far apart that reattachment occurs between the ribs as shown. Figure 7 also indicates that the separated regions upstream and downstream of each rib act along with the rib elements as blockage to the flow. The blockage factors $\beta_{x}$ and $\beta_{y}$ are easily determined, once the geometry of the separated regions is specified.

As suggested by Lewis (1975), the separation streamline on the upstream side of the rib is modeled as a straight line extending from the separation point to the forward tip of the rib. On the basis of the findings of Lawn (1976) and Good and Joubert (1968), the separation point is taken to be one rib height upstream of the element. Similarly, the downstream separation streamline is modeled as a straight line extending from the rearward tip of the rib to the reattachment point. The downstream reattachment point is taken to be $\gamma$ rib heights downstream.

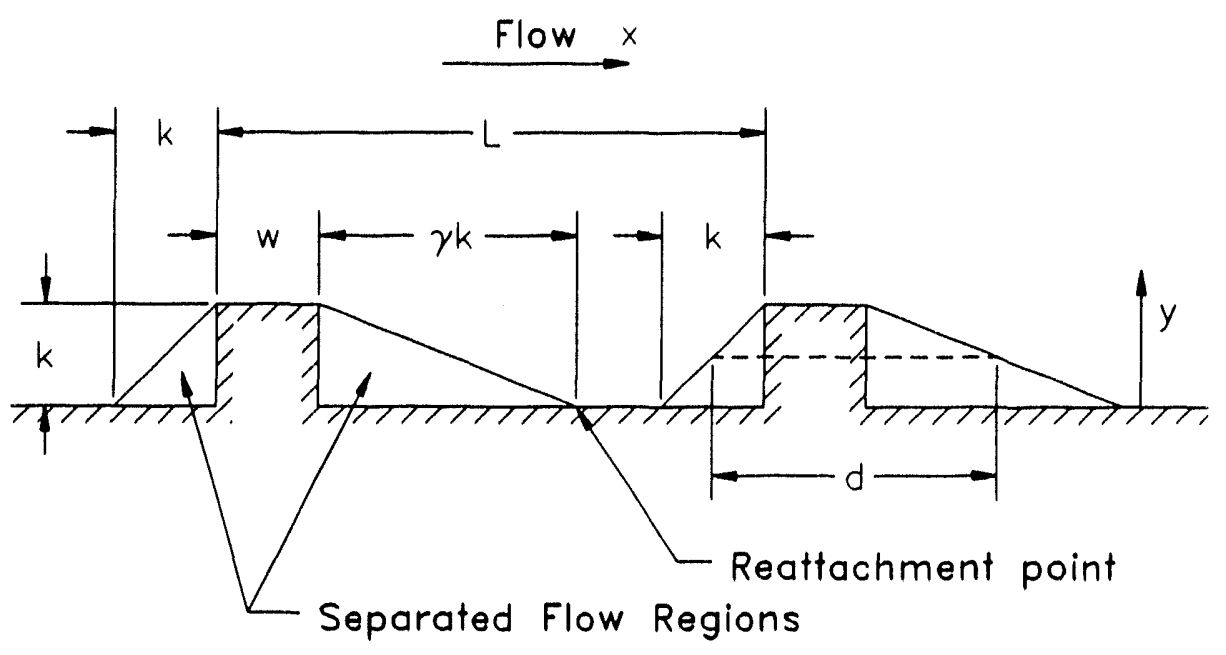

Fig. 7 Simplified flow model of separation and reattachment mechanism. 
In Taylor et al. (1985b, 1989), $\gamma$ is taken to be 5. A more detailed model for $\gamma$, based on the experimental evidence of Faramarzi and Logan (1991) and Mantle (1966), is used in this study. Faramarzi and Logan report that for a single roughness element (infinite pitch-to-height ratios, $\mathrm{L} / \mathrm{k}$ ) the reattachment length, $\gamma$, is a strong function of width-to-height ratio $(w / k)$ when $w / k$ is less than about 2 and is essentially constant for $w / k$ greater than 2 . Their findings also indicate that $\gamma$ is independent of passage Reynolds number. Mantle investigates the effect of $L / k$ on $\gamma$ for square ribs $(w / k=1)$. He reports that reattachment does not occur for $L / k$ less than 6.6 and that for $L / k$ between 6.6 and $12, \gamma$ is essentially a constant value of 4 . His values of $\gamma$ increase from 4 to 8.5 as $\mathrm{L} / \mathrm{k}$ increases from 12 to 28 and remain constant at 8.5 for larger values of $L / k$. Faramarzi and Logan report a value of $\gamma$ $=9.1$ for a square rib of infinite $L / k$. Based on these references, $\gamma$ is modeled by

$$
\gamma=\gamma_{w} \frac{\gamma_{L}}{\gamma_{s}}
$$

where $\gamma_{w}$ is the reattachment length of a single roughness element based on the actual $w / k$ ratio (Faramarzi and Logan), $\gamma_{L}$ is the reattachment length of a square element based on the actual $\mathrm{L} / \mathrm{k}$ ratio (Mantle), and $\gamma_{\mathrm{SS}}$ is the reattacl ment length of a single square roughness element (Faramarzi and Logan). The variations in $\gamma_{w}$ and $\gamma_{S S}$ are approximated by the following linear curve-fits of the data presented by Faramarzi and Logan:

$$
\begin{array}{ll}
\gamma_{w}=-2.6\left(\frac{w}{k}\right)+11.7 & \left(\frac{w}{k}\right) \leq 2 \\
\gamma_{w}=6.5 & \left(\frac{w}{k}\right)>2 \\
\gamma_{s s}=9.1 &
\end{array}
$$


Similarly, the variation in the $\gamma_{L}$ data presented by Mantle is approximated by

$$
\begin{array}{lrl}
\gamma_{L}=4 ; & 6.6 \leq\left(\frac{L}{k}\right) \leq 12 \\
\gamma_{L}=0.3667\left(\frac{L}{k}\right)-1.0672 ; & 12<\left(\frac{L}{k}\right) \leq 28
\end{array}
$$

With the geometry of the separated regions thus specified, the blockage factor $\beta_{y}$, previously defined as the fraction of area open to flow in the radial direction, is seen by examination of Figure 7 to be

$$
\begin{aligned}
& \beta_{y}=1-\frac{d}{L} \\
& d=w+(\gamma+1)(k-y)
\end{aligned}
$$

The axial blockage factor, $\beta_{x}$, is more difficult to visualize. For some $x$ locations, the thow is completely blocked below the crest of the ribs, while for other $x$ locations there is zero blockage. However, due to the inherent $x$-averaging process employed in the derivation of the governing equations, the blockage factor $\beta_{x}$ is an averaged quantity that does not vary in the streamwise direction (i.e., $\partial \beta_{x} / \partial x=0$ ). Averaging $\beta_{x}$ over a rib cycle for any $y$ location below the crests of the ribs reveals that

$$
\beta_{x}=\frac{1}{L} \int_{L} \beta_{x, d \text { ocal }} d x=1-\frac{d}{L}=\beta_{y}
$$

Above the crests of the ribs, both $B_{x}$ and $B_{y}$ are equal to 1 .

III.2.2 Rib-element form-drag coefficient. The detailed local pressure measurements of Lawn (1976) show that the fluid flowing over a rib element results in a nearly constant low pressure on the leeward side of the rib, while the pressure on the windward side decreases from ihe base of the rib to the tip. A direct result of this local 
windward-to-leeward pressure difference is a local drag force on the element, which may be cast in terms of a local drag coefficient defined as

$$
C_{D}=\frac{P-P_{b}}{\frac{1}{2} \rho u^{2}}
$$

which is based on the local velocity, $u$, the local windward-side pressure, $P$, and the essentially uniform leeward-side pressure or base pressure, $P_{b}$.

Good and Joubert (1968) point out that although drag coefficients for bluff bodies immersed in a free stream are essentially constant for all Reynolds numbers above a few thousand, the drag coefficient of a bluff body attached to a wall and immersed in its turbulent boundary layer is Reynolds-number-dependent. Although they do not present a local drag coefficient, $C_{D}$, of the form of Equation 68 , Good and Joubert do present empirical relations for a base-pressure coefficient, $C_{p, b}{ }^{*}$, and windward-side pressure coefficient, $C_{p, w}{ }^{*}$, which for the purposes of the present work are combined to form a single local pressure coefficient, $C_{p}$, defined as

$$
C_{p}=C_{p, w}^{*}-C_{p, b}^{*}=\frac{P-P_{b}}{\frac{1}{2} \rho U^{*^{2}}}
$$

This local pressure coefficient, $\mathrm{C}_{\mathrm{p}}$, takes on the functional form

$$
C_{p}=C_{1} \log \left(\frac{k U^{*}}{v}\right)+C_{2}
$$

where $C_{1}$ and $C_{2}$ are experimentally determined constants. The constants presented by Good and Joubert correspond to various configurations of a single, two-dimensional bluff plate attached to a wall. Such configurations do not correspond to repeated two-dimensional ribs with in-tube flow, and the authors are unaware of any other works that provide functional relations for local pressure coefficients of repeated-rib elements. Therefore, the values of $C_{1}$ and $\mathrm{C}_{2}$ utilized in this study are determined by numerical experimentation to provide the best agreement with the data sets of Webb et al. (1971), to be examined later. 
Good and Joubert reference the pressure coefficient given in Equations 69 and 70 to the friction velocity, a parameter having the units of velocity,

$$
U^{*}=\sqrt{\frac{\tau_{w}}{\rho}}
$$

The friction velocity is used extensively to interpret turbulent flow profiles and provides a basis for the inner-region dimensionless wall coordinates. The bracketed term in Equation 70 is actually the dimensionless wall-coordinate $y^{+}=y^{*} / v$ at the location $y=k$. The particular friction velocity used by Good and Joubert is that which would exist on the smooth wall if a bluff plate were not present. The utility of using the smooth-wall friction velocity is that dimensionless velocity profiles and frictional characteristics of smooth walls have been extensively studied and documented. By defining a reference friction factor, $\mathfrak{f}_{\mathrm{f}, \mathrm{ref}}$, as the friction factor that would exist in a smonth tube at the same Reynolds number as the particular rib-roughened tube under consideration and combining the definitions of friction velocity, Equation 71 , and friction factor, Equation 12, the friction velocity for in-tube flow is expressed as

$$
U^{*}=U_{m} \sqrt{\frac{f_{\text {fref }}}{2}}
$$

Equation 70 may then be cast as

$$
C_{p}=C_{1} \log \left(\frac{\tilde{k}}{2} \operatorname{Re}_{D} \sqrt{\frac{f_{f, r g f}}{2}}\right)+C_{2}
$$

The reference friction factor, $f_{f, r e f}$, is calculated from the Swamee-Jain (1976) approximation by specifying zero roughness:

$$
f_{\text {f,ref }}=\frac{0.0625}{\left[\log \left(\frac{5.74}{R e_{D}^{0.9}}\right)\right]^{2}}
$$


The local drag coefficient, $C_{D}$, is then related to the local pressure coefficient, $C_{p}$, by the expression

$$
C_{D}=\frac{C_{p} \sqrt{\frac{f_{\text {fref }}}{2}}}{\tilde{u}_{\text {rof }}^{2}}
$$

where the local normalized reference velocity, $a_{r e f}$ is defined, in similar fashion with the reference friction factor, as the velocity profile for a smooth tube at the same Reynolds number as the rib-roughened tube under consideration. In the present analysis, the reference velocity profile is obtained from the dimensionless one-seventh power-law approximation

$$
a_{n f}=1.224(\mathfrak{)})^{1 n}
$$

III.2.3 Rib-element Nusselt number. The heat-transfer augmentation due to the presence of rib roughness is often expressed as the ratio of the mean heat-transfer coefficient for the rib-roughened tube to the mean heat-transfer coefficient of a smooth-wall tube at the same Reynolds number (see, for example, Berger and Hau 1979; Liou and Hwang 1992). It is, therefore, convenient to express the local element Nusselt number, $\mathrm{Nu}_{\text {rib, }}$ in terms of the smooth-wall Nusselt number multiplied by a rib enhancement factor, $E_{r}$. The smooth-wall Nusselt number is calculated from the Dittus-Boelter equation (Holman 1986, for example), so that $\mathrm{Nu}_{\text {rib }}$ may be expressed as

$$
N u_{r b b}=0.023 E_{r} \operatorname{Re}_{D}{ }^{0.8} \operatorname{Pr}^{0.4}
$$

Rather than attempting to account for the local variation of heat-transfer coefficients over the rib surface, $\mathrm{Nu}_{\text {rib }}$ is treated as a constant over the rib surface. An average-element heat-transfer coefficient model should be less sensitive to rib geometry and Reynolds number than a local-element heat-transfer model. According to Liou and Hwang (1992), the average value of $E_{r}$ is approximately 2. The data of Berger and Hau (1979), Lewis (1975), and Sato et al. (1992), however, suggest an average value of $E_{r}-3$. In the present analysis, the value of $E_{r}$ is taken to be 3 . 
Altermative methods of modeling the rib-element heat-transfer coefficient are discussed, and compured with the present method, in Appendix A. 


\section{SECTION IV \\ SOLUTION PROCEDURE}

With the specification of constant-property, incompressible flow, the momentum equation is uncoupled from the energy equation and may be solved independently. In this analysis, the momentum equation is first solved to determine the friction factor and velocity profile. The velocity profile is then used in the solution of the energy equations.

\section{IV.1 Momentum Equation}

Since there are two unknowns, the friction factor, $f_{f}$, and the velocity profile, $\tilde{u}(\tilde{y})$, in the momentum equation, an additional equation is required. This equation is provided by applying conservation of muss over the tube cross section

$$
\rho U_{m} A \cdot \int_{A} \beta_{x} p u d A
$$

which for a circulur tube becomes

$$
U_{m} R^{2}=2 \int_{0}^{R} \beta_{x} u r d r
$$

Rearranging and expressing in terms of dimensionless variables yields

$$
\tilde{u}_{m}=1=2 \int_{0}^{1} \beta_{x} a(1-y) d y
$$

The friction fuctor, $f_{p}$, and velocity profile, $\tilde{u}(\tilde{y})$, are then determined using the following procedure:

1. Specify the tube Reynolds number, $R_{D}$, and roughness geometry $(\bar{k}, \bar{w}$, and $\bar{L}$ ).

2. Use the smooth-wall friction factor from Equation 74 as an initial low-side estimate of $f_{j}$.

3. Using the estimated value of $f_{p}$, compute $u(y)$ using the finite-difference procedure in Appendix B. Then calculate $\tilde{u}_{\mathfrak{m}}$ from this velocity profile.

4. Repeat step 3, this time using a high-side estimate of $f_{f}$. 
5. Steps 2.4 produce values of $a_{m}$ that bound 1 . Use the method of fulse position to generute better estimutes of $f_{f}$ to use in step 3 , iterating until $a_{m}=1$.

\section{IV.2 Energy Equation - Constant Heat Flux}

With the velocity profile obtuined from the solution of Equation 4h, the momentum equation, the constant heat-flux energy equation, Equation 50, may then be solved directly for $\theta$ using the finite-difference method given in Appendix B. The Nusselt number is determined using the requirement that the mean value of the dimensionless lemperature equals unity.

$$
\theta_{m}=N u \dot{\theta}_{m}=1=2 N u \int_{0}^{1} \beta_{x} u(1-y) \dot{\theta} d y
$$

or

$$
N u \cdot \frac{1}{\theta_{m}}
$$

\section{IV.3 Energy Equation - Constunt Wall T'emperature}

Equation 55, the constant wall-temperature energy equation, cannot be solved directly for $\theta$ becuuse it also contains $\theta$. The solution is obtuined in an iterative manner by using assumed profiles for $\theta$ and solving for $\theta$, using the following procedure:

1. Assume un initial protile for $\theta=\theta_{1}$. An excellent starting protile is the constant heut-flux protile from Section IV.2. This profile is easily obtuined by setting $\theta_{1}=1$ for all $y$, which artificially forces Equation 55 to become identical to Equation 50.

2. Solve Equation 55 for $\theta$, using the assumed $\theta$ profile and the finite-difference procedure outlined in Appendix B.

3. Compute Nu from Equations 81 and 82 , using $\theta$ from step 2.

4. Repeat steps 2 and 3, using the new assumed profile $\theta_{i}=N u_{i-1} \dot{\theta}_{i-1}$, until a consistent value of $\mathrm{Nu}$ is obtained. Usually, fewer than three iterations are required. 


\section{SECTION $V$ CALIBRATION AND COMPARISON WITH EXPERIMENTS}

This section discusses the calibration and validation of the discrete-element roughness model and compares its predictions with classical smooth-wall results and appropriute cases from the experimental data sets of Webb et al. (1971), Berger and Hau (1979), Mendes and Mauricio (1987), and Baughn and Roby (1992). Appendix C contuins detailed information about the experimental data and the rib geometry for each surface considered.

\section{V.1 Smooth Wall}

In order to verify the general solution procedure and computer coding, the model was compared with classical smooth-wall solutions for both laminur and turbulent flow. The computer program can be used to predict smooth-wall friction fucturs and Nusselt numbers by specifying a vanishingly small roughness.

Table I shows a comparison of the computed predictions with the classical smoothwall laminar solutions given by Kays and Crawford (1980). The agreement is perfiect for the direct solutions of $\mathrm{f}_{\mathrm{f}}$ and $\mathrm{Nu}_{\mathrm{H}}$ and exact within the convergence limits of the iterative solution for $\mathrm{Nu}$. This test demonstrates that the solution procedure is correct and coded properly.

To test the solution procedure and coding of the turbulence model, the program is validated against the classical results for the turbulent smooth-wall case by

TABLE 1 - Laminur Flow Comparisons

\begin{tabular}{|c|c|c|c|c|c|c|}
\hline \multirow[b]{2}{*}{$\mathrm{Re}_{\mathrm{D}}$} & \multicolumn{3}{|c|}{ Present Predictions } & \multicolumn{3}{|c|}{ Classical Solutions } \\
\hline & $f_{f}$ & $\mathrm{Nu}_{\mathrm{HI}}$ & $\mathrm{Nu}_{\mathrm{T}}$ & $f_{1}=16 / R_{0}$ & $\mathrm{Nu}_{\mathrm{H}}$ & $\mathrm{Nu}_{\mathrm{T}}$ \\
\hline $10(0)$ & 0.0160 & 4.364 & 36.54 & 0.016 & 4.364 & 3.6 .58 \\
\hline 20000 & 0.00080 & 4.364 & 3.6 .54 & 0.01018 & 4.364 & 3.6 .58 \\
\hline
\end{tabular}


specifying a vanishingly small roughness. For a vanishingly small roughness, the value of constants $C_{1}$ and $C_{2}$ in Equation 73 are inconsequential, because the drag force on the vanishingly small elements approaches ero. Taking $A^{+}$in the turbulence model to be the traditional value of 26, the agreement with the Swames Jain (1976) expression for friction factor, as shown in Figure 8, is excellent. A constant turbulent Prandil number for smooth walls ( $\operatorname{Pr}_{r_{\mathrm{T}}}=0.9$ for $\operatorname{Pr}<1$ and $\operatorname{Pr}_{r_{\mathrm{T}}}=1.0$ for $\left.\operatorname{Pr}>1\right)$ provides excellent agreement, as shown in Figure 9, with the Dittus-Boelter correlation for Nusselt number (Holman 1986). The Nusselt number predictions shown are for a Prandtl number of 0.71 and a constant heat- Ilux boundary condition. The excellent agreement for the smosth-wall turbulent casce verifies that the turbulence models and solution procedures are coded correctly. Calibration and validation of the roughness model are considered in the remainder of this section.

\section{V.2 Webb et ul. (1971)}

Webb et al. (1971) provided an extensive set of heat-transfer and friction-factor data for fluid flow inside tubes with a wide range of rectangular rib geometries. The friction

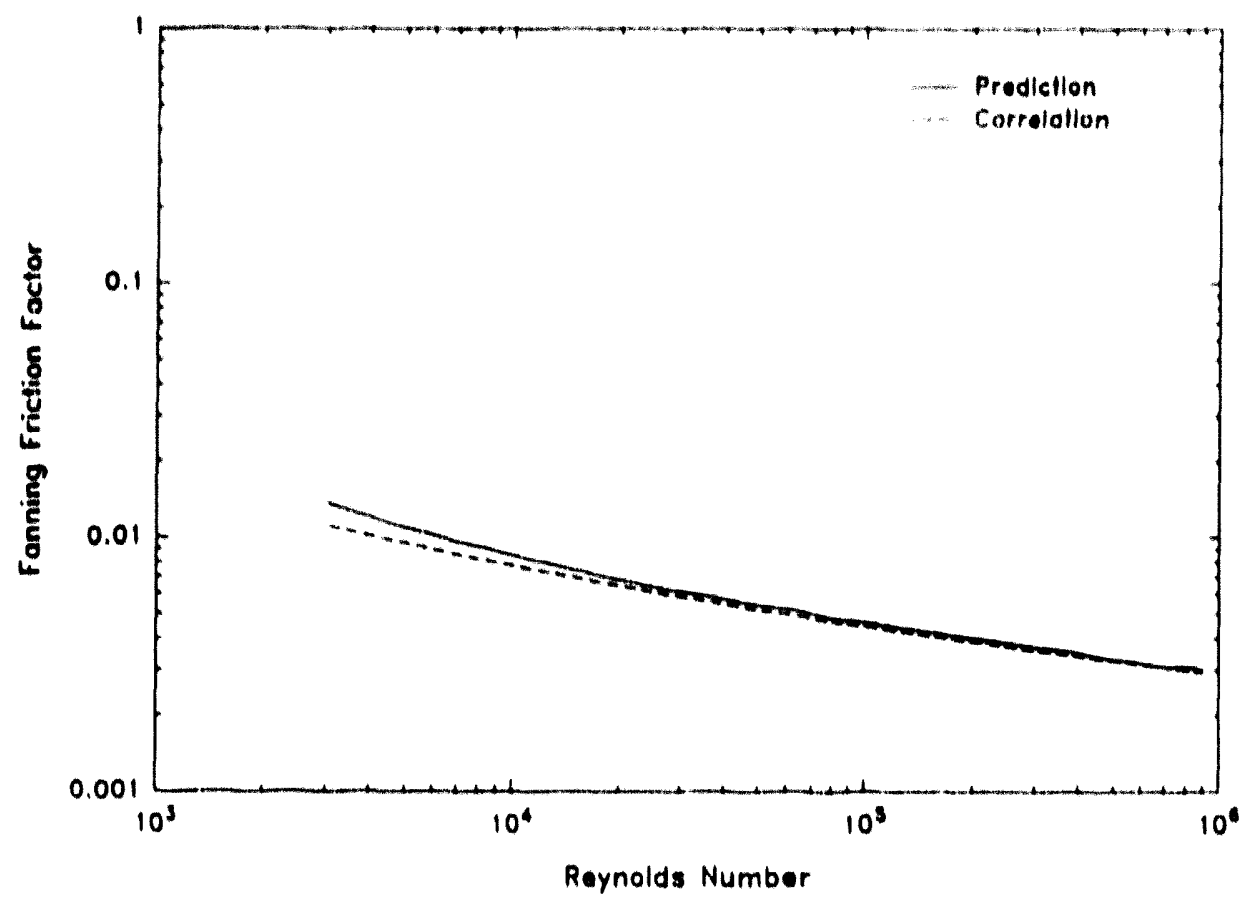

Fig. 8 Comparison of the smosth-wull predletions with the Swamee-Jain (1976) correlation. 


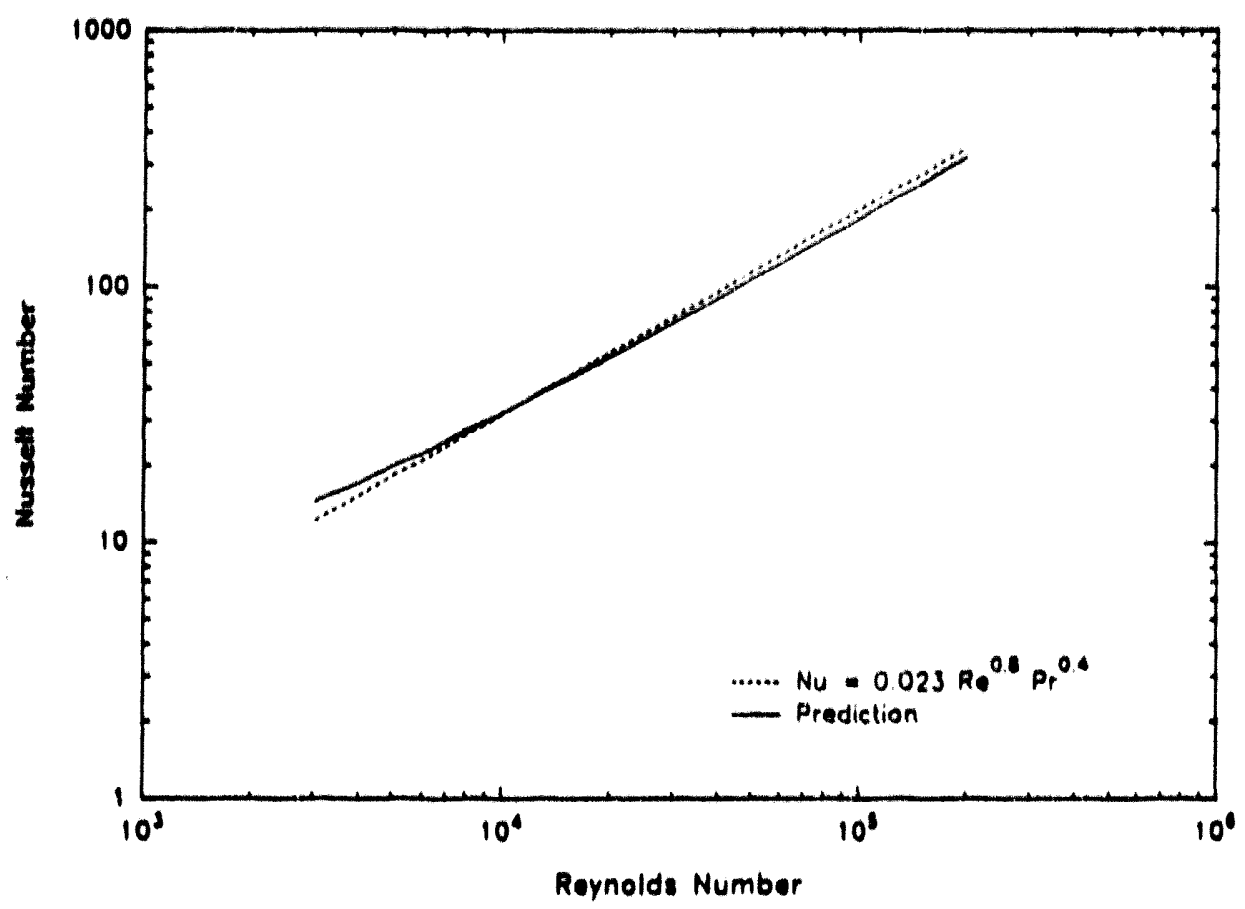

Flg. 9 Comparienon of the smonth-wall Nunselt number predictions with the Dittus. Boeltor equation.

factors were determined with air us the working fluid, without heat input, and they were bused on pressure drop across the entire length of the roughened working section. The heattransfer experiments were conducted with air $(\operatorname{Pr}=0.71)$, water $(\operatorname{Pr}=5.1)$, and $n$-butyl alcohol $(\operatorname{Pr}=21.7)$ under an electrically heated, constant heat-flux boundary condition.

Of wil the data sets examined, this is the most useful in calibrating the values $C_{1}$ and $\mathrm{C}_{2}$ of Equation 73, because it provides the most extensive variution in rib geometries. Figure 10 demonstrates the effects of varying the rib height, $k$, from very short ribs $(k / D=0.01)$ to relatively tall ribs $(k / D=0.04)$ while holding the rib width, $w$, the tube diameter, $D$, and the rib spacing-to-height ratio, $L / K$, constant. Holding the rib width constunt also allows $w / k$ to vary from $w / k=0.254$ (a slender rib) to $w / k=1.0$ (a square rib).

Figure 11 shows the effects of varying the rib spacing from $L / k=10$ to $L / k=40$ while holding the rib height, rib width, and tube diameter constant. 


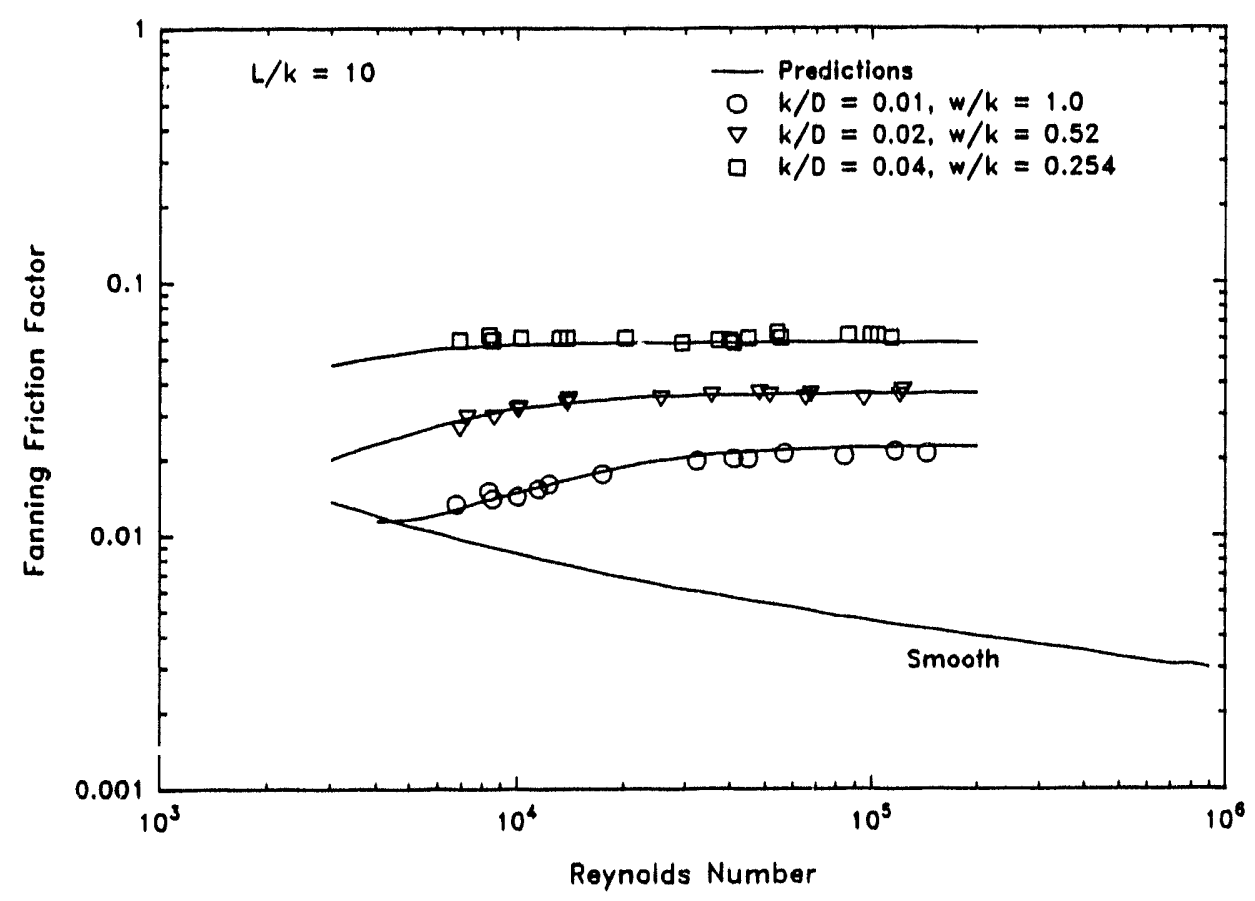

Fig. 10 Comparison of friction factor predictions with the data of Webb et al. (1971) for $L / k=10$ and varying $k / D$ and $w / k$ ratios.

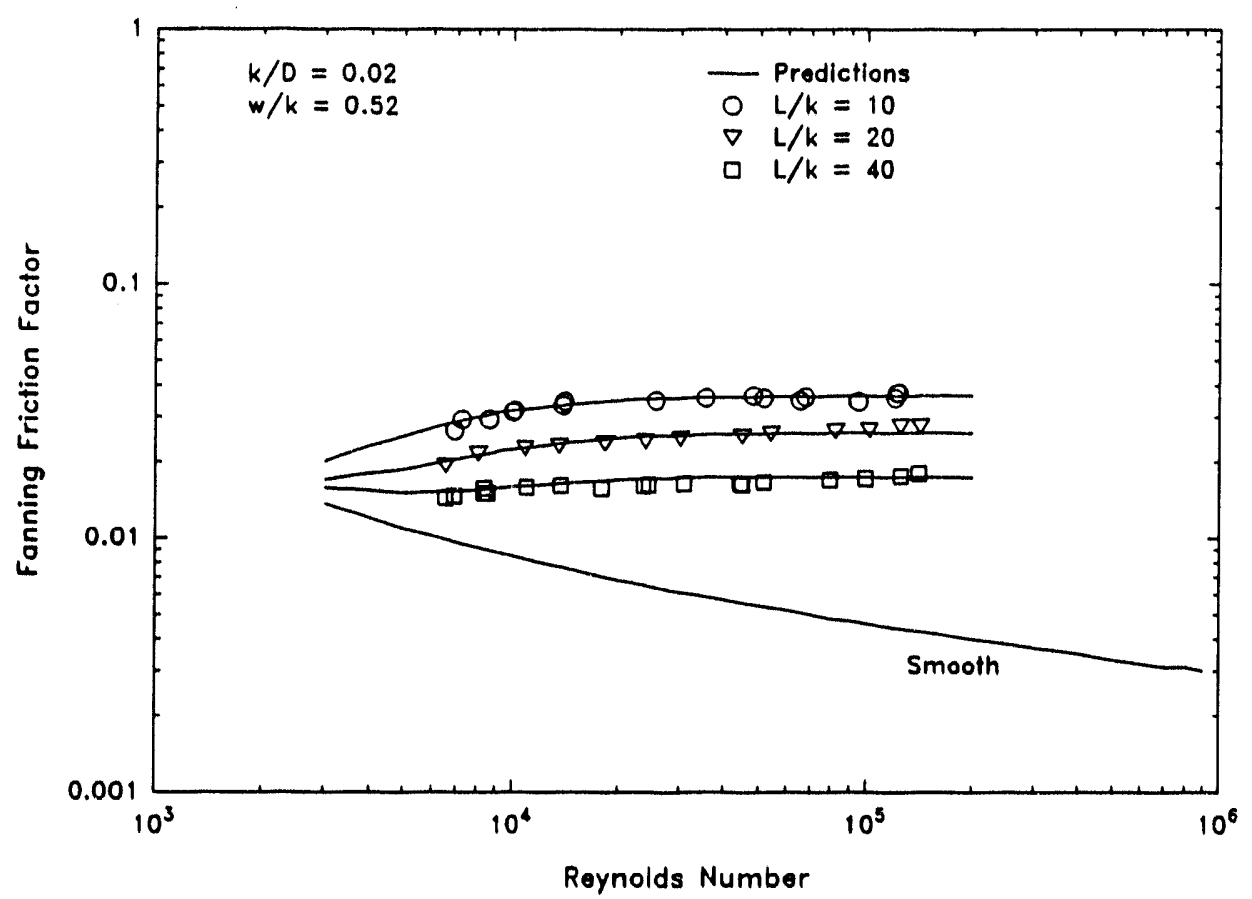

Fig. 11 Comparison of friction factor predictions with the data of Webb et al. (1971) for $k / D=0.02, w / k=0.52$, and varying $L / k$ ratios. 
The values of $\mathrm{C}_{1}$ and $\mathrm{C}_{2}$ that best model these data sets are

$$
\begin{aligned}
& C_{1}=2846\left(\frac{L}{k}\right)^{-0.5} \\
& C_{2}=-0.4 C_{1}
\end{aligned}
$$

Equation 83 is valid for all roughness geometries in Figures 10 and 11, with the exception of the $k / D=0.01$ geometry. For this geometry, the roughness height is of the same order as the smooth-wall viscous sublayer thickness over the range of Reynolds numbers examined. With most of the roughness element buried within the viscous sublayer, it is expected that the drag mechanism is dominated by the viscous sublayer and should deviate from Equation 83 because of the dominant effect of the viscous sublayer. The formdrag characteristics begin to deviate from Equation 83 at values of $\mathrm{k} / \mathrm{D}$ below about 0.02 ; hence, the value of $C_{1}$ is adjusted when $k / D$ is less than 0.02 by the following relation:

$$
C_{i(A D)}=C_{i}\left(\frac{1-0.4}{1-\tilde{k}}\right)^{19.66}
$$

Equation 84 is based on a relation given by Castro and Fackrell (1978), which relates the drag coefficients of bluff plates attached to a wall (an arrangement they refer to as "fence" flow) as measured in a wind tunnel, where the upper tunnel wall constricts the flow, to the drag coefficient of the same "fence" located where the flow is not restricted by an upper wall. Interestingly, their findings indicate that the drag-coefficient deviation is significant at low values of fence-height to boundary-layer thickness and relatively insignificant at high values of fence-height to boundary-layer thickness. This is directly analogous to the deviation from Equation 83 encountered only at values of rib height-to-diameter ratio below 0.02 .

Equation 83 reveals that for modest $k / D$ ratios (i.e., $k / D>0.02$ ), rib geometries with identical L $/ \mathrm{k}$ ratios exhibit similar form-drag characteristics regardless of the height-todiameter ratios or width-to-height ratios. Conversely, rib geometries of different $\mathrm{L} / \mathrm{k}$ ratios exhibit dissimilar form-drag characteristics, as demonstrated by the $\mathrm{L} / \mathrm{k}$ dependence in Equation 83. The model's treatment of all rib geometries of equal $\mathrm{L} / \mathrm{k}$ ratios as similar in roughness is consistent with the rib-roughness literature convention of defining geometrically similar rib roughness. A family of rib geometries is geometrically similar if $L / k$ is constant 
and the rib shape does not change. By this definition, the $\mathrm{L} / \mathrm{k}=10$ rib geometries of Figure 10 are not exactly geometrically similar, because the $w / k$ ratio, and hence the rib shape, also varies with $\mathrm{k} / \mathrm{D}$. This variation in rib shape, however, is insufficient to cause a significant deviation from geometrically similar behavior. Otherwise, Webb et al. could not have correlated their data with only one friction similarity function.

As demonstrated by Taylor et al. (1985a, 1992a, 1992b), the traditional smooth-wall value of $\mathrm{A}^{+}=26$ in the van Driest damping function of Equation 57 is appropriate for the three-dimensional distributed-roughness model. For the two-dimensional rib roughness, a value of $\mathrm{A}^{+}=26$ also provides excellent agreement with the data in the hydraulically smooth regime. The friction factor in this regime is dependent only on the Reynolds number because the roughness is within the viscous sublayer. However, in the transitionally rough regime, in which the friction factor depends on the roughness and the Reynolds number, the calculations with $\mathrm{A}^{+}=26$ underpredict the data. Much better agreement is obtained by lowering the value of $\mathrm{A}^{+}$to 15 in this regime. In the fully rough regime, in which the friction factor is independent of the Reynolds number, friction is no longer dominated by viscous shear, but by the drag forces on the roughness elements. The value of $\mathrm{A}^{+}$in this regime is relatively unimportant, and satisfactory agreement is obtained with the data using any $\mathrm{A}^{+}$of order 10 .

The variation of $\mathrm{A}^{+}$between the hydraulically smooth and transitionally rough flow regimes is obtained by comparing the value of $\mathrm{A}^{+}$required for good agreement in each regime to the value of the dimensionless inner-region coordinate $\mathrm{k}^{+}$, defined as the value of $\mathrm{y}^{+}$at $\tilde{\mathrm{y}}=\tilde{\mathrm{k}}$, where $\mathrm{y}^{+}$is given by

$$
y^{+}=\frac{\tilde{y}}{2} \operatorname{Re}_{D} \sqrt{\frac{f_{\text {fref }}}{2}}
$$

By referencing the value of $\mathrm{k}^{+}$to the reference friction factor, $\mathrm{f}_{\mathrm{f}, \text { ref }}$, the height of the ribs is physically compared to what would be the viscous sublayer thickness in a smooth tube at the same Reynolds number. The value of $\mathrm{y}^{+}$at the edge of a smooth-wall viscous sublayer is typically taken to be $y^{+}=5$. For values of $\mathrm{k}^{+}<5$, the ribs are buried within the viscous sublayer, the wall appears smooth to the flow, and excellent agreement is obtained by using a value of $\mathrm{A}^{+}=26$. For values of $\mathrm{k}^{+}$greater than 5 , the lower value of $\mathrm{A}^{+}=15$ provides good 
agreement. The lower value of $\mathrm{A}^{+}$in the van Driest damping function required to obtain good agreement in this flow regime forms the basis for the following hypothesis. When $\mathrm{k}^{+}$is greater than 5 , the ribs are taller than what would have been the viscous sublayer thickness if the tube were smooth. At this point, the viscous sublayer in the tube has been destroyed, and local turbulent shear layers with their own local viscous sublayers develop from the reattachment points between each pair of ribs. This breaking up and restarting of local viscous sublayers results in an overall reduction in the capacity to damp out turbulent fluctuations near the wall, as demonstrated by the lower value of $\mathrm{A}^{+}$.

A smooth transition between the hydraulically smooth regime and the transitionally rough regime is provided by linearly varying $\mathrm{A}^{+}$from 26 at $\mathrm{k}^{+}=0$ (the pure smooth-wall condition) to 15 at $\mathrm{k}^{+}=5$ (the transitionally rough regime). $\mathrm{A}^{+}$is held constant at 15 for larger values of $\mathrm{k}^{+}$.

The smooth-wall value of $\mathrm{A}^{+}$is appropriate for the three-dimensional, distributedroughness model but inappropriate for the two-dimensional, rib-roughness model, because the flow is fundamentally different for the two types of roughness. Rib-type roughness elements cause streamline curvature as well as separation from and reattachment to the smooth wall, while three-dimensional, distributed roughness elements allow the flow to pass around and between the elements without forcing separation from and reattachment to the wall. Thus, a three-dimensional roughness element may protrude up through the tube viscous sublayer without destroying it, as would a two-dimensional rib.

The predictions plotted in the previously referenced Figures 10 and 11 were generated by the discrete-element rib-roughness model after the above calibration procedure. The excellent agreement with the data throughout the hydraulically smooth, transitionally rough, and fully rough flow regimes over the wide range of rib geometries demonstrates the overall validity of the momentum-equation roughness-model calibration.

Figures 12-14 present the comparisons of the Nusselt number predictions with the data for the same rib geometries as in Figure 10, illustrating the effects of varying the k/D ratio. The agreement is excellent, with the exception of the tallest rib geometry, $k / D=0.04$, 


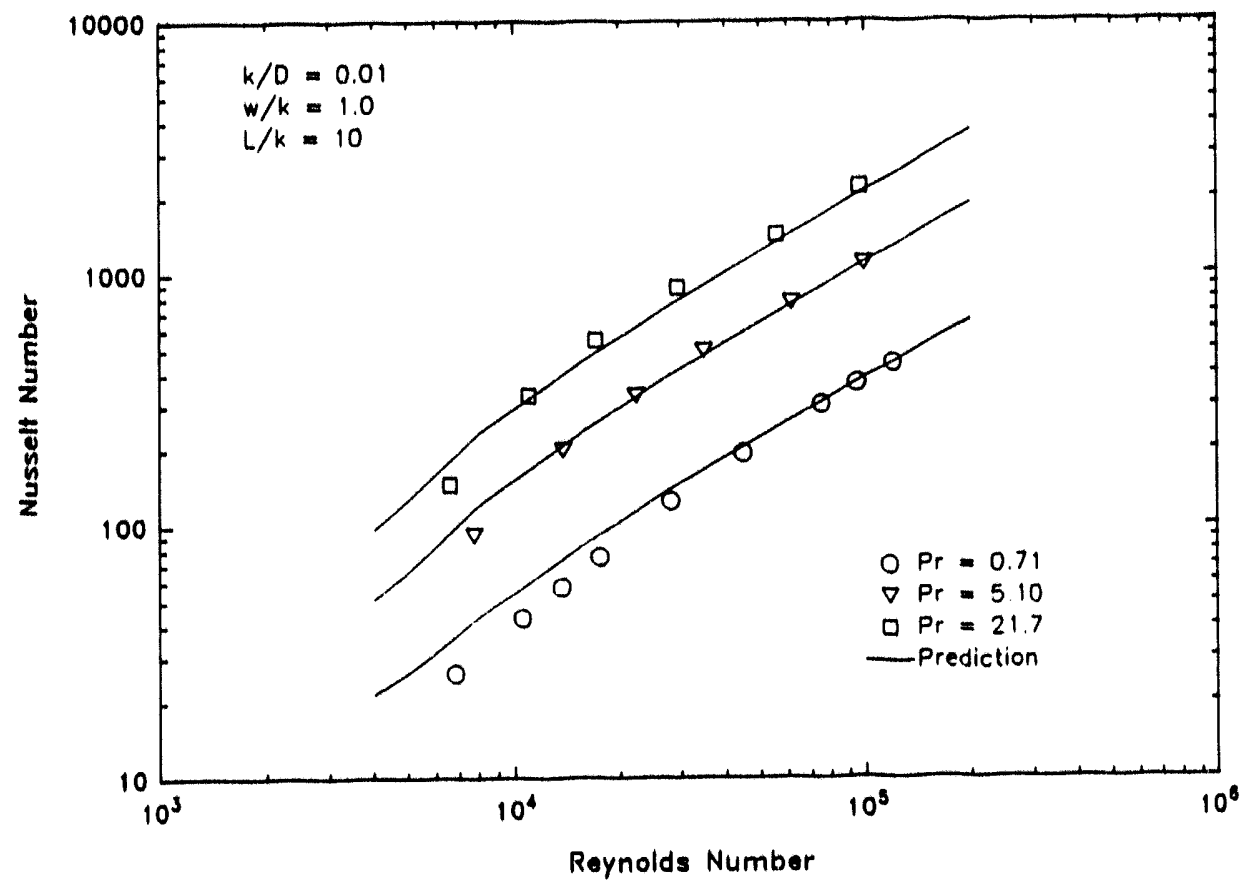

Fig. 12 Comparison of Nusselt number predictions with the data of Webb et al. (1971) for the $k / D=0.01, L / k=10$ geometry with various Prandtl numbers.

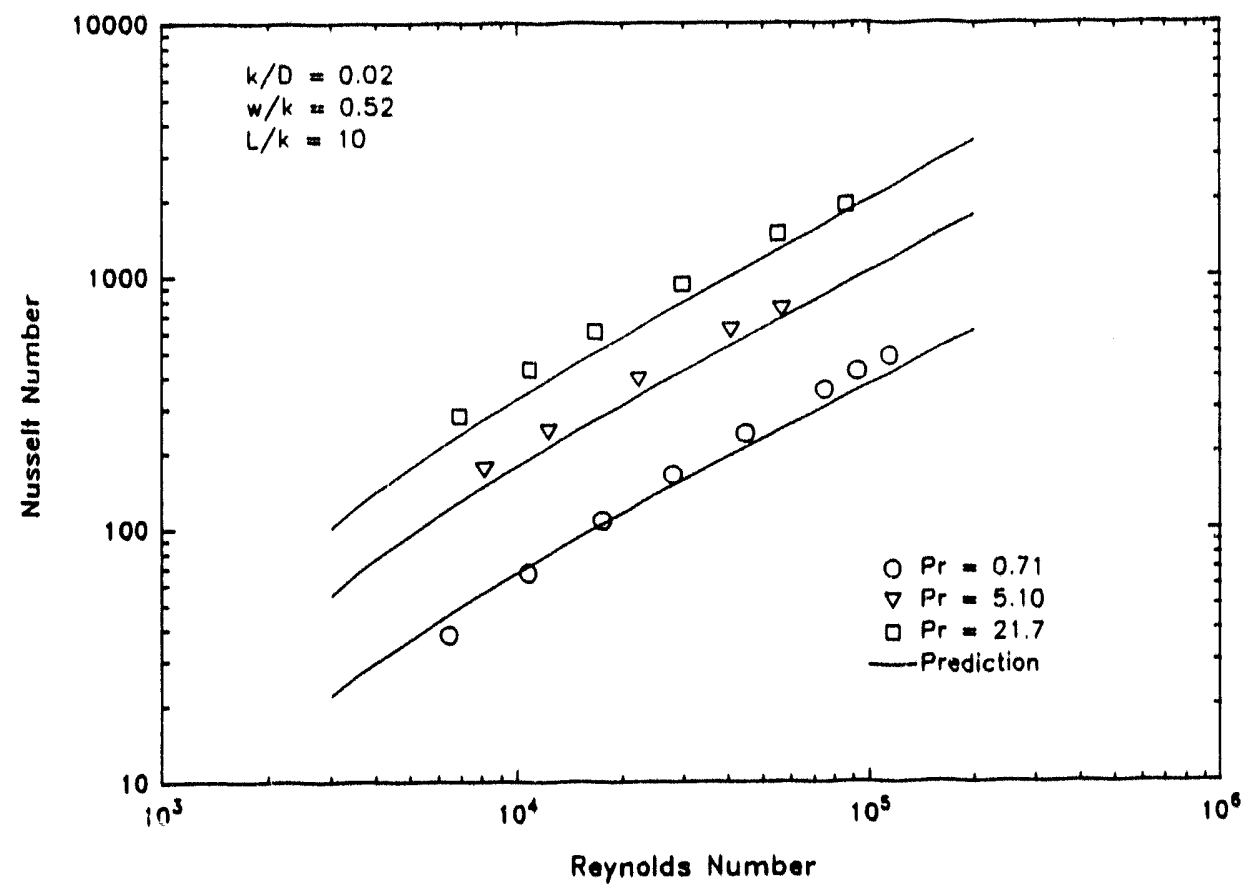

Fig. 13 Comparison of Nusselt number predictions with the data of Webb et al. (1971) for the $k / D=0.02, L / k=10$ geometry with various Prandtl numbers. 


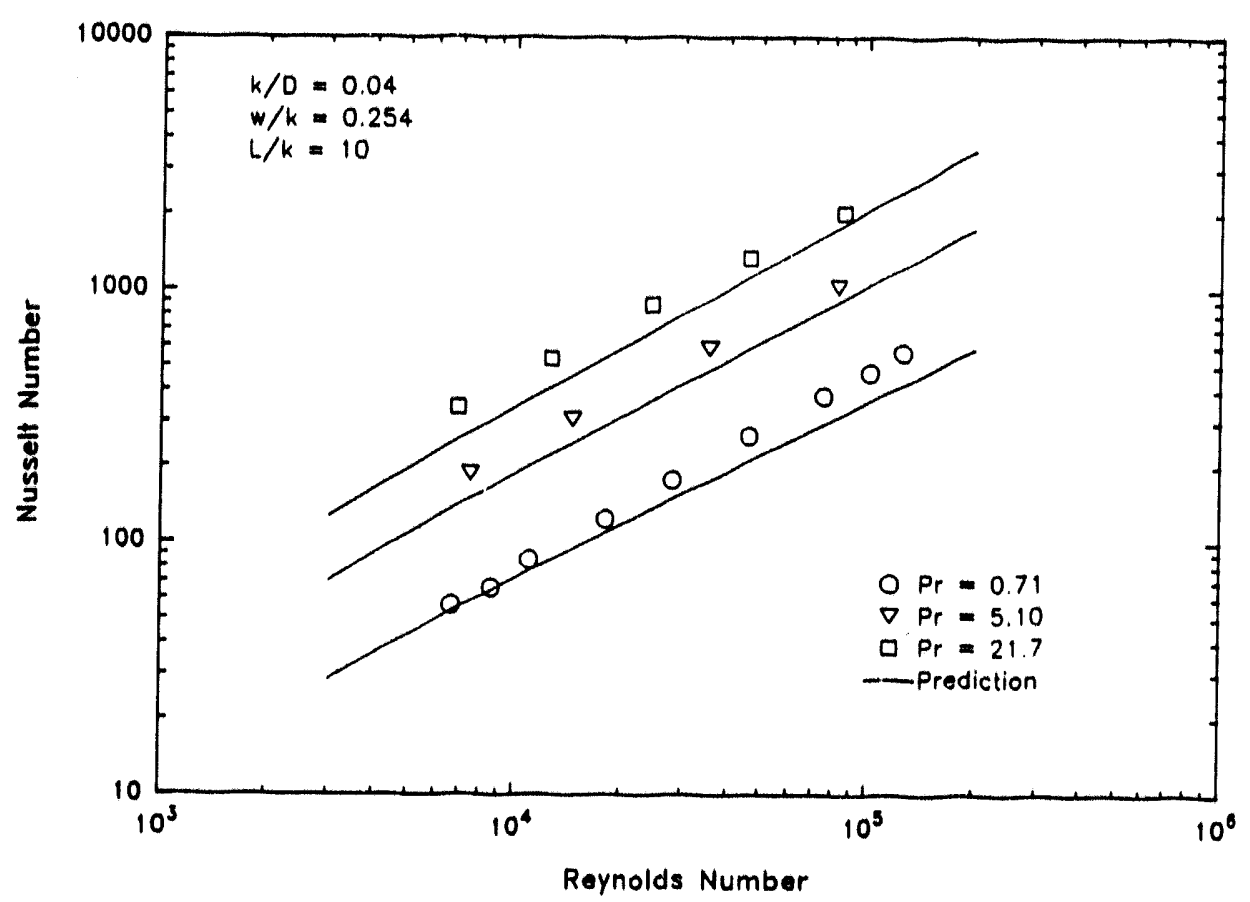

Fig. 14 Comparison of Nusselt number predictions with the data of Webb et al. (1971) for the $k / D=0.04, L / k=10$ geometry with various Prandtl numbers.

which underpredicts the data by about $25 \%$; even in this case, the predictions and the data are still within reasonable agreement, considering that the accuracy of a typical heat-transfer correlation is usually $\pm 25 \%$ (Holman 1986). Figures 15 and 16 present comparisons of the Nusselt numbers with the $k / D=0.02$ geometry of Figure 11 for $L / k$ ratios of $L / k=20$ and $\mathrm{L} / \mathrm{k}=40$, respectively. Again, the agreement is excellent. Examination of Figures 12-16 reveals that the relatively simple $\mathrm{Nu}_{\text {rib }}$ and constant $\mathrm{Pr}_{\mathrm{T}}$ models discussed in Sections III. 1 and III.2 reliably capture the heat-transfer effects of varying the rib height and rib pitch.

\section{V.3 Berger and Hau (1979)}

Berger and Hau (1979) used an electrochemical-analogue technique to measure the mass-transfer distribution in tubes roughened with small square tibs for Reynolds numbers ranging from 10,000 to 250,000 and Schmidt numbers ranging from 1,000 to 7,000 . Frictionfactor data were not presented. By the mass-/heat-transfer analogy, the measured masstransfer coefficients represent constant-wall-temperature heat-transfer coefficients, with 


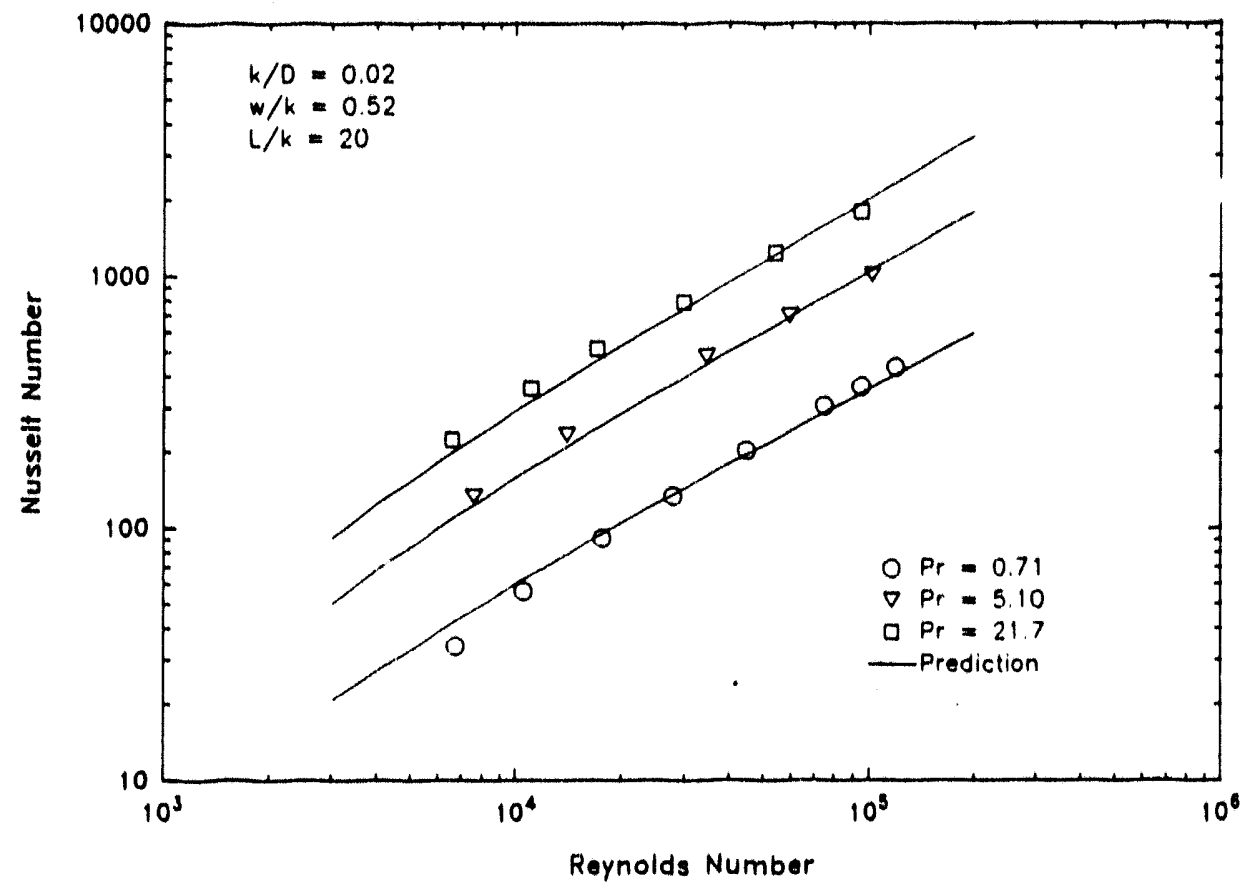

Fig. 15 Comparison of Nusselt number predictions with the data of Webb et al. (1971) for the $k / D=0.02, L / k=20$ geometry with various Prandtl numbers.

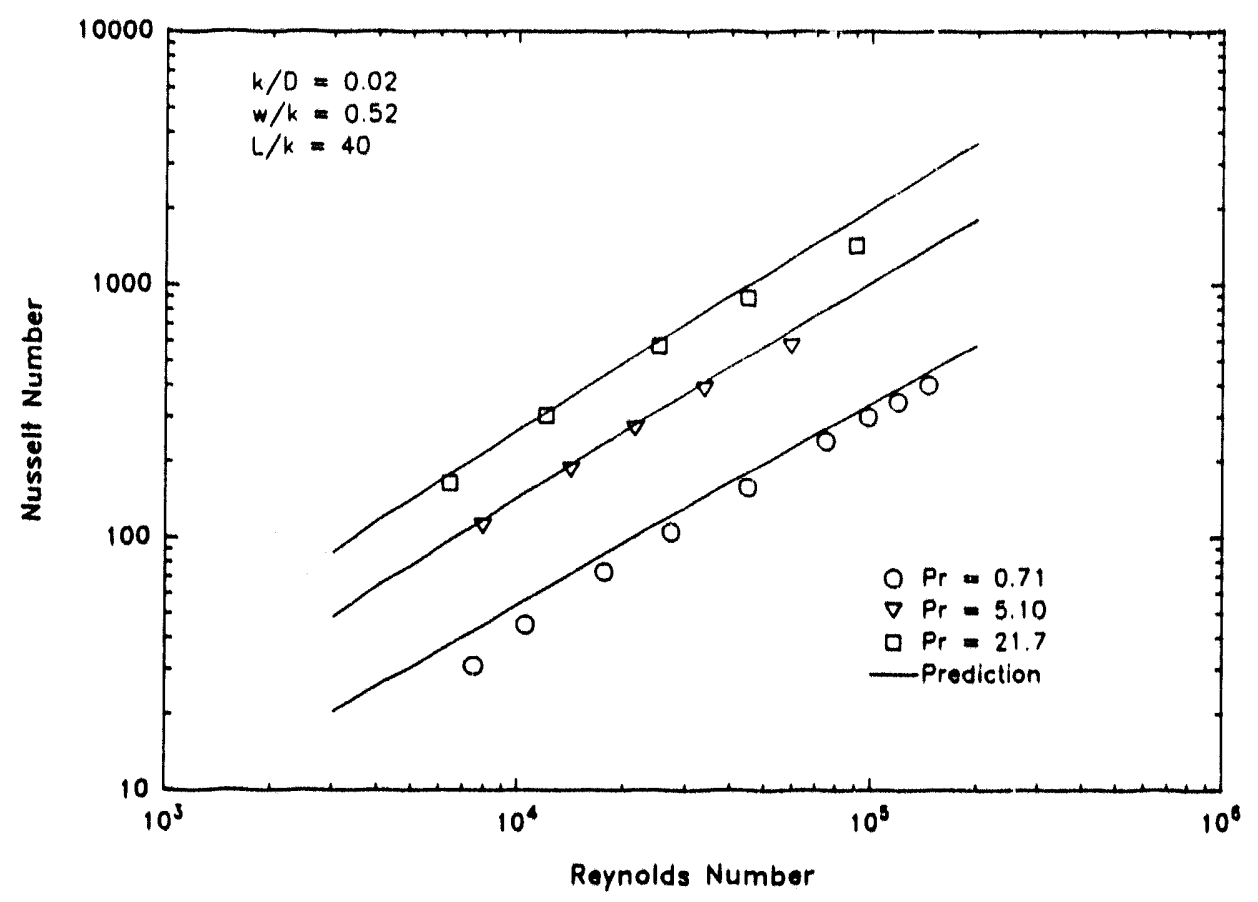

Fig. 16 Comparison of Nusselt number predictions with the data of Webb et al. (1971) for the $k / D=0.02, L / k=40$ geometry with various Prandtl numbers. 
Schmidt numbers corresponding to Prandtl numbers. The rib pitches tested by Berger and Hau were $L / k=10,7,5$, and 3 ; however, only the $L / k=10$ case is considered appropriate for comparison. Reattachment does not occur between ribs for the closely spaced rib geometries of $L / K=3$ and $L / k=5$, and the validity of the present rib-roughness model for 6.6 $<\mathrm{L} / \mathrm{k}<10$ is uncertain.

Figure 17 presents a comparison of the predictions with a correlation representing the $L / k=10$ data set of Berger and Hau. For clarity, only the extremities of the Prandtl number range are plotted. The agreement is acceptable over the Reynolds number range from $10,0(0)$ to 60,000 , but the data are significantly overpredicted at higher Reynolds numbers (as much as $40 \%$ at $\operatorname{Re}=250,000$ for $\operatorname{Pr}=7000$ ). Given the very high Prandtl numbers, this is considered to be reasonable agreement. Well-established smooth-tube heat-transfer correlations are typically valid over a small range of Prandtl numbers (the Dittus-Boelter equation, for example, is only valid for $0.6<\operatorname{Pr}<100$ ). Even the considerably more complicated Petukhov equation (Holman 1986) retains its superior $10 \%$ accuracy only up to Prandtl numbers of 2000.

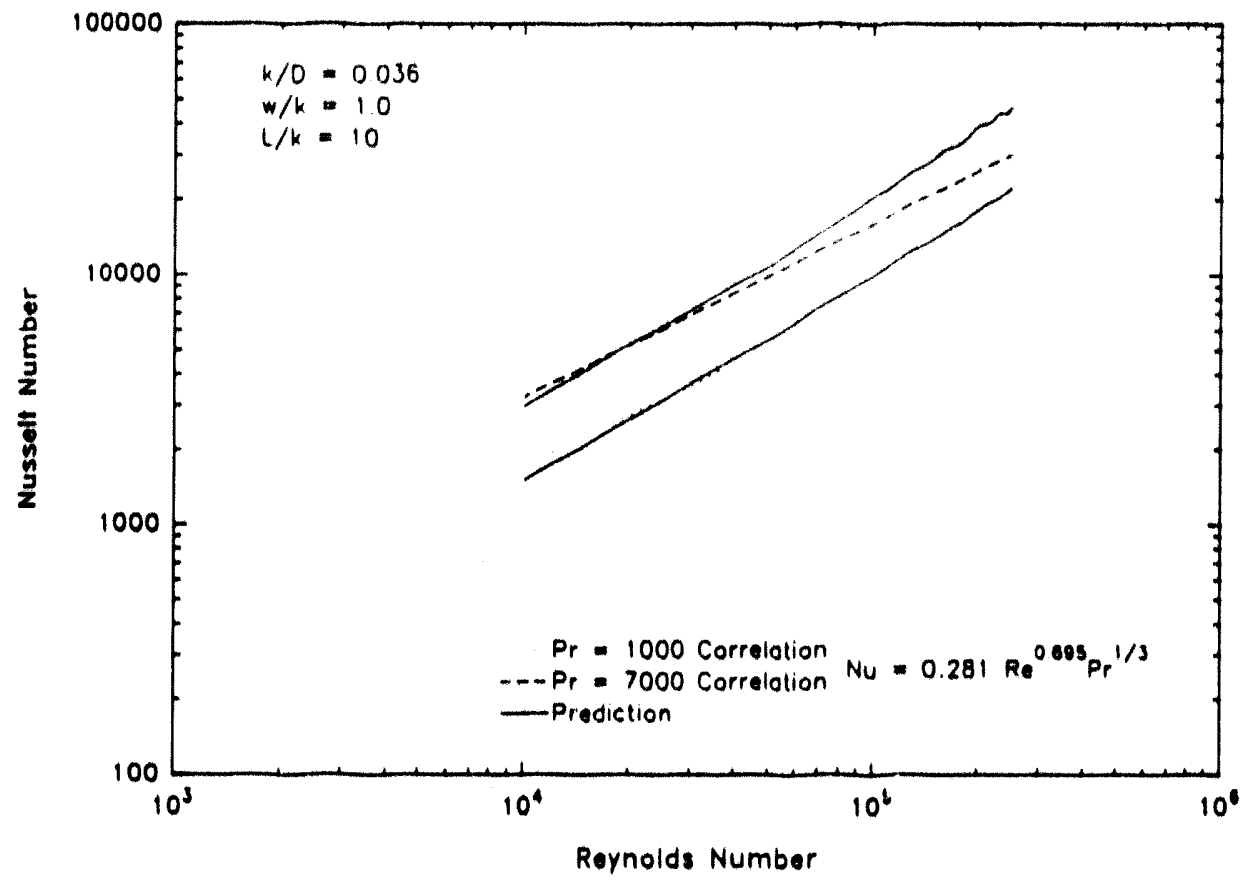

Fig. 17 Coniparison of Nusselt number predictions with the data of Berger and Hau (1979). 


\section{V.4 Mendes and Mauricio (1987)}

Mendes and Mauricio (1987) present friction-factor and heat-transfer data for tubes roughened with ribs of various geometries (L/k ratios from 41015 and $\mathrm{k} / \mathrm{D}$ ) ratios of 0.05 and 0.10) with Reynolds numbers ranging from 5,000 to $70,(0) 0$. The naphthalene sublimation technique utilized in these experiments yields mass-transfer coefficients analogous to constantwall-temperature heat-transfer coefficients corresponding to a Prandtl number of 2.5. The friction-factor data were taken from a set of brass test sections of identical geometry to the naphthalene-coated test sections and were based on the pressure drop between rib cyeles.

Figure 18 shows a comparison between the friction-factor predictions and the values reported by Mendes and Mauricio as a function of $L / k$. The Reynolds number dependence is not shown, because Mendes and Mauricio found the friction factors to be essentially independent of Reynolds number over the Reynolds number range investigated. The present discrete-element model also predicts fully rough flow as characterized by an essentially constant friction factor over the Reynolds number range. The rib geometries of $L / k=4$ and $L / k=6$ do not allow flow reattachment between ribs and have, therefore, been omitted. The agreement with $\mathrm{k} / \mathrm{D}=0.05$ geometry is very good, although the predictions slightly

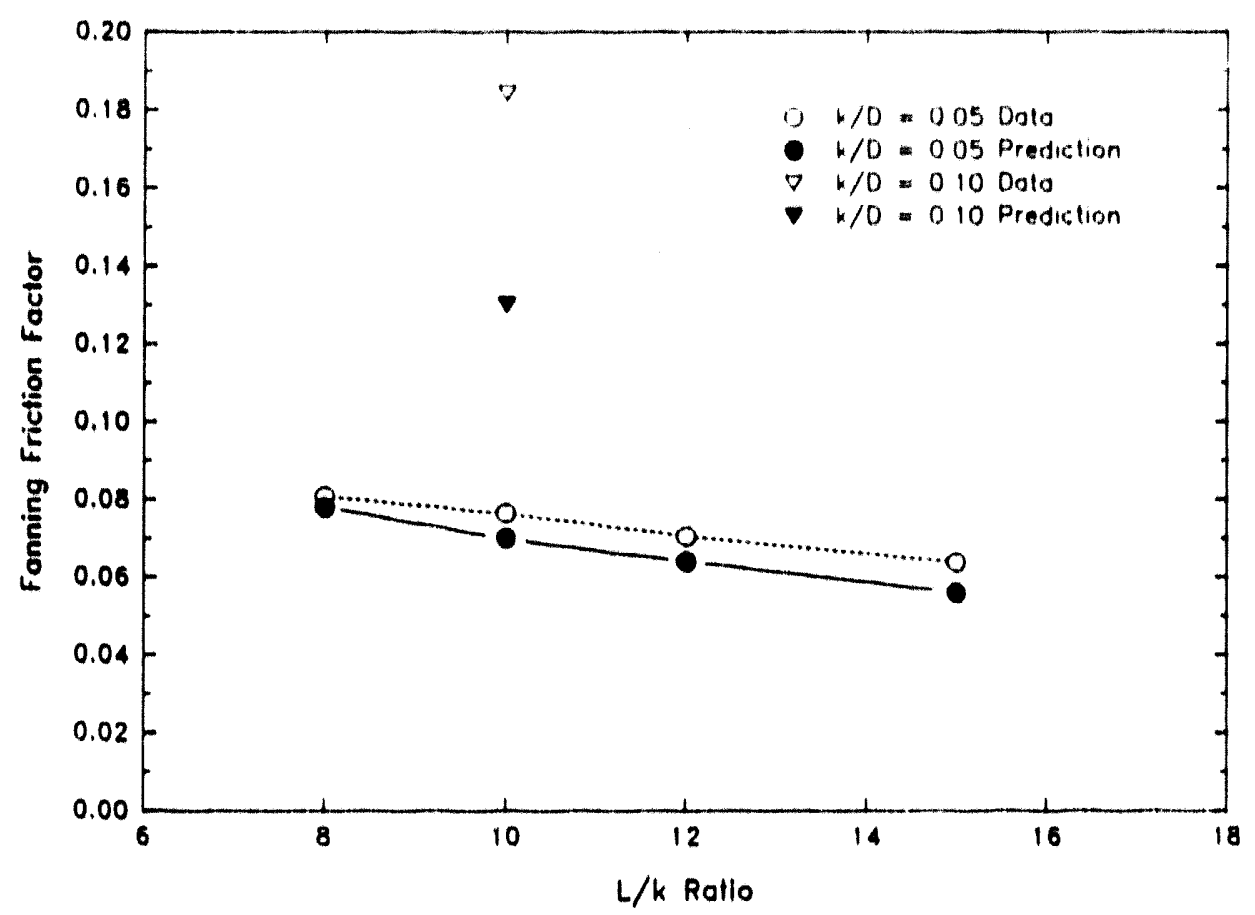

Fig. 18. Comparison of friction fuctor predictions with the data of Mendes and Mauricio (1987). 
underpredict the data. The agreement is within $4 \%$ at $L / K=8$, decreasing to about $12 \%$ at $L / k=15$.

The agreement for the $k / \mathrm{D}=0.10$ geometry is imperfect; the data are underpredicted by about $30 \%$. This $k / D$ ratio is almost double the largest, $k / D=0.056$, for which the model has thus far been validated. The typical flow regime over which the model has been successful is one of a constant-pressure-gradient, fully developed core flow with embedded periodic flow regions extending into the core flow about two rib heights above the tips of the ribs (Berger and Hau 1979). It is expected that very tall ribs, such as $k / D=0.10$, which physically make up $36 \%$ of the cross-sectional area of the tube, produce a significant periodicity within the core flow-field velocity. Such a periodic flow regime is still compatible with the assumptions of fully developed flow (in the periodic sense, as discussed in Section II.2) and could be handled by determining form-drag and reattachment-length models appropriate for such periodic variations in the core flow.

The Nusselt number comparisons for the same rib geometries are presented in Figure 19. The predictions for the $k / D=0.05$ geometry reflect the same trends as the data,

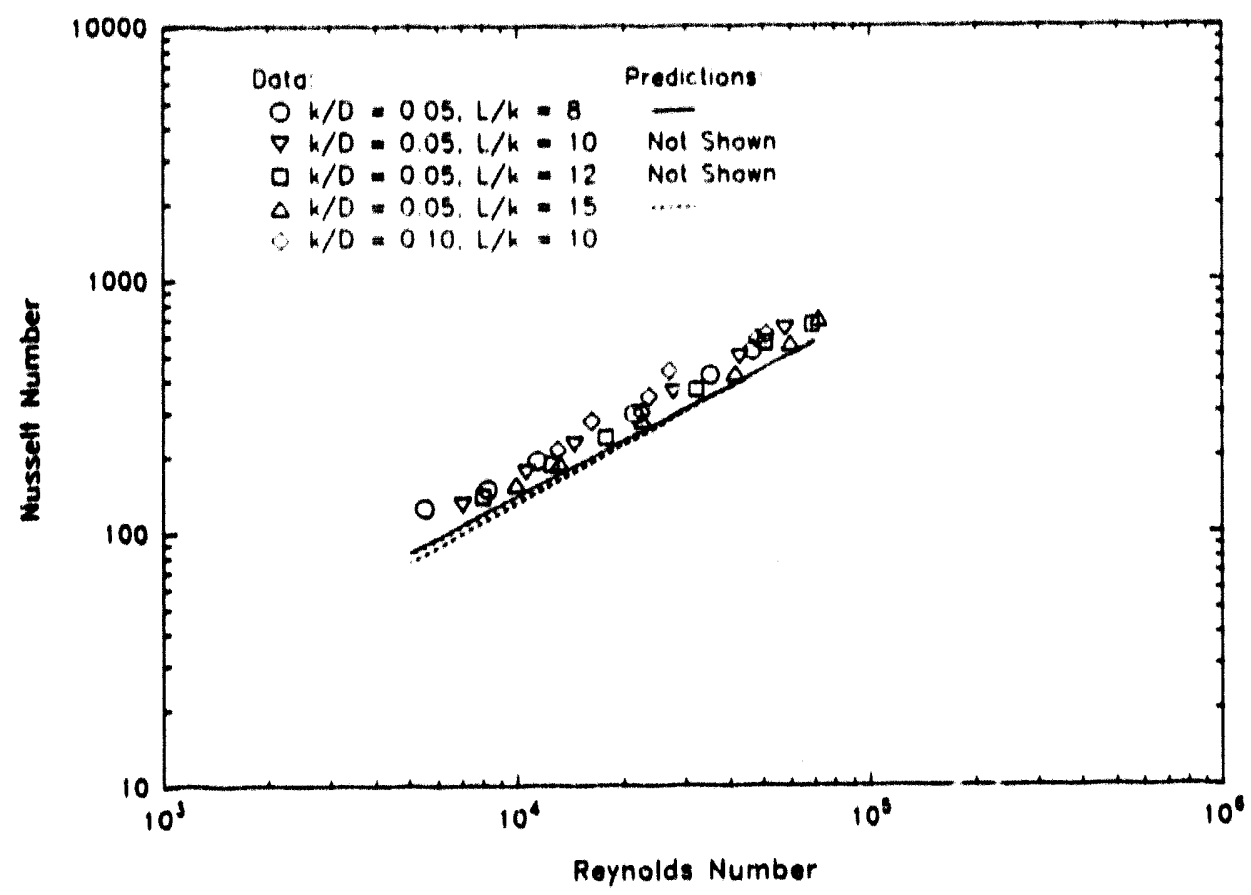

Fig. 19. Comparison of Nusselt number predictions with the data of Mendes and Mauricio (1987). 
but the data are generally underpredicted by 10 to $20 \%$. The model predicts lower Nusselt numbers for the $k / D=0.10$ geometry than for the $k / D=0.05, L / k=8$ geometry, whereas the data show that the $k / D=0.10$ geometry attains the highest level of heut-transfer enhancement. Because the velocity-profile information obtained in the momentum-equation solution is utilized in the energy-equation solution, much of this disagreement may be attributed to the momentum-equation solution, which (as shown in Figure 18) underestimuted the friction factor for the $k / D=0.10$ geometry. This also suggests that an accurate friction-factor model and calibration are needed if accurute Nusselt number predictions are to generated.

\section{V.S Buughn and Roby (1992)}

Baughn and Roby (1992) conducted experiments to determine the locul and average heat-transfer coefficients of a circular-ribbed duct with square ribs with height-10-dianeter ratio $(\mathrm{k} / \mathrm{D})$ of 0.0625 and pitch-10-height ratio $(\mathrm{L} / \mathrm{k})$ of 18 . Friction-fuctor data were not taken in these experiments. The average Nusselt number data (taken as averages from Figure 6 of Baughn and Roby) are plotted in Figure 20, along with predicted values from the present discrete-element rib-roughness model, over a Reynolds number range from $25,0001068,000$. The predictions are in excellent agreement with the data.

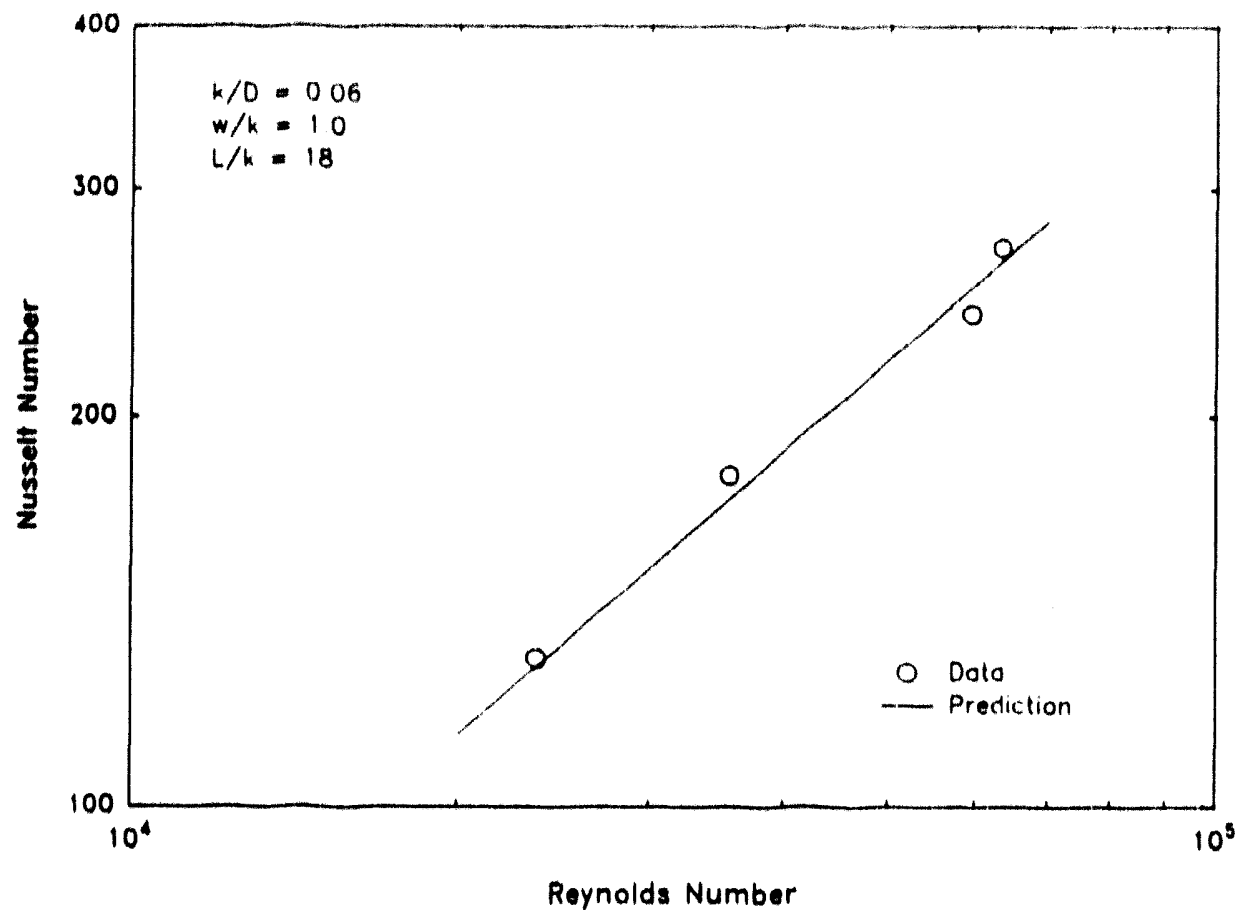

Fig. 20 Comparison of the Nusselt number predictions with the data of Buughn and Roby (1992). 


\section{SECTION VI UNCERTAINTY AND RANGE OF VALIDITY}

When the program discussed in this report is used in the prediction mode to determine the friction fuctor of a rib-roughened tube geometry, the accuracy of the computed result depends primarily upon two factors: (1) the uncertainty of the model itself and (2) the uncertainties of input variables, such as $k, w, L, D$ and $R_{D}$. The model uncertainty results from disagreement of the predictions with the validation data and experimental uncertainty in these data. The effects of uncertainties in the input variables, although an important issue in design work, are beyond the scope of this investigation. Only the model uncertainty is addressed here.

The uncertainty associated with the empirical nuture of the model itself is determined by comparing the comput $d$ results with accepted experimental data and well-known solutions. Comparisons of the predictions with data from the heat-transfer literuture indicate that the current friction factor and Nusselt number model is consistently valid over the following range of rectungular rib geometries: rib-height to hydraulic-diameter ratios ( $k / D)$ from 0.01 to 0.0625 , rib height-to-width ratios (w/k) from I to 0.254 , and rib pitch-10-height ratios $(\mathrm{L} / \mathrm{k})$ from 10 to 40 . The model is also valid for smooth tubes $(\mathrm{k} / \mathrm{D}$ ratios approaching zero and L/k ratios approaching infinity) if one uses the typical smooth-wall turhulent Prandt numbers. The variation of $\mathrm{Pr}_{\mathrm{T}}$ for $\mathrm{k} / \mathrm{D}$ between zero and 0.01 and for $\mathrm{L} / \mathrm{k}$ greater than 40 cannot be properly determined without further experimental data. However, the heat-transfer characteristics of such geometries approach that of a smooth tube and, consequently, are of little interest to the heat-exchanger specialist. The excellent agreement over the Prandtl number range $0.71<\operatorname{Pr}<21.7$ demonstrutes the model's ability to predict $\operatorname{Pr}$ dependence on heat transfer. The very reasonable agreement with the very large Prandtl number $(1000<\mathrm{Pr}$ $<7000$ ) data of Berger and Hau (1979) suggests that the model is valid over a much wider Prandtl number range, although comparisons with additional data are necessary to substantiate this claim. The data sets of Mendes and Mauricio suggest that the friction-factor model is not valid for very large $k / D$ ratios, where the core flow of the tube may be very strongly influenced by the roughness. It is expected that the present model could be successfully 
extended to such flow regimes by adopting reattachment-length and form-drag models suitable for such flows. However, Figures 18 and 19 show that the $\mathrm{k} / \mathrm{D}=0.10$ geometry provides an almost negligible increase in heat-transfer enhancement but a $240 \%$ increase in friction factor as compared to the $k / D=0.05$ geometry of equal rib spacing. Such large $k / D$ geometries depart from the desirable characteristics of potentially useful geometries and are of little interest to heat-exchunger designers.

Within the ranges deemed valid above, the disagreement with the friction-factor data is about $5 \%$, except in the case of the $k / D=0.05, L / k=15$ geometry of Mendes and Mauricio, where the disagreement is about $12 \%$. The disagreement with the Nusselt number data is typically about $10 \%$ and at most $25 \%$. The data sets used to validate the model have an experimental uncertainty as well, which is estimuted from experience with these types of experiments to be \pm 5 to $\pm 10 \%$ for both the friction factor and Nusselt number. Combining these uncertainties in a root-sum-square fashion (Coleman and Steele 1989) results in overall model uncertainties within the validation range of $\pm 710 \pm 16 \%$ for the friction factor and \pm 11 to $\pm 27 \%$ for the Nusselt number. It is likely that the model is valid for $k / D$ and $w / k$ ratios outside the above ranges, but such cases have not yet been validated. 


\section{SEC'TION VII CONCLUSIONS AND RECOMMENDATIONS}

A discrete-element computational model for the prediction of fully developed, turbulent friction factors and Nusselt numbers in tubes with two-dimensional, rectangular, rib-lype roughness with the separation and reattachment mechanism has been successfully developed, calibrated, and validated.

In comparisons of the computational results of the model with appropriate data sets from the literature, the friction-factor prediction model shows very good to excellent agreement throughout the hydraulically smooth, transitionally rough, and fully rough flow regimes over a wide range of rectangular-rib geometries. Such agreement over the wide range of roughness geometries and Reynolds numbers examined demonstrates that the momentum-exchange mechanisms of fully developed turbulent tlow over two-dimensional rib roughness have been successfully modeled. The very good agreement of the Nusselt number prediction model over the same wide range of rib geometries, Reynolds numbers, and Prandll numbers indicates that the heat-exchange mechanisms have also been successfully modeled by using the velocity profile obtained from the friction-factor/momentum-equation solution and the relatively simply $\mathrm{Nu}_{\text {rib }}$ and constant $\mathrm{Pr}_{\mathrm{T}}$ models.

Based on the results ohtained in this investigation, it is recommended for further study that the two-dimensional rib-roughness model be extended to other rib-roughness geometries, including the following:

1. Ribs of nonrectangular shape.

2. Closer rib spacings corresponding to the separation and recirculation mechanism (where the leeward separated flow does not reattach between ribs but merges with the windward separation zone of the following rib), and

3. Nontransverse ribs (helix angles other than $90^{\circ}$ ), which induce a spiral component to the flow.

Also, some of the modeling refinements proposed in Appendix $A$ could be incorporated into the present model, as well as those (listed above) considered for future 
investigation. However, much more detailed information is needed regarding local turbulent Prandtl numbers and local rib heat-transfer distributions before these refinements can become practical. 


\section{REFERENCES}

Adams, J. C., and Hodge, B. K., 1977, "The Calculation of Compressible Transitional Turbulent and Relaminarizational Boundary Layers over Smooth and Rough Surfaces Using an Extended Mixing-Length Hypothesis," AIAA Paper 77-682.

Arman, B., and Rabas, T. J., 1992, "Influence of Prandtl Number and Effects of Disruption Shape on the Performance of Enhanced Tubes with the Separation and Reattachment Mechanism," Argonne National Laboratory Report ANL/ESD-16, Argonne, III.

Baughn, J. W., and Roby, J., 1992, "Enhanced Turbulent Heat Transfer in Circular Ducts with Transverse Ribs," Enhanced Heat Transfer, ASME HTD-Vol. 202, pp. 9-15.

Berger, F. P., and Hau, K.-F, F.-L, 1979, "Local Mass/Heat Transfer Distribution on Surfaces Roughened with Small Square Ribs," Int. Journal of Heat Mass Transfer, Vol. 22, pp. 16451656.

Bradshaw, P., and Wong, F. Y. F., 1972, "The Reattachment and Relaxation of a Turbulent Shear Layer," Journal of Fluid Mechanics, Vol. 46, pp. 113-135.

Castro, L. P., and Fackrell, J. E., 1978, "A Note on Two-Dimensional Fence Flows, With Emphasis on Wall Constraint," Journal of Industrial Aerodynamics, Vol. 3, pp. 1-20.

Christoph, G. H., 1982, "Law of the Wall Analysis for Turbulent Heating on Rough Surfaces," AIAA Paper 82-0197. 
Christoph, G. H., and Pletcher, R. N., 1983, "Prediction of Rough-Wall Skin Friction and Heat Transfer," AIAA Journal, Vol. 21, No. 4, pp. 509-515.

Coleman, H. W., and Steele, W. G., 1989, Experimentation and Uncertainty Analysis for Engineers, John Wiley, New York.

Faramarzi, J., and Logan E., 1991, "Reattachment Length Behind a Single Roughness Element in Turbulent Pipe Flow," Trans. ASME, Journal of Fluids Engineering, Vol. 113, pp. 712-714.

Finson, M. L., 1975, "A Reynolds Stress Model for Boundary Luy. 'Iransition with Applications to Rough Surfaces," AFOSR-TR-76-0322.

Finson, M. L., and Wu, P. K. S., 1979, "Analysis of Rough Wall Turbulent Heating with Applications to Blunted Flight Vehicles," AIAA Paper 79-008.

Finson, M. L., and Clark, A. S., 1980, "The Effects of Surface Roughness Character on Turbulent Reentry Heating," AIAA Paper 80-1459.

Finson, M. L., 1982, "A Model for Rough Wall Turbulent Heating and Skin Friction," AIAA Paper 82-0199.

Good, M. C., and Joubert, P. N., 1968, "The Form Drag of Two-Dimensional Bluff-Plates Immersed in Turbulent Boundary Layers," Journal of Fluid Mechanics, Vol. 31, 1968, pp. $547-582$.

Holman, J. P., 1986, Heat Transfer, 6th Edition, McGraw-Hill, New York. 
Hosni, M. H., Coleman, H. W., and Taylor, R. P., 1989, "Measurement and Calculation of Surface Roughness Effects on Turbulent Flow and Heat Transfer," Report TFD-89-1, Mech. and Nuc. Engr. Dept., Miss. State Univ.

Hosni, M. H., Coleman, H. W., and Taylor, R. P., 1991, "Measurements and Calculations of Rough-Wall Heat Transfer in the Turbulent Boundary Layer," Int. Journal of Heat Mass Transfer, Vol. 34, No. 4/5, pp. 1067-1081.

Kays, W. M., and Crawford, M. E., 1980, Convective Heat and Mass Transfer, 2nd Edition, McGraw-Hill, New York.

Lawn, C. J., 1976, "Flow Measurements for Establishing the Mechanisms of Heat Transfer from a Rib-Roughened Surface," Central Electricity Generating Board, Berkeley Nuclear Laboratories, Report RD/B/N3514.

Lewis, M. J., 1975, "An Elementary Analysis for Predicting the Momentum and Heat-Transfer Characteristics of a Hydraulically Rough Surface," Trans. ASME, Journal of Heat Transfer, Vol. 97, pp. 249-254.

Lin, T. C., and Bywater, R. J., 1980, "The Evaluation of Selected Turbulence Models for High-Speed Rough Wall Boundary Layer Calculations," AIAA Paper 80-0132.

Liou, T.-M., and Hwang, J.-J., 1992, "Turbulent Heat Transfer Augmentation and Friction in Periodic Fully Developed Channel Flows," Trans. ASME, Journal of Heat Transfer, Vol. 114, pp. 56-64. 
Mantle, P. L., 1966, "A New Type of Roughened Heat Transfer Surface Selected by Flow Visualization Techniques," Proc. Third Int. Heat-Transfer Conf., Vol. 1, pp. 45-55.

Mendes, P. R. S., and Mauricio, M. H. P., 1987, "Heat Transfer, Pressure Drop, and Enhancement Characteristics of the Turbulent Flow through Internally Ribbed Tubes," Convective Transport, ASME HTD-Vol. 82, pp. 15-22.

Moody, L. F., 1944, "Friction Factors for Pipe Flow," Trans. ASME, Vol. 66, pp. $671-684$.

Nikuradse, J., 1933, "Strömungsgesetze in Rauhen Rohren," Forschg. Arb. Ing.-Wes, No. 361.

Rabas, T. J., 1989, "Selection of the Energy-Efficient Enhancement Geometry for SinglePhase Turbulent Flow Inside Tubes," Heat Transfer Equipment Fundamentals, Design, Applications and Operating Problems, ASME HTD-Vol. 108, pp. 193-204.

Reynolds, A. J., 1975, "The Prediction of Turbulent Prandtl and Schmidt Numbers," Int. Journal of Heat Mass Transfer, Vol. 18, pp. 1055-1069.

Sato, H., Hishida, K., and Maeda, M., 1992, "Characteristics of Turbulent Flow and Heat Transfer in a Rectangular Channel with Repeated Rib Roughness," Experimental Heat Transfer, Vol. 5, pp. 1-16.

Scaggs, W. F., Taylor, R. P., and Coleman, H. W., 1988a, "Measurement and Prediction of Rough Wall Effects on Friction Factor - Uniform Roughness Results, Trans. ASME, Journal of Fluids Engineering, Vol. 110, pp. 385-391. 
Scaggs, W. F., Taylor, R. P., and Coleman, H. W., 1988b, "Measurement and Prediction of Rough Wall Effects on Friction Factors in Turbulent Pipe Flow," Report TFD-88-1, Mech. and Nuc. Engr. Dept., Miss. State Univ.

Schlichting, H., 1936, Experimentelle Untersuchungen Zum Rauhigkeits-Problem, IngenieurArchive., Vol. VII, No. 1, pp. 1-34.

Schlichting, H., 1979, Boundary Layer Theory, 7th Edition, McGraw-Hill, New York.

Swamee, P. K., and Jain, A. K., 1976, "Explicit Equations for Pipe Flow Problems," Proc. ASCE. Journal of Hyd. Div., Vol. 102, Hy5, p. 567.

Taylor, R. P., and Hodge, B. K., 1992a, Validated Heat-Transfer and Pressure-Drop Predictions Based on the Discrete Element Method: Phase 1, Three-Dimensional Roughness, Argonne National Laboratory Report ANL/ESD/TM-31, Argonne, Ill.

Taylor, R. P., and Hodge, B. K., 1992b, "Fully Developed Heat Transfer and Pressure Drop Predictions for Pipes with 3-Dimensional Roughness," Fundamentals of Forced Convection Heat Transfer, ASME HTD-Vol. 210, pp. 75-84.

Taylor, R. P., Coleman, H. W., and Hodge, B. K., 1984, "A Discrete Element Prediction Approach for Turbulent Flow over Rough Surfaces," Report TFD-84-1, Mech. and Nuc. Engr. Dept., Miss. State Univ.

Taylor, R. P., Coleman, H. W., and Hodge, B. K., 1985, "Prediction of Turbulent Rough-Wall Skin Friction Using a Discrete Element Approach," Trans. ASME, Journal of Fluids Engineering, Vol. 107, pp. 251-257. 
Taylor, R. P., Scaggs, W. F., and Coleman, H. W., 1988, "Measurement and Prediction of Nonuniform Surface Roughness on Turbulent Flow Friction Coefficients," Trans. ASME, Journal of Fluids Engineering, Vol. 110, pp. 380-384.

Taylor, R. P., Coleman, H. W., and Hodge, B. K., 1985a, "Prediction of Turbulent RoughWall Skin Friction Using a Discrete Element Approach," ASME Paper 85-FE-2.

Taylor, R. P., Hodge, B. K., and Coleman, H. W., 1985b, "Prediction of Turbulent Skin Friction for Two-Dimensional, Rib-Type Surface Roughness Using a Discrete-Element Approach," AFWAL-TR-85-3091, Flight Dynamics Laboratory, Wright-Patterson Air Force Base, Ohio.

Taylor, R. P., Hodge, B. K., and Coleman, H. W., 1989, "A Discrete Element Model for Turbulent Skin Friction Prediction for Rib-Type Surface Roughness," Int. Journal of Heat and Tech., Vol. 7, No. 1, pp. 29-48.

Webb, R. L., Eckert, E. R. G., and Goldstein, R. J., 1971, "Heat Transfer and Friction in Tubes with Repeated-Rib Roughness," Int. Journal of Heat Mass Transfer, Vol. 14, pp. 601617.

White, F. M., 1991, Viscous Fluid Flow, 2nd Edition, McGraw-Hill, New York. 
APPENDIX A

ALTERNATIVE FORMULATIONS AND ROUGHNESS MODELS FOR THE ENERGY EQUATION 


\section{APPENDIX A \\ ALTERNATIVE FORMULATIONS AND ROUGHNESS MODELS FOR THE ENERGY EQUATION}

\section{A.1 Rib-Element Heat-Transfer Models}

Alternatives to the rib-element heat-transfer model, $\mathrm{Nu}_{\mathrm{rib}}=\mathrm{E}_{\mathrm{r}} \mathrm{Nu}_{\mathrm{smooth}}$, discussed in Section III.2 are presented in this Appendix. The 1, udel of Section III.2 was chosen for this study, the first application of the 2-D rib-roughness discrete-element model to predict heat transfer, in lieu of the more involved models below because (1) it is usually more effective to begin the development of a new prediction method and program with a simple model and refine the model as the development progresses, (2) the model yields amazingly good results in spite of its simplicity, and (3) the more advanced methods examined below require more detailed rib heat-transfer data than are currently available and/or extensive calibration of empirical constants to fit the data. Because the turbulent Prandtl number has a dramatic effect on the predicted heat transfer, calibration of more complex rib heat-transfer models may be futile until the $\mathrm{Pr}_{\mathrm{T}}$ dependence has been unambiguously established.

The first suggested refinement to the $\mathrm{Nu}_{\text {rib }}$ model of Section III.2 is to use the Petukhov equation (Holman 1986, for example), which has superior accuracy over a wider range of Prandtl numbers, rather than the Dittus-Boelter equation for the smooth-wall Nusselt number, $\mathrm{Nu}_{\text {smooth }}$. However, $\mathrm{Nu}_{\text {rib }}$ is obtained by multiplying $\mathrm{Nu}_{\text {smooth }}$ by an enhancement factor, $E_{r}$, which is highly subjective. The added complexity and computational overhead of the Petukhov equation is not justified until the proper value of $\mathrm{E}_{\mathrm{r}}$ is determined. As a whole, the information from Liou and Hwang (1992), Berger and Hau (1979), Lewis (1975), Sato et al. (1992), and Baughn and Roby (1992) indicates that $E_{r}$ varies with rib geometry. Prandtl number, and tube Reynolds number, but the manner of variation is inconclusive.

A better way of modeling the rib element heat transfer, although less amenable to the current rib-roughness heat-transfer literature, is to abandon the $\mathrm{Nu}_{\mathrm{rib}}=\mathrm{E}_{\mathrm{r}} \mathrm{Nu} \mathrm{u}_{\text {smowth }}$ concept and 
to specify that the average rib element heat transfer follows the same functional form as that of noncircular cylinders in cross-flow (Holman 1986, for example):

$$
N u_{r b b}=C R e_{k}^{m} \operatorname{Pr} 1 / 3
$$

The rib Reynolds number is

$$
R e_{k}=\frac{u_{k} k}{v}=\frac{1}{2} R e_{D} u_{k} k
$$

where the characteristic velocity, $a_{k}$, is the velocity averaged over the fuce of the element,

$$
a_{k}=\int_{0}^{k} a d y
$$

Values of $C$ and $m$ for various shapes of noncircular cylinders in a uniform cross-flow abound (some are tabulated in Holman 1986), but few experiments have been carried out for noncircular cylinders immersed in boundary layers (i.e., flow over a rib-roughened wall). Implementation of this model would require either an extensive experimental program to determine values of $\mathrm{C}$ and $\mathrm{m}$ for ribs of different geometries immersed in boundary layers or an extensive matrix of numerical solutions with the current program, which would not be effective unless the $\operatorname{Pr}_{\mathrm{T}}$ variation is established.

A more fundamental approuch would be to develop a model for the local variation of heat-transfer coefficients over the surface of the ribs. Some experimenters (Baughn and Roby 1992, for example) have carried out experiments to determine the local rib-surface heattransfer variation, but much more data for different sizes and shapes of ribs under various flow conditions are required before an accurate, local rib heat-transfer model can be developed. The required detailed data may be alternatively determined from Navier-Stokes numerical calculations, such as those discussed by Arman and Rabas (1992).

The above models are suggested as future improvements to be made as more information regarding turbulent Prandtl number and local rib-element heat-transfer data becomes available. 


\section{A.2 Alternative Energy-Equation Formulations}

If the area open to radial conduction, $A_{r e}$ due to the smooth portion of the wall between the ribs is divided into two sections, such that one section is due to conduction through the attached flow region between the elements and the other is due to conduction through the windward and leeward separated zones, the general energy equation, Equation 26. takes the form

$$
\begin{aligned}
& \frac{N u_{t+1} K F_{A} r}{2 R L \delta y}\left(T_{0}-T\right)-\rho u r \beta_{x} c_{p} \frac{\partial T}{\partial x} \\
& +K \frac{\partial}{\partial y}\left(r \beta_{s} \frac{\partial T}{\partial y}\right)+K \frac{\partial}{\partial y}\left[r \beta_{y}\left(1+\frac{K r}{K}\right) \frac{\partial T}{\partial y}\right]=0
\end{aligned}
$$

where

$$
\beta_{s}=\frac{(y+1)(k-y)}{L}
$$

now represents the fraction of area open to radial conduction through the separated regions on the windward and leeward sides of the ribs. It is furthermore assumed that the eddy conductivity in the slower moving fluid in the separated regions is negligible as compared to that in the attached flow region. This formulation of the energy equation can be rearranged and nondimensionalized in the same munner as the constant heat-flux and constant walltemperature versions of the original formulation of Equation 26. The constant heat-flux version becomes

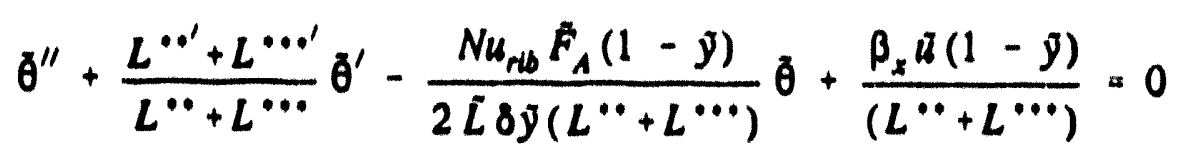

where

$$
L \cdot=\beta_{y}\left(1-\frac{K_{r}}{K}\right)
$$


and

$$
L \cdots=\beta \text {, }
$$

This formulation was found to be very sensitive to the reattachment length model. It does, however, seem to be a more fundamental approach and should be reconsidered as more accurate reattachment length models are developed.

Still another way to solve the heat-transfer problem is to formulate the energy equation without roughness effects |set $\beta_{x}=\beta_{y}=1$ and $N u_{\text {rib }}=0$ in Equation 26|, which then becomes the fumiliar smooth-wall energy equation. This smooth-wall energy equation is solved using the rough-wall velocity protile obtained from the momentum equation solution. The Nusselt number from this solution is then multiplied by an appropriate weighting fuctor to obtain the augmented Nusselt number, $\mathrm{Nu}_{\mathrm{Au}}$, of the rib-roughened tube.

The heat transfer per rib cycle in a rib-roughened tube may be expressed in terms of the augmented Nusselt number as

$$
q_{0}=\pi K L N u_{A \cup O}\left(T_{0}-T_{m}\right)
$$

Following the approach of Lewis (1975), the heat transfer per rib cycle in a tube roughened with rectangular ribs may also be expressed as

$$
q_{0}=\pi K\left[(L-w) N u_{\text {mall }}+k N u_{\text {front }}+w N u_{\text {sop }}+k N u_{\text {mour }}\right]\left(T_{0}-T_{m}\right)
$$

Expressing the Nusselt numbers for the front, top, and rear surfaces of the ribs as the wall Nusselt number multiplied by an appropriate weighting factor, $\omega$, the above equation may be written as

$$
q_{0}=\pi K N u_{\text {mall }}\left[L+K\left(\omega_{\text {front }}+\omega_{\text {mar }}\right)+w\left(\omega_{\text {sop }}-1\right)\right]\left(T_{0}-T_{m}\right)
$$

Comparing Equations $A-9$ and $A-11$ reveals that

$$
N u_{A \cup O}=N u_{\text {wall }} \frac{\left[L+k\left(\omega_{\text {mons }}+\omega_{\text {mear }}\right)+w\left(\omega_{\text {op }}-1\right)\right]}{L}
$$

In the above equations, $\mathrm{Nu} \mathrm{wall}_{\text {il }}$ is the Nusselt number obtained from the solution of the smooth-wall energy equation by using the rough-wall velocity profile. 
Using weighting factors of $\omega_{\text {front }}=\omega_{\text {top }}=4.0$ and $\omega_{\text {rear }}=0.5$ yields results comparable to the results obtained from the equations developed in Section II.4 with the roughness heat-transfer models of Section III.2. Although this method yields good results, it is not used in this study, simply because it does not conform to the basic idea of the discreteelement method of incorporating the roughness effects directly into the governing equations. 
APPENDIX B

THE IMPLICIT FINITE-DIFFERENCE METHOD 


\section{APPENDIX B THE IMPLICIT FINITE-DIFFERENCE METHOD}

The following implicit finite-difference method is reproduced essentially unchanged from Taylor and Hodge (1992a) and is included for completeness.

The equations are written in the general form

$$
w^{\prime \prime}+\gamma_{1} w^{\prime}+\gamma_{2} w+\gamma_{3}=0
$$

where $w=\tilde{u}$ for the momentum equation and $w=\tilde{\theta}$ for the energy equation. The prime indicates differentiation with respect to $\eta=\tilde{y}$.

The derivatives in Equation B-I are approximated by finite-difference formulas in the grid network shown in Figure B-1. A geometrically expanding grid is used in the $\eta$-direction. The expanding-grid recursion formula is

$$
\left.\Delta \eta\right|_{n}=R(\Delta \eta)_{n-1}
$$

where $R$ is a constant (taken here as $R=1,063$ ). The first $\eta$-step, $\left.\Delta \eta\right|_{1}$, must be specified and is taken here as $\left.\Delta \eta\right|_{1}=0.701 \times 10^{-5}$. The expanding $\eta$-grid is chosen because it concentrates the points near the surface where the gradients are the steepest. With $R=1,063$, $\left.\Delta \eta\right|_{1}=0.701 \times 10^{-5}$, and $N=150$, the largest $\eta$ value is unity, forcing 150 points to exactly fit in the tube radius. On a typical run about half of the $\eta$-points are in the lower $5-11$ \% of the boundary layer.

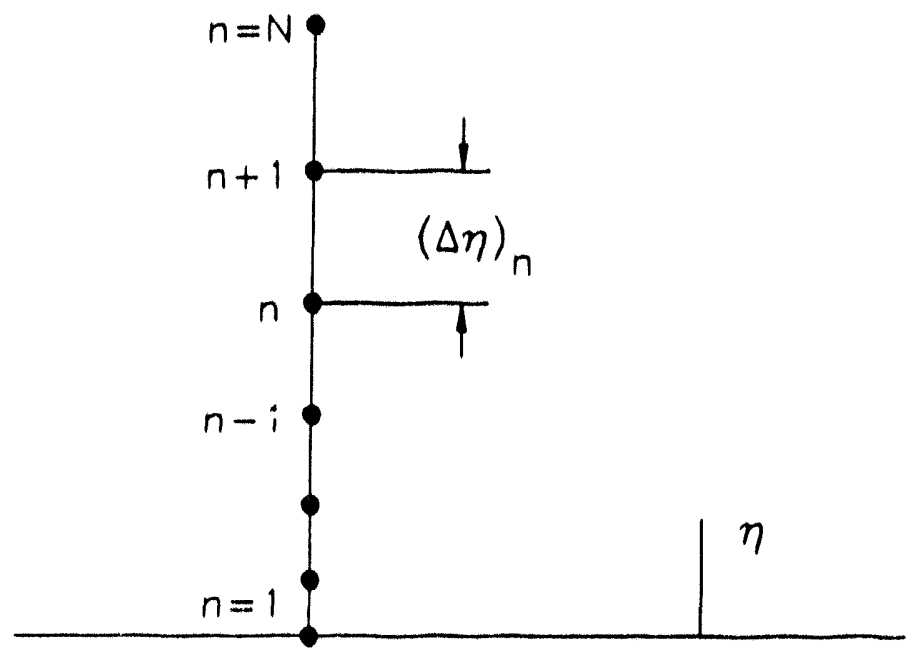

Fig. B-1 Schematic layout of expanding grid. 
The derivatives with respect to $\eta$ are approximated by using a three-point Lagrangian interpolation formula. The dependent variable $w$ is approximated in the range $\eta_{n \cdot 1} \leq \eta \leq \eta_{n+1}$ by a Lagrangian polynomial

$$
w(\eta)=\sum_{1=n-1}^{n+1} L_{l} w_{1}+E
$$

where

$$
\begin{aligned}
& n+1 \\
& \text { II }\left(\eta-\eta_{j}\right) \\
& j=n-1 \\
& L_{i}=\frac{j \neq i}{n+1} \\
& j=n-1 \\
& j \neq l
\end{aligned}
$$

Taking the first and second derivatives of Equation B-3 and evaluating at $\eta=\eta_{n}$ yields the finite-difference formulae

$$
\begin{aligned}
& \left.\frac{\partial^{2} w}{\partial \eta^{2}}\right|_{n}=\frac{2\left[w_{n+1}+R w_{n-1}-(1+R) w_{n}\right]}{(\Delta \eta)_{n}^{2}+R(\Delta \eta)_{n-1}^{2}}+E^{\prime \prime} \\
& \left.\frac{\partial w}{\partial \eta}\right|_{n}=\frac{\left[w_{n+1}-R^{2} w_{n-1}-\left(1-R^{2}\right) w_{n}\right]}{(\Delta \eta)_{n}+R^{2}(\Delta \eta)_{n-1}}+E^{\prime}
\end{aligned}
$$

where

$$
\left.\Delta \eta\right|_{n}=\eta_{n+1}-\eta_{n}
$$

The errors can be shown to be as follows:

$$
\begin{aligned}
& E^{\prime}=-(1 / 6) w^{\prime \prime \prime}(\Delta \eta)_{n}(\Delta \eta)_{n-1} \text { and } \\
& \left.E^{\prime \prime}=-1 / 12\right) w^{\prime \prime \prime \prime}(\Delta \eta)_{n}(\Delta \eta)_{n+1} .
\end{aligned}
$$

The usefulness of the expanding grid is apparent. Near the wall, where the derivatives are large, small values of $\Delta \eta$ are required to give small truncation errors. Far from the wall, the derivatives are small, and larger $\Delta \eta$ values are acceptable. 
Substituting and rearranging yields a system of $\mathrm{N}-2$ algebraic equations

$$
A_{n} w_{n-1}+B_{n} w_{n}+C_{n} w_{n+1}=D_{n}
$$

where

$$
n=2,3, \ldots, N-1
$$

The coefficients $A, B, C$, and D are given by

$$
\begin{gathered}
A_{n}=\frac{2 R}{S_{1}}-\frac{R^{2} \gamma_{1}}{S_{2}} \\
E_{n}=-\frac{2(1+R)}{S_{1}}-\frac{\gamma_{1}\left(1-R^{2}\right)}{S_{2}}+\gamma_{2} \\
C_{n}=\frac{2}{S_{1}}+\frac{\gamma_{1}}{S_{2}} \\
D_{n}=-\gamma_{3}
\end{gathered}
$$

where

$$
S_{1}=(\Delta \eta)_{n}^{2}+R(\Delta \eta)_{n-1}^{2} \text { and } S_{2}=(\Delta \eta)_{n}+R^{2}(\Delta \eta)_{n-1} \text {. }
$$

The $N$ - 2 equations are linear if the terms $A_{n}, B_{n}, C_{n}$, and $D_{n}$ are taken to be constants at a station $\mathrm{n}$. This is the case for the energy equations, Equations 50) and 55, and for Equation 17, the laminar version of the momentum equation for smooth tubes. The resulting set of algebraic equations can be solved directly, as discussed below. For turbulent flow, the momentum equation is nonlinear because the eddy viscosity depends on the velocity profile, and, for rough-wall flows, the drag-force term contains $\tilde{u} \cdot \tilde{u}$. To overcome this problem, the following linearization procedure is adopted. The velocity profile is initially assumed to be the 1/7-power law. The eddy viscosity and the first ũ in the drag term are determined based on this profile. The resulting linear set of equations is solved for a second approximation to $\tilde{u}$. This procedure is continued in an iterative manner until convergence is attained. 
The equations that result from an expansion of Equations B-7 are shown in

Figure B-2a. The value $w_{1}$ is always specified, $w_{1}=0$, based on the wall boundary condition for the particular equation. However, the value $w_{N}$ is not known, and Equations B-7 result in $N-2$ equations and $N-1$ unknowns. The additional equation is provided by the boundary condition

$$
\left.\frac{\partial w}{\partial \eta}\right|_{N}=\frac{R^{2} w_{N-2}-\left[R^{2}+2 R+1\right] w_{N-1}+(2 R+1) w_{N}}{(\Delta \eta)_{N}+R^{2}(\Delta \eta)_{N-1}}=0
$$

Solving for $w_{N}$ gives

$$
w_{N}=\frac{(R+1)^{2}}{2 R+1} w_{N-1}-\frac{R^{2}}{2 R+1} w_{N-2}
$$

These equations are transformed into an easily solved form, Figure B-2b, by the relations

$$
\begin{gathered}
\lambda_{2}=\frac{B_{2}}{C_{2}} \\
E_{2}=\frac{\left(D_{2}-A_{2} w_{1}\right)}{C_{2}} \\
\lambda_{n}=\frac{B_{n}}{C_{n}}-\frac{A_{n}}{\left(C_{n} \lambda_{n-1}\right)} \quad n=3, N-2 \\
E_{n}=\frac{D_{n}}{C_{n}}-\frac{\left(A_{n} E_{n-1}\right)}{\left(C_{n} \lambda_{n-1}\right)} \quad n=3, N-2
\end{gathered}
$$




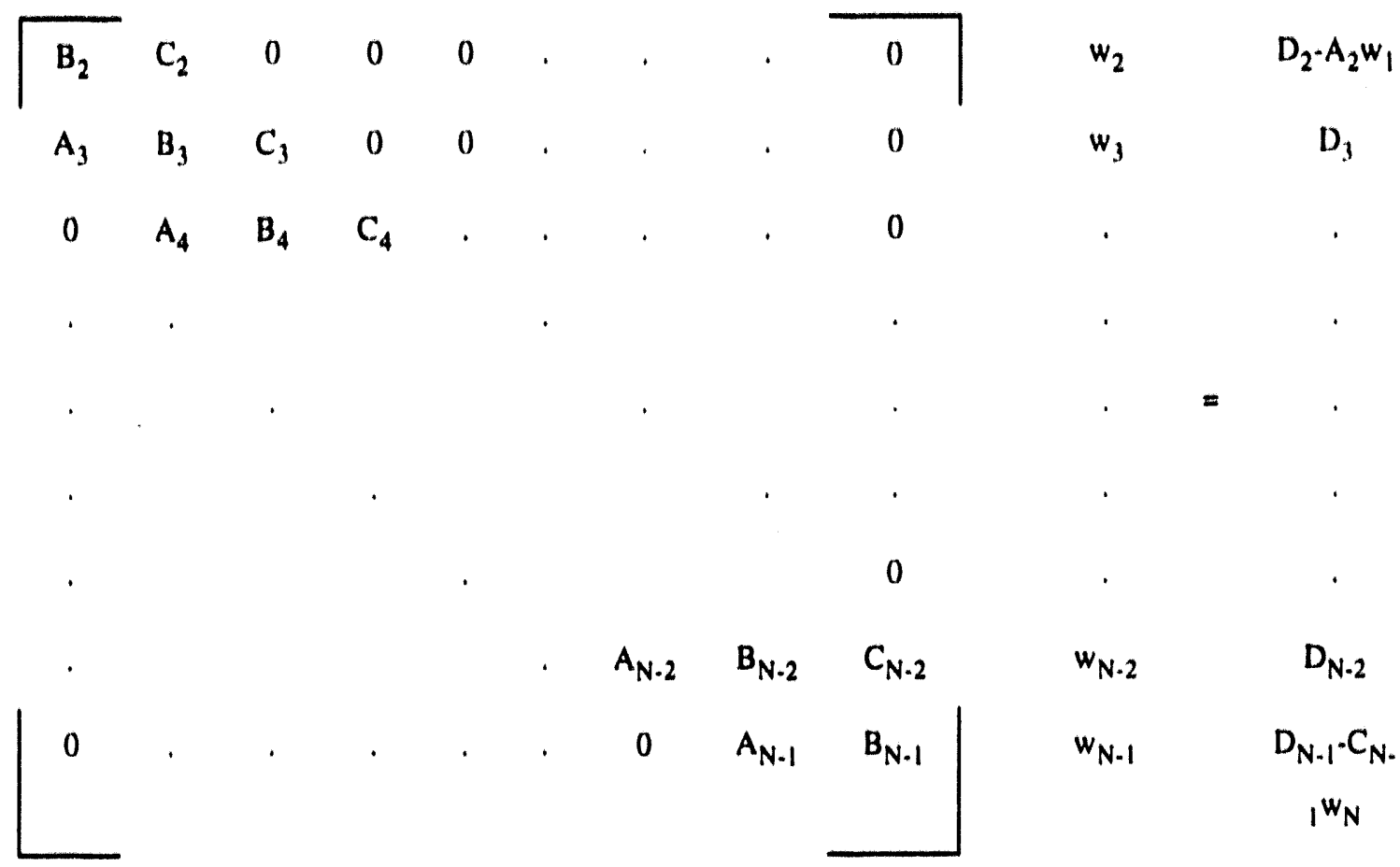

(a)

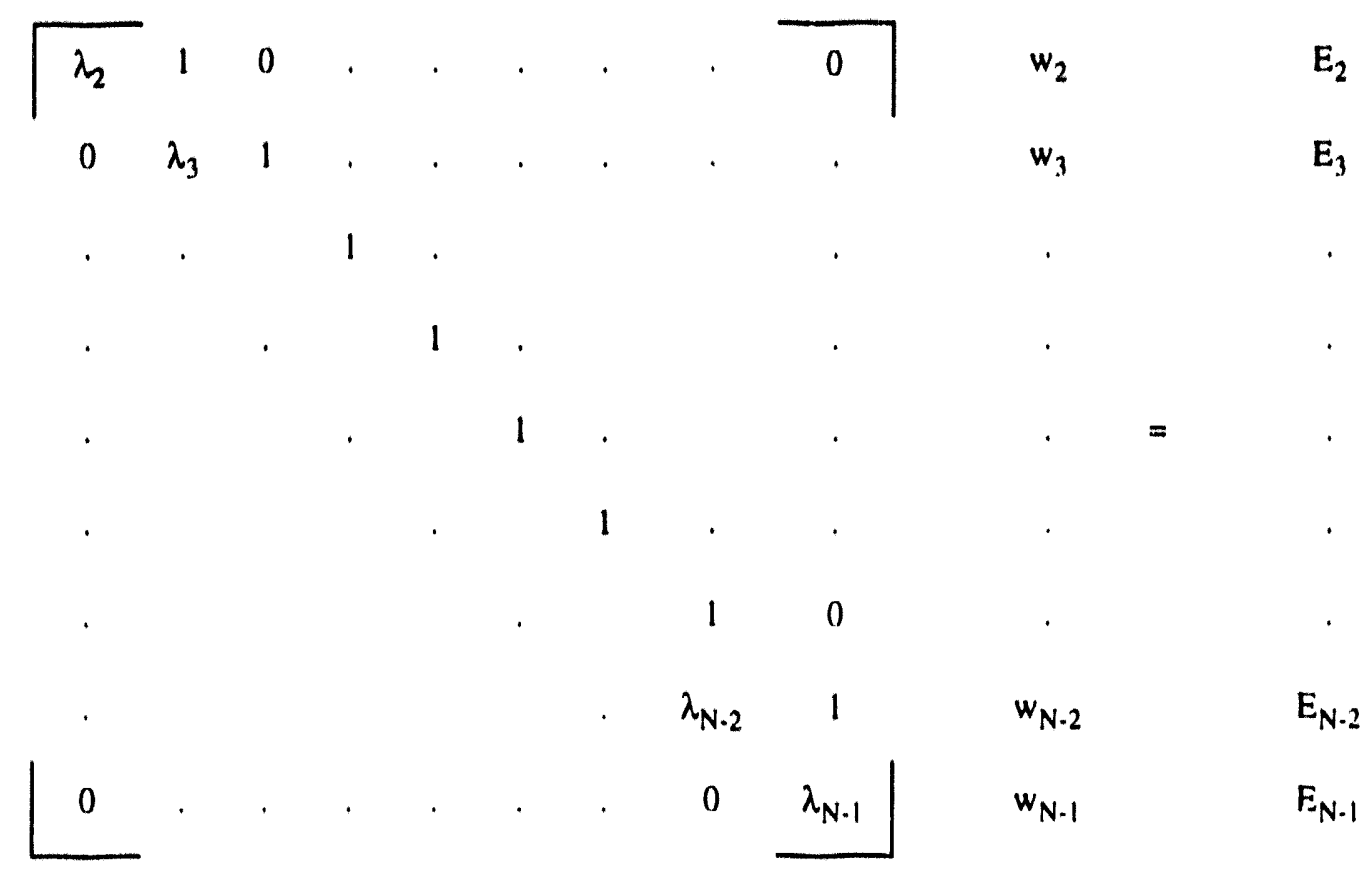

(b)

Fig. B-2 Matrix from linearized equations: (a) tridiagonal form and (b) transformed form. 


$$
\begin{gathered}
\lambda_{N-1}=B_{N-1}+C_{N-1} \frac{(R+1)^{2}}{2 R+1}-\frac{\left(A_{N-1}-C_{N-1} \frac{R^{2}}{2 R+1}\right)}{\lambda_{N-2}} \\
E_{N-1}=D_{N-1}-\frac{\left(A_{N-1}-C_{N-1} \frac{R^{2}}{2 R+1}\right) E_{N-2}}{\lambda_{N-2}}
\end{gathered}
$$

The transformed equations are solved for the $w_{n}$ values by starting at stution $N-1$

$$
w_{N-1}=\frac{E_{N-1}}{\lambda_{N-1}}
$$

and back-substituting

$$
w_{n}=\frac{E_{n}}{\lambda_{n}}-\frac{w_{n+1}}{\lambda_{n}} \quad n=N-2, N-3, \ldots .2
$$


APPENDIX C

EXPERIMENTAL DATA AND PROGRAM INPUT 


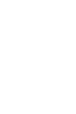

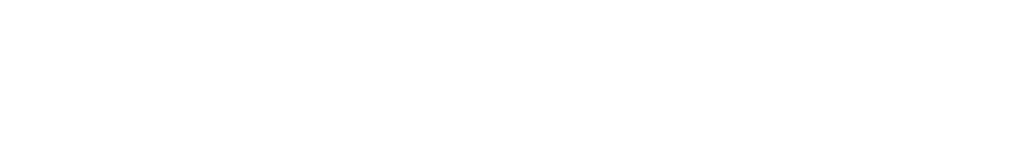




\section{APPENDIX C \\ EXPERIMENTAL DATA AND PROGRAM INPUT}

The data points in the graphical comparisons presented in Section $V$ were carefully scaled from figures presented in the referenced articles/papers. In this Appendix, each tube/rib geometry is first identified by the tube designations used in this work and the referenced works. The physical rib and tube dimensions used as program input are then given, followed by the tabulated data points for the particular tube as read from the figures of the referenced works. 


\section{Tubes of Webbes all (1971)}

Tube Designution:

This work:

W0110 (k/D $=0.01, L / k=10, w / k=1.0)$

Webb et al.:

$01 / 10$ of Figure 6

Program Input:

Rib width:

$$
\begin{aligned}
& w=0.38 \\
& K=0.3683 \\
& L=3.683 \\
& D=36.83
\end{aligned}
$$

\section{Experimental Dutu:}

Tubles C.I and C.2 


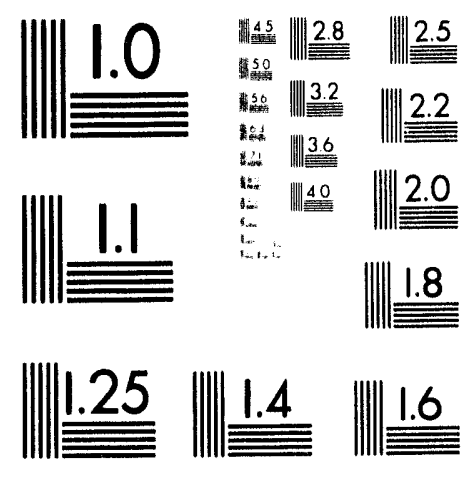



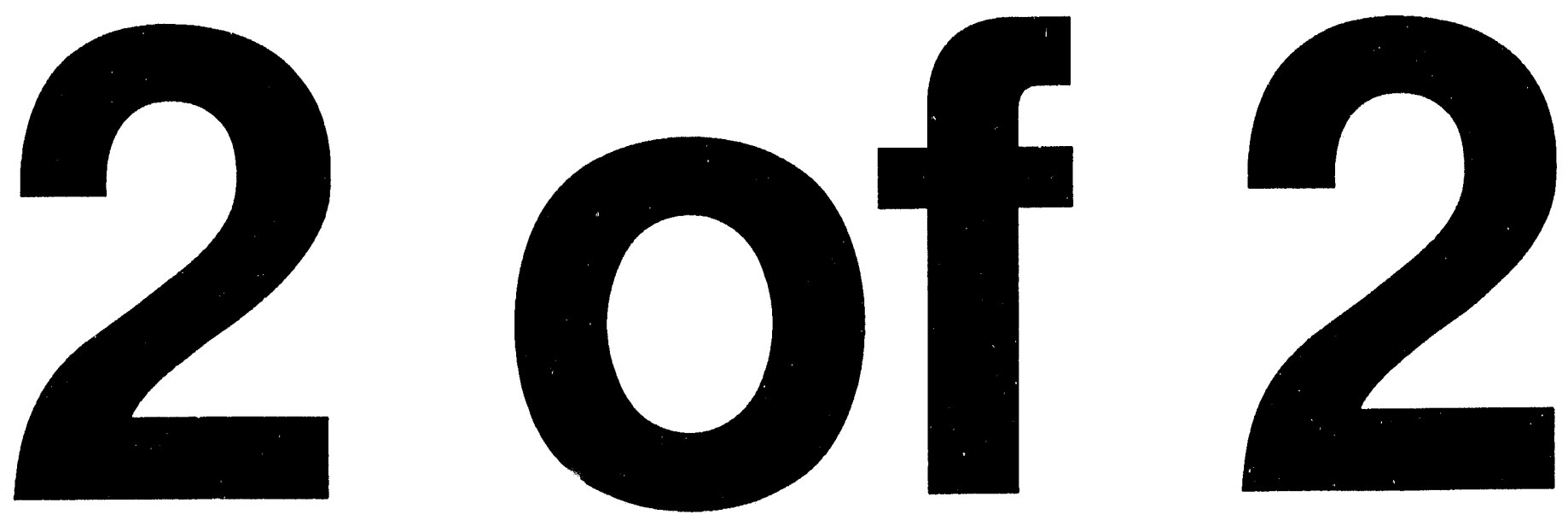
TABLE C-1 - Friction Data for Tube W0110

\begin{tabular}{rrrcrc}
\hline Pt. & $\mathrm{Re}_{\mathrm{D}}$ & $\mathrm{f}_{\mathrm{f}}$ & $\mathrm{Pt}$. & $\mathrm{Re}_{\mathrm{D}}$ & $\mathrm{f}_{\mathrm{f}}$ \\
\hline 1 & 6744 & 0.01332 & 8 & 32295 & 0.01966 \\
2 & 8323 & 0.01493 & 9 & 40800 & 0.02011 \\
3 & 8520 & 0.01394 & 10 & 44799 & 0.02011 \\
4 & 10035 & 0.01426 & 11 & 56597 & 0.02106 \\
5 & 11546 & 0.01528 & 12 & 84214 & 0.02058 \\
6 & 12385 & 0.01599 & 13 & 116821 & 0.02154 \\
7 & 17586 & 0.01753 & 14 & 144177 & 0.02106 \\
\hline
\end{tabular}

TABLE C-2 - Heat-Transfer Data for Tube W0110

\begin{tabular}{|c|c|c|c|c|c|c|c|c|}
\hline \multirow[b]{2}{*}{ Pt. } & \multicolumn{3}{|c|}{$\operatorname{Pr}=0.71$} & \multicolumn{2}{|c|}{$\operatorname{Pr}=5.10$} & \multicolumn{3}{|c|}{$\operatorname{Pr}=21.7$} \\
\hline & $\mathrm{Re}_{\mathrm{D}}$ & St & $\mathrm{Nu}$ & $\mathrm{Re}_{\mathrm{D}}$ & $\mathrm{Nu}$ & $\mathrm{Re}_{\mathrm{D}}$ & St & $\mathrm{Nu}$ \\
\hline 1 & 6823 & 0.00545 & 26 & 77590.00233 & 92 & 6588 & 0.00102 & 146 \\
\hline \multirow[t]{2}{*}{2} & & 0.00570 & 43 & 139200.00284 & 201 & 11018 & 0.00138 & 330 \\
\hline & 10515 & & & & & & & \\
\hline 3 & 13758 & 0.00584 & 57 & 222170.00290 & 329 & 17180 & 0.00146 & 544 \\
\hline 4 & 17586 & 0.00597 & 75 & 346410.00280 & 495 & 29412 & 0.00138 & 880 \\
\hline 5 & 28068 & 0.00625 & 125 & 614220.00244 & 766 & 55939 & 0.00117 & 1425 \\
\hline 6 & 44799 & 0.00611 & 194 & 991870.00215 & 1090 & 96895 & 0.00105 & 2201 \\
\hline 7 & 74924 & 0.00570 & 303 & -. $\quad$-. & -. & -. & -. & -. \\
\hline 8 & 94656 & 0.00545 & 366 & -- & -- & -- & -- & -- \\
\hline 9 & 119584 & 0.00520 & 442 & -- & .. & -- & -- & .. \\
\hline
\end{tabular}


Tube Designation:

This work:

Webb et al.:

$\mathrm{W} 0210(\mathrm{k} / \mathrm{D}=0.02, \mathrm{~L} / \mathrm{k}=10, \mathrm{w} / \mathrm{k}=0.52)$

$02 / 10$ of Figure 6 and Figure 7

Program Input:

Rib width:

$w=0.38$

Rib height:

$\mathrm{k}=0.7366$

Rib pitch:

$\mathrm{L}=7.366$

Tube diameter:

$\mathrm{D}=36.83$

Experimental Data:

Tables C-3 and C-4 
TABLE C-3 - Friction Data for Tube W0210

\begin{tabular}{rrrrrr}
\hline Pt. & $\mathrm{Re}_{\mathrm{D}}$ & $\mathrm{f}_{\mathrm{f}}$ & $\mathrm{Pt}$. & $\mathrm{Re}_{\mathrm{D}}$ & $\mathrm{f}_{\mathrm{f}}$ \\
\hline 1 & 6903 & 0.02648 & 10 & 48054 & 0.03649 \\
2 & 7234 & 0.02935 & 11 & 51545 & 0.03566 \\
3 & 8620 & 0.02935 & 12 & 65119 & 0.03415 \\
4 & 10035 & 0.03144 & 13 & 67443 & 0.03608 \\
5 & 10153 & 0.03180 & 14 & 94656 & 0.03446 \\
6 & 13920 & 0.03330 & 15 & 120990 & 0.03566 \\
7 & 14084 & 0.03446 & 16 & 122413 & 0.03734 \\
8 & 25563 & 0.03486 & 17 & 123852 & 0.03734 \\
9 & 35460 & 0.03566 & & & \\
\hline
\end{tabular}

TABLE C-4 - Heat-Transfer Data for Tube W(1210

\begin{tabular}{|c|c|c|c|c|c|c|c|c|c|}
\hline \multirow[b]{2}{*}{ Pt. } & \multicolumn{3}{|c|}{$\operatorname{Pr}=0.71$} & \multicolumn{3}{|c|}{$\operatorname{Pr}=5.10$} & \multicolumn{3}{|c|}{$\operatorname{Pr}=21.7$} \\
\hline & $\mathrm{Re}_{\mathrm{D}}$ & St & $\mathrm{Nu}$ & $\mathrm{Re}_{\mathrm{D}}$ & St & $\mathrm{Nu}$ & $R_{\mathrm{e}} \mathrm{D}$ & St & $\mathrm{Nu}$ \\
\hline 1 & 6436 & 0.00823 & 38 & 8131 & 0.00414 & 172 & 6903 & 0.00188 & 281 \\
\hline 2 & 10764 & 0.00872 & 67 & 12385 & 0.00386 & 244 & 10890 & 0.00181 & 429 \\
\hline 3 & 17586 & 0.00862 & 108 & 22217 & 0.00345 & 390 & 16783 & 0.00166 & 6()$^{3}$ \\
\hline 4 & 28068 & 0.00823 & 164 & 40800 & 0.00294 & 611 & 29758 & 0.00144 & 932 \\
\hline 5 & 44799 & 0.00751 & 239 & 56597 & 0.00256 & 738 & 55289 & 0.00123 & 1475 \\
\hline 6 & 74924 & 0.00670 & 356 & & & & 86206 & 0.00102 & 1914 \\
\hline 7 & 92469 & 0.00640 & 420 & & & & & & \\
\hline 8 & 114122 & 0.00597 & 484 & & & & & & \\
\hline
\end{tabular}


Tube Designation:

This work:

$\mathrm{W} 0410(\mathrm{k} / \mathrm{D}=0.04, \mathrm{~L} / \mathrm{k}=10, \mathrm{w} / \mathrm{k}=0.252)$

Webb et al.:

04/10 of Figure 6

Program Input:

Rib width:

$\mathrm{w}=0.38$

Rib height:

$\mathrm{k}=1.4732$

Rib pitch:

$\mathrm{L}=14.732$

Tube diameter:

$\mathrm{D}=36.83$

Experimental Data:

Tables C-5 and C-6 
TABLE C-5 - Friction Data for Tube W0410

\begin{tabular}{cccccc}
\hline Pt. & $\operatorname{Re}_{\mathrm{D}}$ & $\mathrm{f}_{\mathrm{f}}$ & $\mathrm{Pt}$. & $\mathrm{Re}_{\mathrm{D}}$ & $\mathrm{f}_{\mathrm{f}}$ \\
\hline 1 & 6903 & 0.05904 & 10 & 39857 & 0.05904 \\
2 & 8323 & 0.06181 & 11 & 40800 & 0.05770 \\
3 & 8520 & 0.05904 & 12 & 44799 & 0.06041 \\
4 & 10272 & 0.06041 & 13 & 54012 & 0.06324 \\
5 & 13284 & 0.06041 & 14 & 55289 & 0.06041 \\
6 & 13920 & 0.06041 & 15 & 86206 & 0.06181 \\
7 & 20234 & 0.06041 & 16 & 99187 & 0.06181 \\
8 & 29412 & 0.05770 & 17103934 & 0.06181 \\
9 & 37158 & 0.05904 & 18114122 & $0.06(1) 41$ \\
\hline
\end{tabular}

TABLE C-6 - Heat-Transfer Data for Tube W0410

\begin{tabular}{|c|c|c|c|c|c|c|c|c|c|}
\hline \multirow[b]{2}{*}{ Pt. } & \multicolumn{3}{|c|}{$\operatorname{Pr}=0.71$} & \multicolumn{3}{|c|}{$\mathrm{Pr}=5.10$} & \multicolumn{3}{|c|}{$\operatorname{Pr}=21.7$} \\
\hline & $\mathrm{Re}_{\mathrm{D}}$ & $\mathrm{St}$ & $\mathrm{Nu}$ & $\mathrm{Re}_{\mathrm{D}}$ & St & $\mathrm{Nu}$ & $\mathrm{Re}_{\mathrm{D}}$ & St & $\mathrm{Nu}$ \\
\hline 1 & 6666 & 0.01187 & 56 & 7492 & 0.00486 & 186 & 69() 3 & 0.00228 & 342 \\
\hline 2 & 8620 & 0.01083 & 66 & 14586 & 0.00414 & 308 & 12677 & 0.00194 & 535 \\
\hline 3 & 11018 & 0.01083 & 85 & $35460)$ & 0.000325 & 589 & 24395 & 0.00160 & 876 \\
\hline 4 & 18002 & 0.00966 & 123 & 82269 & 0.00247 & 1037 & 46398 & 0.00133 & 1341 \\
\hline 5 & 28068 & 0.00882 & 176 & & & & 8.5205 & 0.00110 & 2026 \\
\hline 6 & 46398 & $0.00) 804$ & 26.5 & & & & & & \\
\hline 7 & 74924 & 0.000717 & 382 & & & & & & \\
\hline 8 & 101533 & 0.00655 & 472 & & & & & & \\
\hline 9 & 125308 & 0.00640 & 569 & & & & & & \\
\hline
\end{tabular}


Tube Designation:

This work:

$\mathrm{W} 0220(\mathrm{k} / \mathrm{D}=0.02, \mathrm{~L} / \mathrm{k}=20, \mathrm{w} / \mathrm{k}=0.52)$

Webb et al.:

$02 / 20$ of Figure 7

Program Input:

Rib width:

$w=0.38$

Rib height:

$\mathrm{k}=0.7366$

Rib pitch:

$\mathrm{L}=14.732$

Tube diameter:

$\mathrm{D}=36.83$

Experimental Data:

Tables C-7 and C-8 
TABLE C-7 - Friction Data for Tube W0220

\begin{tabular}{rrrrrr}
\hline Pt. & $\operatorname{Re}_{\mathrm{D}}$ & $\mathrm{f}_{\mathrm{f}}$ & $\mathrm{Pt}$. & $\mathrm{Re}_{\mathrm{D}}$ & $\mathrm{f}_{\mathrm{f}}$ \\
\hline 1 & 6512 & 0.02011 & 8 & 44799 & 0.02648 \\
2 & 8036 & 0.02255 & 9 & 54012 & 0.02709 \\
3 & 10890 & 0.02361 & 10 & 82269 & 0.02772 \\
4 & 13598 & 0.02416 & 11 & 101533 & 0.02804 \\
5 & 18428 & 0.02472 & 12 & 125308 & 0.02902 \\
6 & 23831 & 0.02529 & 13 & 142501 & 0.02902 \\
7 & 30108 & 0.02588 & 14 & & \\
\hline
\end{tabular}

TABLE C-8 - Heat-Transfer Data for Tube W(1220

\begin{tabular}{|c|c|c|c|c|c|c|c|c|c|}
\hline \multirow[b]{2}{*}{$\mathrm{Pt}$. } & \multicolumn{3}{|c|}{$\operatorname{Pr}=0.71$} & \multicolumn{3}{|c|}{$\operatorname{Pr}=5.10$} & \multicolumn{3}{|c|}{$\operatorname{Pr}=21.7$} \\
\hline & $\mathrm{Re}_{\mathrm{D}}$ & St & $\mathrm{Nu}$ & $\mathrm{Re}_{\mathrm{D}}$ & St & $\mathrm{Nu}$ & $\mathrm{Re}_{\mathrm{D}}$ & St & $\mathrm{Nu}$ \\
\hline 1 & 6744 & 0.00713 & 34 & 7580 & 0.00346 & 134 & 6588 & 0.00157 & 225 \\
\hline 2 & 10515 & 0.00754 & 56 & 13920 & 0.00331 & 235 & 11018 & 0.00150 & 359 \\
\hline 3 & 17586 & 0.00729 & 91 & 34641 & 0.00273 & 482 & 16980 & 0.00140 & 517 \\
\hline 4 & 27742 & 0.00681 & 134 & 59306 & 0.00231 & 697 & 29758 & 0.00123 & 791 \\
\hline 5 & 44799 & 0.00637 & 203 & 101533 & 0.00195 & 1008 & 54012 & 0.00106 & 1240) \\
\hline 6 & 74924 & 0.00575 & 306 & & & & 946.56 & $0.00(0) 87$ & 1794 \\
\hline 7 & 94656 & 0.00544 & 365 & & & & & & \\
\hline 8 & 119584 & 0.00514 & 436 & & & & & & \\
\hline
\end{tabular}


Tube Designation:

This work:

Webb et al.:

W0240 $(\mathrm{k} / \mathrm{D}=0.02, \mathrm{~L} / \mathrm{k}=40, \mathrm{w} / \mathrm{k}=0.52)$

02/40 of Figure 7

\section{Program Input:}
Rib width:
$w=0.38$
Rib height:
Rib pitch:
$k=0.7366$
Tube diameter:
$\mathrm{L}=29.464$
$D=36.83$

\section{Experimental Data:}

Tables C-9 and C-10 
TABLE C-9 - Friction Data for Tube W0240

\begin{tabular}{rrrrrc}
\hline Pt. & $\mathrm{Re}_{\mathrm{D}}$ & $\mathrm{f}_{\mathrm{f}}$ & $\mathrm{Pt}$ & $\mathrm{Re}_{\mathrm{D}}$ & $\mathrm{f}_{\mathrm{f}}$ \\
\hline 1 & 6512 & 0.01493 & 10 & 24395 & 0.01694 \\
2 & 6903 & 0.01528 & 11 & 30820 & 0.01713 \\
3 & 8323 & 0.01563 & 12 & 44278 & 0.01713 \\
4 & 8323 & 0.01637 & 13 & 44799 & 0.01694 \\
5 & 8520 & 0.01563 & 14 & 51545 & 0.01733 \\
6 & 11018 & 0.01655 & 15 & 79434 & 0.01773 \\
7 & 13758 & 0.01674 & 16 & 99187 & 0.01794 \\
8 & 18002 & 0.01637 & 17 & 125308 & 0.01835 \\
9 & 23554 & 0.01674 & 18 & 140845 & 0.01878 \\
\hline
\end{tabular}

TABLE C-10 - Heat-Transfer Data for Tube W0240

\begin{tabular}{|c|c|c|c|c|c|c|c|c|c|}
\hline \multirow[b]{2}{*}{$\mathrm{Pt}$. } & \multicolumn{3}{|c|}{$\mathrm{Pr}=0.71$} & \multicolumn{3}{|c|}{$\mathrm{Pr}=5.10$} & \multicolumn{3}{|c|}{$\operatorname{Pr}=21.7$} \\
\hline & $\operatorname{Re}_{\mathrm{D}}$ & St & $\mathrm{Nu}$ & $\mathrm{Re}_{\mathrm{D}}$ & St & $\mathrm{Nu}$ & $\mathrm{Re}_{\mathrm{D}}$ & St & $\mathrm{Nu}$ \\
\hline 1 & 7492 & 0.00582 & 31 & 7943 & 0.00273 & 111 & 6436 & 0.00117 & 164 \\
\hline 2 & 10515 & 0.00609 & 45 & $14(084$ & 0.002 .58 & 18.5 & 11958 & 0.00117 & 304 \\
\hline 3 & 17586 & 0.00582 & 73 & 21452 & 0.00247 & 270 & 24972 & 0.001106 & 573 \\
\hline 4 & 27101 & 0.00544 & 105 & 33841 & $0.0(1) 223$ & 385 & 44799 & 0.000091 & 888 \\
\hline 5 & 44799 & 0.00497 & 158 & 59306 & $0.0(0188$ & 569 & $9(1) 332$ & $0.00(0) 73$ & 1429 \\
\hline 6 & 74924 & 0.00454 & 241 & & & & & & \\
\hline 7 & 98034 & 0.00429 & 299 & & & & & & \\
\hline 8 & 119584 & 0.00405 & 344 & & & & & & \\
\hline 9 & 145872 & 0.00387 & $4(1) 1$ & & & & & & \\
\hline
\end{tabular}


Tubes of Berger and Hau (1979)

Tube Designation:

This work:

BH03610 (k/D $=0.036, L / k=10)$

Berger and Hau: $\mathrm{p} / \mathrm{e}=10$, Figures $1(\mathrm{a}), 3,4,5$ and 6

Program Input:

Rib width:

Rib height:

Rib pitch:

Tube diameter:

$$
\begin{aligned}
& w=4 \\
& k=4 \\
& L=40 \\
& D=110
\end{aligned}
$$

\section{Experimental Data:}

Equation 3 of Berger and Hau:

$$
S t_{R}=0.281 R e^{-0.305} S c^{-0.67}
$$

or

$$
N u=0.281 R e_{D}^{0.695} S c^{0.33}
$$


Tubes of Mendes and Mauricio (1987)

Tube Designation:

This work:

MM0508 (k/D $=0.05, L / k=8)$

Mendes and Mauricio: $\quad H / D=0.05, P / H=8$ of Figures 4 and 7

\section{Program Input:}

Rib width:

$w=1$

Rib height:

Rib pitch:

$k=2.25$

Tube diameter:

$\mathrm{L}=18$

$\mathrm{D}=45$

\section{Experimental Data:}

TABLE C-11 - Friction and Heat-Transfer Data for Tube MM0508

\begin{tabular}{ccccc}
\hline Point & $\operatorname{Re}_{\mathrm{D}}$ & $\mathrm{f}_{\mathrm{D}}$ & $\mathrm{f}_{\mathrm{f}}=\mathrm{f}_{\mathrm{D}} / 4$ & $\mathrm{Sh}=\mathrm{Nu}$ \\
\hline 1 & 5508 & & & 125 \\
2 & 8268 & & & 149 \\
3 & 11340 & & & 193 \\
4 & 21331 & 0.3233 & 0.0808 & 295 \\
5 & 35272 & & & 420 \\
6 & 46542 & & & 524 \\
\hline
\end{tabular}


Tube Designation:

This work: $\quad \operatorname{MM0510}(\mathrm{k} / \mathrm{D}=0.05, \mathrm{~L} / \mathrm{k}=10)$

Mendes and Mauricio: $\quad \mathrm{H} / \mathrm{D}=0.05, \mathrm{P} / \mathrm{H}=10$ of Figures 4 and 7

Program Input:
Rib width:
Rib height:
$\mathrm{w}=1$
Rib pitch:
$\mathrm{k}=1.8$
Tube diameter:
$\mathrm{L}=18$
$\mathrm{D}=36$

Experimental Data:

TABLE C-12 - Friction and Heat-Transfer Data for Tube MM0510

\begin{tabular}{crccc}
\hline Point & $\operatorname{Re}_{\mathrm{D}}$ & $\mathrm{f}_{\mathrm{D}}$ & $\mathrm{f}_{\mathrm{f}}=\mathrm{f}_{\mathrm{D}} / 4$ & $\mathrm{Sh}=\mathrm{Nu}$ \\
\hline 1 & 7037 & & & 129 \\
2 & 10563 & & & 174 \\
3 & 14488 & & & 224 \\
4 & 27607 & 0.3057 & 0.0764 & 359 \\
5 & 42525 & & & 494 \\
6 & 57577 & & & 637 \\
\hline
\end{tabular}


Tube Designation:

This work: $\quad$ MM0512 $(\mathrm{k} / \mathrm{D}=0.05, \mathrm{~L} / \mathrm{k}=12)$

Mendes and Mauricio: $\quad \mathrm{H} / \mathrm{D}=0.05, \mathrm{P} / \mathrm{H}=12$ of Figures 4 and 7

Program Input:

$\begin{array}{ll}\text { Rib width: } & \mathrm{w}=1 \\ \text { Rib height: } & \mathrm{k}=1.5 \\ \text { Rib pitch: } & \mathrm{L}=18 \\ \text { Tube diameter: } & \mathrm{D}=30\end{array}$

\section{Experimental Data:}

TABLE C-13 - Friction and Heat-Transfer Data for Tube MM0512

\begin{tabular}{crccc}
\hline Point & $\mathrm{Re}_{\mathrm{D}}$ & $\mathrm{f}_{\mathrm{D}}$ & $\mathrm{f}_{\mathrm{f}}=\mathrm{f}_{\mathrm{D}} / 4$ & $\mathrm{Sh}=\mathrm{Nu}$ \\
\hline 1 & 8005 & & & 139 \\
2 & 12491 & & & 187 \\
3 & 17693 & & & 238 \\
4 & 32228 & 0.2819 & 0.0705 & 368 \\
5 & 50611 & & & 531 \\
6 & 68526 & & & 662 \\
\hline
\end{tabular}


Tube Designation:

This work: $\quad$ MM0515 $(\mathrm{k} / \mathrm{D}=0.05, \mathrm{~L} / \mathrm{k}=15)$

Mendes and Mauricio: $\quad \mathrm{H} / \mathrm{D}=0.05, \mathrm{P} / \mathrm{H}=15$ of Figures 4 and 7

Program Input:

Rib width:

$w=1$

Rib height:

Rib pitch:

$\mathrm{k}=1.2$

$\mathrm{L}=18$

Tube diameter:

$\mathrm{D}=24$

\section{Experimental Data:}

TABLE C-14 - Friction and Heat-Transfer Data for Tube MM0515

\begin{tabular}{crccc}
\hline Point & $\operatorname{Re}_{\mathrm{D}}$ & $\mathrm{f}_{\mathrm{D}}$ & $\mathrm{f}_{\mathrm{f}}=\mathrm{f}_{\mathrm{D}} / 4$ & $\mathrm{Sh}=\mathrm{Nu}$ \\
\hline 1 & 9904 & & & 156 \\
2 & 13152 & & & 189 \\
3 & 22606 & & & 278 \\
4 & 41442 & 0.2551 & 0.0638 & 425 \\
5 & 59464 & & & 559 \\
6 & 71690 & & & 698 \\
\hline
\end{tabular}


Tube Designation:

This work:

MM1010 (k/D $=0.10, L / k=10)$

Mendes and Mauricio: $\quad H / D=0.10, P / H=10$ of Figures 4 and 7

Program Input:

Rib width:

Rib height:

$w=1$

Rib pitch:

$\mathrm{k}=1.8$

Tube diameter:

$\mathrm{L}=18$

$\mathrm{D}=18$

\section{Experimental Data:}

TABLE C-15 - Friction and Heat-Transfer Data for Tube MM1010

\begin{tabular}{crccc}
\hline Point & $\mathrm{Re}_{\mathrm{D}}$ & $\mathrm{f}_{\mathrm{D}}$ & $\mathrm{f}_{\mathrm{f}}=\mathrm{f}_{\mathrm{D}} / 4$ & $\mathrm{Sh}=\mathrm{Nu}$ \\
\hline 1 & 12984 & & & 213 \\
2 & 16166 & & & 276 \\
3 & 22461 & & & 299 \\
4 & 23497 & 0.7366 & 0.1842 & 345 \\
5 & 26905 & & & 436 \\
6 & 47758 & & & 581 \\
7 & 50939 & & & 608 \\
\hline
\end{tabular}


Tube of Baughn and Roby (1992)

Tube Designation:

This work:

Baughn and Roby:
BR0618 $(\mathrm{k} / \mathrm{D}=0.0625, \mathrm{~L} / \mathrm{k}=18)$

Ribbed duct

Program Input:

Rib width:

$$
\begin{aligned}
& w=0.3125 \\
& k=0.3125 \\
& L=18 \\
& D=5.0
\end{aligned}
$$

\section{Experimental Data:}

The following data are average values from Figure 6 of Baughn and Roby.

TABLE C-16 - Heat-Transfer

Data for Tube BRO618

\begin{tabular}{ccc}
\hline Point & $\mathrm{Re}_{\mathrm{D}}$ & $\mathrm{Nu}$ \\
\hline 1 & 23600 & 130 \\
2 & $3550(0)$ & 180 \\
3 & 59400 & 240 \\
4 & 63400 & 270 \\
\hline
\end{tabular}



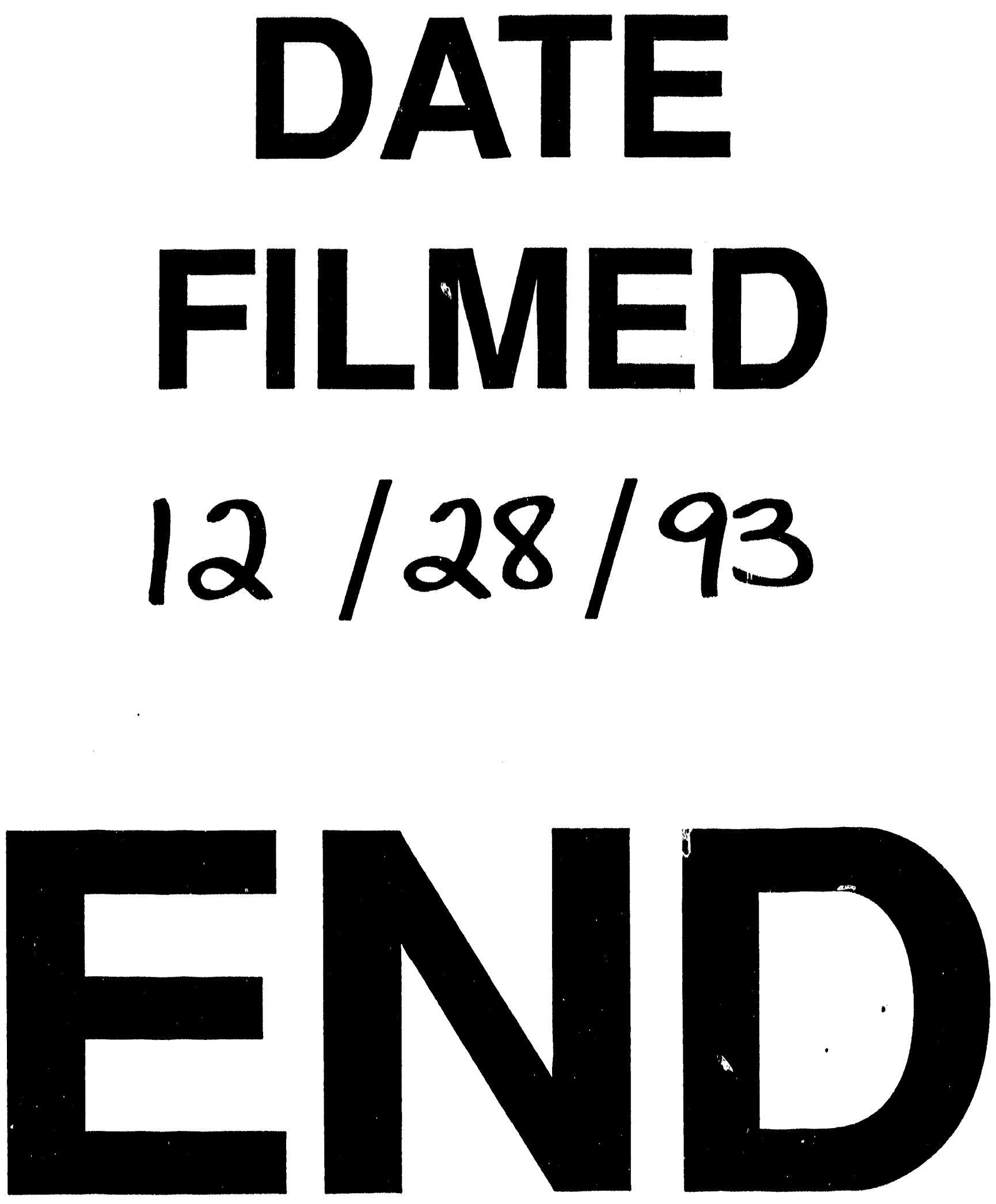


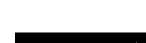

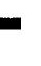

